\title{
Glycan characterization and manipulation using phospholipid additives for capillary electrophoresis
}

Stephanie A. Archer-Hartmann

West Virginia University

Follow this and additional works at: https://researchrepository.wvu.edu/etd

\section{Recommended Citation}

Archer-Hartmann, Stephanie A., "Glycan characterization and manipulation using phospholipid additives for capillary electrophoresis" (2012). Graduate Theses, Dissertations, and Problem Reports. 4826.

https://researchrepository.wvu.edu/etd/4826

This Dissertation is protected by copyright and/or related rights. It has been brought to you by the The Research Repository @ WVU with permission from the rights-holder(s). You are free to use this Dissertation in any way that is permitted by the copyright and related rights legislation that applies to your use. For other uses you must obtain permission from the rights-holder(s) directly, unless additional rights are indicated by a Creative Commons license in the record and/ or on the work itself. This Dissertation has been accepted for inclusion in WVU Graduate Theses, Dissertations, and Problem Reports collection by an authorized administrator of The Research Repository @ WVU.

For more information, please contact researchrepository@mail.wvu.edu. 


\title{
GLYCAN CHARACTERIZATION AND MANIPULATION USING PHOSPHOLIPID ADDITIVES FOR CAPILLARY ELECTROPHORESIS
}

\author{
by Stephanie A. Archer-Hartmann
}
Dissertation submitted to the Eberly College of Arts and Sciences at West Virginia University in partial fulfillment of the requirements for the degree of Doctor of Philosophy in Chemistry

\author{
Approved by: \\ Lisa A. Holland, Ph.D., Committee Chair \\ Jonathan Boyd, Ph.D. \\ Fred L. King, Ph.D. \\ David Lederman, Ph.D. \\ Harry O. Finklea, Ph.D.
}
Chemistry Department Morgantown, West Virginia 2012
Keywords: glycans, capillary electrophoresis, phospholipid, MCF7, Trastuzumab
Copyright (C) 2012 Stephanie A. Archer-Hartmann





\section{Glycan Characterization and Manipulation using Phospholipid Additives for Capillary Electrophoresis}

\section{Stephanie A. Archer-Hartmann}

Protein glycosylation is of interest in a number of emerging fields, and plays important functional roles in cellular biology. The analysis of these molecules is nontrivial because they exhibit great complexity in both monomer makeup and linkages of these monomers. As a result, a common challenge that analytical techniques face is the separation of linkage glycan isomers. This dissertation is based on the research leading to the development of a phospholipid-capillary electrophoresis method that allows for highly efficient separations and the non-covalent incorporation of enzymes and lectins for in-capillary interactions. Glycans were removed from glycoproteins through enzymatic means, then labeled with the fluorescent tag 9- aminopyrene-1,3,6-trisulfonic acid. This label provides charge to the otherwise neutral glycan, as well as the very low limits of detection (15fM) that laser induced fluorescence detection affords. Separations efficiencies, based on hydrodynamic volume, were as high as 640,000 theoretical plates. These methods not only provide superior separations efficiencies, but also crucial structural information about the glycans themselves. This method is amenable for a wide variety of lectins/enzymes for use, and has been conducted in a number of different capillary inner diameters. The method was used to probe glycans solutions taken from MCF7 immortalized breast cancer cells, as well as glycans from the therapeutic antibody, Trastuzumab. Only microgram amounts of these proteins were need to provide the glycans necessary for analysis. These samples display a number of high and low 
abundance glycans that were well resolved. The identity of these glycans were confirmed with the use of glycan standards as well as a number of monomer and linkage-specific enzymes and lectins. Multiple enzymes may be used singly, or in tandem, to systematically remove glycan monomers and discern layers of information about the glycans in use. 


\section{DEDICATION:}

This document is dedicated to my grandmothers, Marian Archer and Nettie Brannon. Although they were both gone before I could really know them, their legacies inspired me to become what I am today.

\section{THANK YOU:}

To my husband, Jon Hartmann - for your years of support, patience, and willingness to pick up the phone for chinese delivery.

To my parents, Robert and Bonnie Archer - because I know you'll always love me, no matter where I go or what I do.

To my in-laws Teresa Wayman and Paul Hartmann - for responding to my thoughts on whether or not to attend graduate school with a resounding "Well, why not?!" 


\section{ACKNOWLEDGEMENTS:}

I would like to acknowledge my advisor, Dr. Lisa Holland for all the lessons she's taught me, both as a student and as an emerging professional. She pushed me to always go one step further and work one hour longer. Looking back on the last five years, I'm amazed at how much I was able to accomplish because of her guidance. Thank you Dr Holland, for helping me become the person I am today.

I would like to acknowledge and thank my committee members, Dr. Lisa A. Holland, Jonathan Boyd, Fred L. King, David Lederman, and Harry Finklea for their invaluable support as mentors and instructors.

I would like to thank the West Virginia Graduate Student Fellowships in Science Technology Engineering and Math (STEM) program as well as the United States Pharmacopeia (USP)'s Fellowship program. Not only did these programs provide the funding for me to focus my full attention on research, but they provided a number of opportunities for me to further develop as a researcher and professional.

I would like to acknowledge my lab mates (past and present) : Dr Theron Pappas, Dr Christian White, Dr Liliya Bykova, Dr. Ruijuan Luo, Ted Langan, Xingwei Wu, Brandon Durney, Vincent Nyakubaya, Tyler Davis, and Hanyu Fan. Thank you for the assistance, support, teamwork, dancing hamsters, and flying Peeps. You have been a joyous part of my life, and I wish you all nothing but the best in years to come. 


\section{TABLE OF CONTENTS}

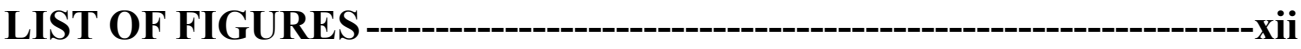

LIST OF TABLES - -

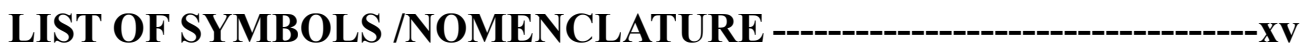

\section{Chapter 1}

Introduction to Capillary Electrophoresis, Phospholipid Materials, and

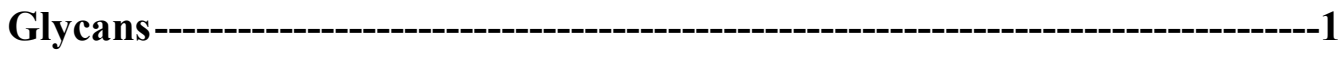

1.0 Introduction --_-

1.1.1 Theory of Capillary Electrophoresis -------------------------------3

1.1.2 Instrumentation of Capillary Electrophoresis ---------------------4

1.1.3 Electrophoretic Mobility and Electroosmotic Flow ----------------6

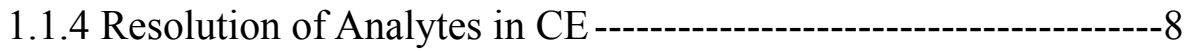

1.2 Phospholipid Separations -

1.2.1 Phospholipid Separations -------------------------------------------12

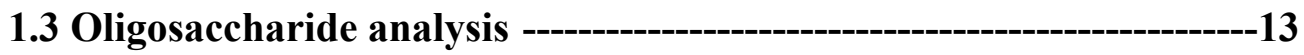

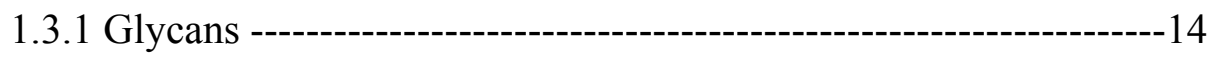

1.3.2 Derivatization of Glycans for CE separations ----------------------17

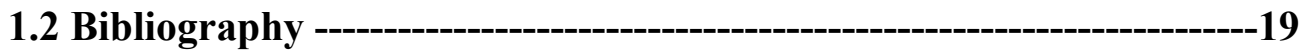

\section{Chapter 2}

Development of Phospholipid Assisted CE for Efficient Glycan Separations --o---24

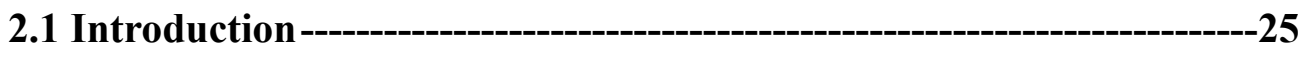

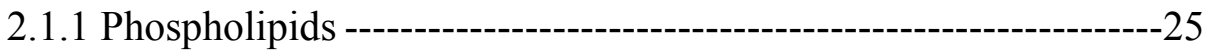

2.1.2 Effects of Phospholipid Composition on Separations

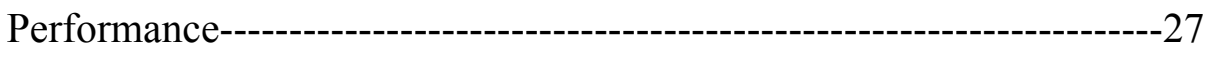


2.1.3 Utilization of Bicelle Coatings and Separations Media

2.1.4 Effects of Q-value, Hydration and Temperature--------------------28

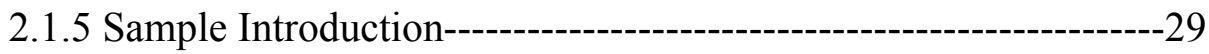

2.2 Experimental ---------------------------------------------------------------------30

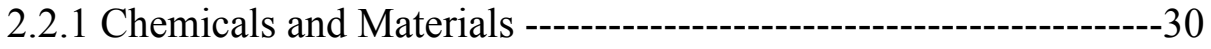

2.2.3 Glycan Labeling and Preparation -------------------------------------30

2.2.4 Phospholipid Preparation-------------------------------------------------32

2.2.5 Capillary Electrophoresis ---------------------------------------------32

2.3 Results and Discussion ---------------------------------------------------------34

2.3.1 Effects of Capillary Inner Diameter------------------------------------34

2.3.2 Optimization of Injection-----------------------------------------34

2.3.3 Effects of Capillary Length on Efficiency --------------------------38

2.3.4 Effects of Electric Field Strength on Efficiency -------------------39

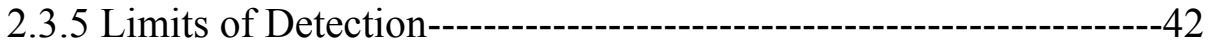

2.4 Conclusions------------------------------------------------------------------------42

2.5 Bibliography ------------------------------------------------------------------------43

\section{Chapter 3}

Optimization of In-Capillary Interactions of Glycans to Lectins and

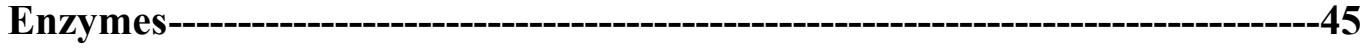

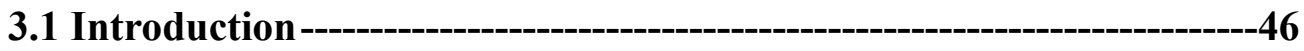

3.1.1 Lectins -------------------------------------------------------------------47

3.1.2 Mass Spectrometry ------------------------------------------------------48

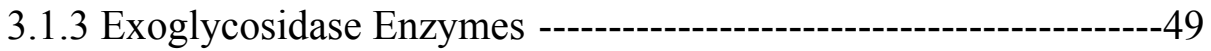

3.2 Experimental ---------------------------------------------------------------------50 
3.2.1 Chemicals and Materials:----------------------------------------50

3.2.2 Preparation and Derivatization of Glycan Standards ---------------51

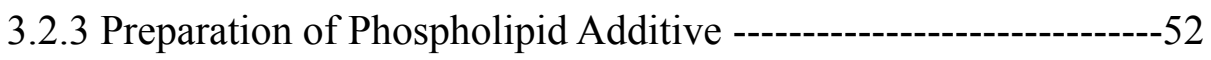

3.2.4 Capillary Electrophoresis ------------------------------------------53

3.2.5 Enzymatic Reactions------------------------------------------------------54

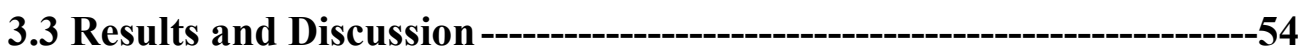

3.3.1 Methods of Glycan Identification using Standards -----------------55

3.3.2 Utilization of Lectins and Enzymes for Glycan

Characterization ---_-

3.3.3 In-Capillary Reactions of Glycans to Lectins ----------------------58

3.3.4 Concanavalin A -----------------------------------------------------------59

3.3.5 Use of Enzymes for In-Capillary Analysis--------------------------62

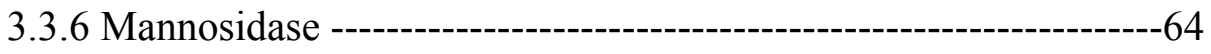

3.3. 7 Galactosidase--------------------------------------------------------------67

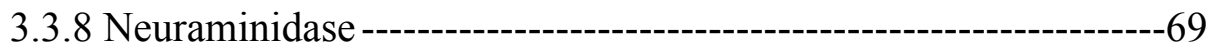

3.3.9 Multiple enzyme Methods ---------------------------------------------70

3.3.11 In-Capillary Sequential Enzymatic Reactions:---------------------74

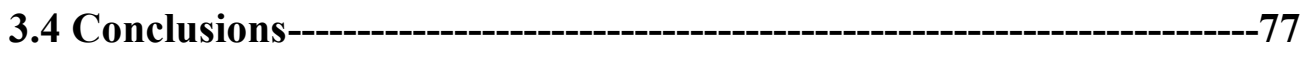

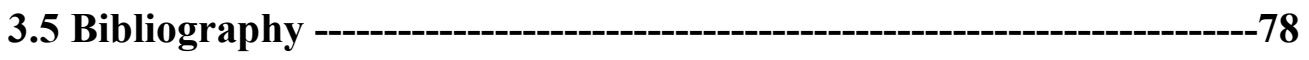

\section{Chapter 4}

Applications of Method to Biological Samples: MCF7 and Trastuzumab---81

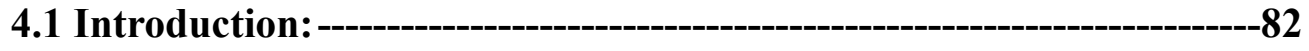

4.1.1 Glycomics and Clinical Biomarker Research ----------------------82

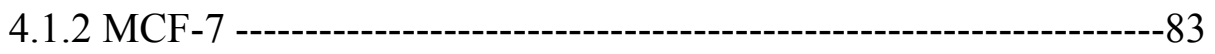


4.1.3 Therapeutical Biologics and Antibodies------------------------------84

4.1.4 Antibody Structure and the Effects of glycosylation ---------------84

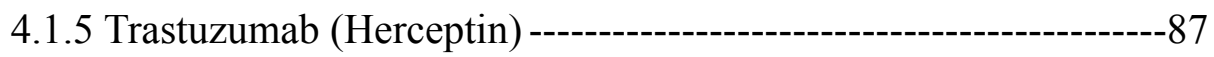

4.1.6 Quality by Testing vs Quality by Design-----------------------------89

\subsection{Experimental -}

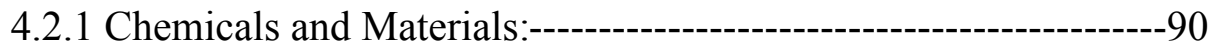

4.2.2 Culture of MCF7 Cells and Protein Isolations ---------------------91

4.2.3 Preparation and Derivatization of Glycans from MCF7 and

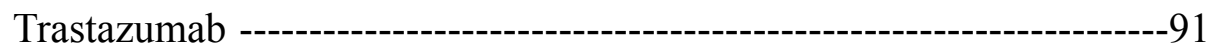

4.2.4 Preparation of Phospholipid Additive ----------------------------93

4.2.5 Capillary Electrophoresis ---------------------------------------------93

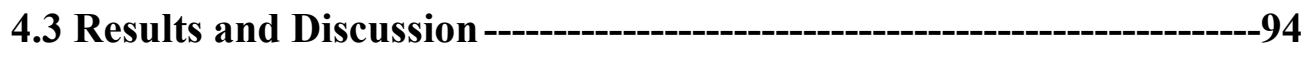

4.3.1 Separation of Glycans from MCF7 Cells and Identification with

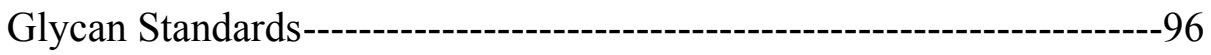

4.3.2 Analysis of MCF7 with Concanavalin A--------------------------96

4.3.3 Analysis of MCF7 with galactosidase, mannosidase --------------98

4.3.4 Identification of the major glycans from Trastuzumab-------------100

4.3.5 Separations of glycans from Trastuzumab --------------------------100

4.3.6 Characterization of sialyated glycans from Trastuzumab---------103

4.3.7 Analysis with multiple in-capillary enzymes ------------------------105

4.3.8 Use of multiple enzyme plugs to Characterize Major Glycans from Trastuzumab ------------------------------------------------------------106

4.3.9 Benefits of Using In-Capillary Analysis for Multiple Enzyme

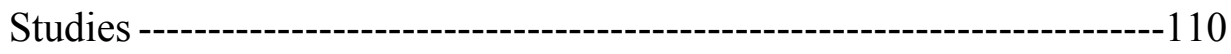

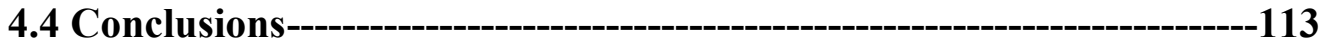

4.5 Future Directions: ---_-114 
4.6 Bibliography

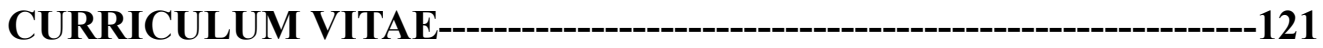




\section{LIST OF FIGURES}

\section{Chapter 1 Figures}

Figure 1-1: Schematic of CE instrument and Electropherogram ------------- 5

Figure 1-2: Separation of Ions in CE -------------------------------------------- 7

Figure 1-3: Supramolecular assemblies of DMPC/DHPC bicelles------------11

Figure 1-4: Glycan monomers typical to N-type glycans----------------------15

Figure 1-5: High Mannose, Complex, and Hybrid type glycans -------------16

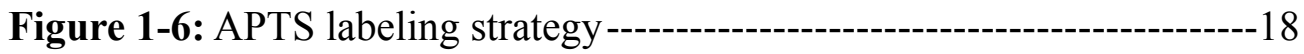

\section{Chapter 2 Figures}

Figure 2-1: Structures of DMPC and DHPC --------------------------------------26

Figure 2-2: Plot of Plate Height vs Electric Field Strength---------------------41

\section{Chapter 3 Figures}

Figure 3-1: Electropherogram of glycan standards -----------------------------56

Figure 3-2: Schematic of Lectin plugs for CE-----------------------------------59

Figure 3-3: Electropherogram of Con-A modified Glycan separations------61

Figure 3-4: Schematic of Enzyme plugs for CE --------------------------------63

Figure 3-5: Schematic of Multiple Incubation times with Enzyme modified

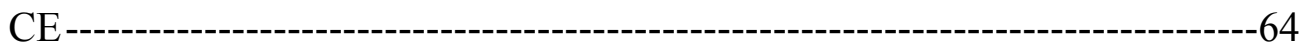

Figure 3-6: Electropherogram of Mannosidase modified glycans ------------66

Figure 3-7: Electropherogram of Galactosidase modified glycans-----------68 
Figure 3-8: AIV glycan structure with enzymatic targets.

Figure 3-9: Bench-top multi-enzyme analysis of glycan from AGP ---------73

Figure 3-10: On-line multi-enzyme analysis of glycans -----------------------76

\section{Chapter 4 Figures}

Figure 4-1: Structure of IgG and glycosylation ---------------------------------87

Figure 4-2: Electropherogram of glycans from MCF7-------------------------98

Figure 4-3: Enhanced electropherogram of glycans from MCF7-------------99

Figure 4-4: Major glycan structures from Trastuzumab -----------------------100

Figure 4-5: Electropherogram of glycans from Trastuzumab -----------------102

Figure 4-6: Electropherogram of Neuraminidase modified glycans from

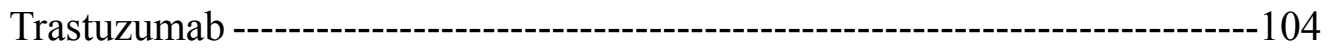

Figure 4-7: Schematic of Multiple Enzymes for CE ---------------------------106

Figure 4-8: Schematic of multiple enzyme analysis and electropherogram of

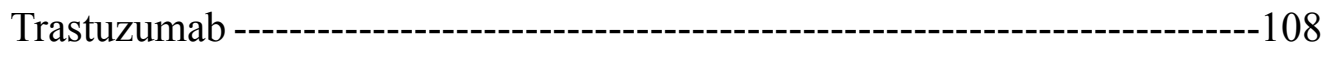

Figure 4-9: Electropherogram of multi-enzyme modified glycans from

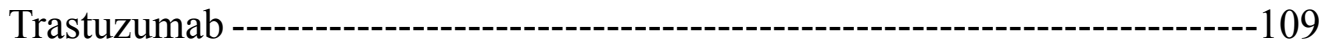

Figure 4-10: Comparison of bench top methods for multiple enzyme

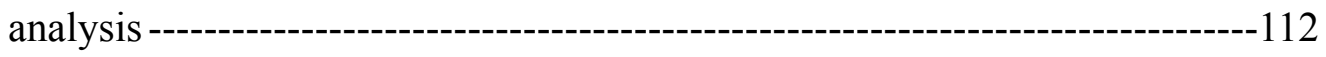




\section{LIST OF TABLES \\ Chapter 2}

Table 2-1: Comparison of Pre-Plug Size ----------------------------------------35

Table 2-2: Comparison of two Pre-plug sizes ------------------------------------35

Table 2-3: Effect of post plug size---------------------------------------------------36

Table 2-4: Effect of Injection Size on Area Reproducibility ------------------37

Table 2-5: Effect of Injection Size on Precision and Plate Count--------------37

Table 2-6: Effect of Length on Separation Efficiency (branched) ------------39

Table 2-7: Effect of Length on Separation Efficiency (linear) ----------------39 


\section{LIST OF SYMBOLS /NOMENCLATURE}

1. AGP - $\alpha$-acid glycoprotein

2. ANTS - 8-aminonaphthalene-1,3,6-trisulfonic acid

3. APTS - 1-aminopyrene-3,6,8-trisulfonic acid

4. CBQCA - 3- (4-carboxybenzoyl)-2-quinolinecarboxaldehyde

5. CE - capillary electrophoresis

6. CEC - capillary electrochromatography

7. CGE - capillary gel electrophoresis

8. CEIF - capillary isoelectric focusing

9. CZE - capillary zone electrophoresis

10.i.d. - inner diameter

11.DHPC - 1,2-dihexanoyl-sn-glycero-3-phosphocholine

12.DMPC -1,2-dimyristoyl-sn-glycero-3-phosphocholine

13.ek - electrokinetic

14.EOF - electroosmotic flow

15. ESI - electrospray ionization

16.HPLC - high performance liquid chromatography

17.L - length of the capillary

18.Leff - effective length of the capillary

19.LIF - laser induced fluorescence

20.MEKC - micellar electrokinetic chromatography

21.MS - mass spectrometry 
22. MALDI - Matrix-assisted laser desorption/ionization

23. $\boldsymbol{\eta}$ - viscosity

24.o.d. - outer diameter

25. $q$ - charge

26. q value - ratio of [DMPC]/[DHPC $]$

27.UV - ultraviolet 


\section{Chapter 1}

\section{Introduction to Capillary Electrophoresis, Phospholipid \\ Materials, and Glycans}




\subsection{Introduction}

Capillary electrophoresis (CE) is a rapid separations method that provides high resolution and separation efficiencies. CE is well suited for the separations of biological molecules because as a microscale technique it uses very low volumes of analyte per analysis. With optical methods such as laser induced fluorescence (LIF), low limits of detection may be achieved. CE separations have been used in the analysis of glycans [1-4]. Recently phospholipid additives were incorporated into CE separations for the separation of glycans [5]. This research explored the effects of temperature, phospholipid content, and composition on the performance of the separation. The use of phospholipid media is attractive for CE separations because it separates glycans efficiently and the material is easily incorporated into separation capillaries.

The research covered in this body of work further investigates the use of phospholipid additives in CE for the analysis of glycans. This research documents the expanded and practical applications of this separations technique. Chapter 1 discusses the fundamentals of capillary electrophoresis, phospholipid materials, and glycans. Previous work by Luo et al demonstrated the first use of phospholipids in capillary electrophoresis for the analysis of glycans. Chapter 2 covers the expanded optimization of glycan separations since that first publication. It covers the effects of modified injection protocol and separation conditions for on-column detection. Chapter 3 covers the expansion of the existing separation methodology to include glycan-specific selectors such as enzymes and lectins, for on-capillary analysis of glycans. Finally, these methods are applied to the real 
world samples of glycans taken from MCF7 immortalized breast cancer cells and the therapeutic antibody Trastuzumab in Chapter 4. This work covers research that has been published in:

Archer-Hartmann, S.A., Crihfield, C.L., Holland, L.A., On-Line Enzymatic Sequencing of Glycans from Trastuzumab by Phospholipid Capillary Electrophoresis, Electrophoresis,

2011. accepted

Archer-Hartmann, S.A., Sargent, L.M., Lowry, D.T., Holland, L.A., Microscale Exoglycosidases Processing and Lectin Capture of Glycans with Phospholipid Assisted Capillary Electrophoresis Separations, Analytical Chemistry, 2011. 83: p. 2740-2747

Luo, R., Archer-Hartmann, S.A., Holland, L.A., Transformable Capillary Electrophoresis for Oligosaccharide Separations Using Phospholipid Additives, Analytical Chemistry, 2010. 82: p. $1228-1233$

\subsubsection{Theory of Capillary Electrophoresis}

To better understand the separations processes that make the developed methods described in subsequent chapters possible, this section will cover the basics of capillary electrophoresis (CE). CE was first reported in the 1980s by the Jorgenson group [6,7]. CE is characterized as providing rapid, efficient separations of molecules based on their charge-to-size ratios. Applications of CE methodologies include profiling a number of analytes in bioanalysis such small molecule pharmaceuticals, analysis of peptides and 
proteins, oligonucleotides, and DNA [8]. A number of methods exist in the capillary electrophoresis family including capillary isotachophoresis (CITP), capillary isoelectric focusing (CIEF), micellar electrokinetic capillary chromatography (MEKC), and capillary gel electrophoresis (CGE). Additionally methods for capillary electrophoresis can be easily adapted to microfluidic methods for the development of portable and disposable means of analysis.

\subsubsection{Instrumentation of Capillary Electrophoresis}

At its most fundamental, CE instrumentation is comprised of three general parts: a narrow bore ( $\sim 10$ to $100 \mu \mathrm{m}$ i.d.) capillary made from fused silica that is filled with and held between two buffer vials, a power supply to provide voltage, and a method of detection. The fused silica capillary is narrow bore and is often coated in polyimide to prevent breakage. The capillary can be cut to a specified length with a ceramic cutter. To prepare a window for optical modes of detection, a propane or butane torch is frequently used to remove a small segment of the the polyimide coating. The placement of anode inlet and cathode-outlet to the capillary for separation is known as normal polarity. Switching the the cathode and anode for separation (cathode-inlet and anode-outlet) is known as a reverse polarity separation. Commercial instrumentation often incorporates methods of automated sample handling, as well as methods of temperature control for the samples and thermostatting of the capillary. Commercial CE instruments are often available with a number of pre-equipped detection modes, such as UV-absorbance 
detection or laser induced fluorescence (LIF). Commercial CE instruments also are amenable for on-line coupling to electrospray ionization-mass spectrometry.

Following the application of voltage within the capillary, analytes are separated and eluted, based on their charge-to-size ratio. Figure 1-1 provides the basic schematic for this instrument, as well as a basic electropherogram readout.
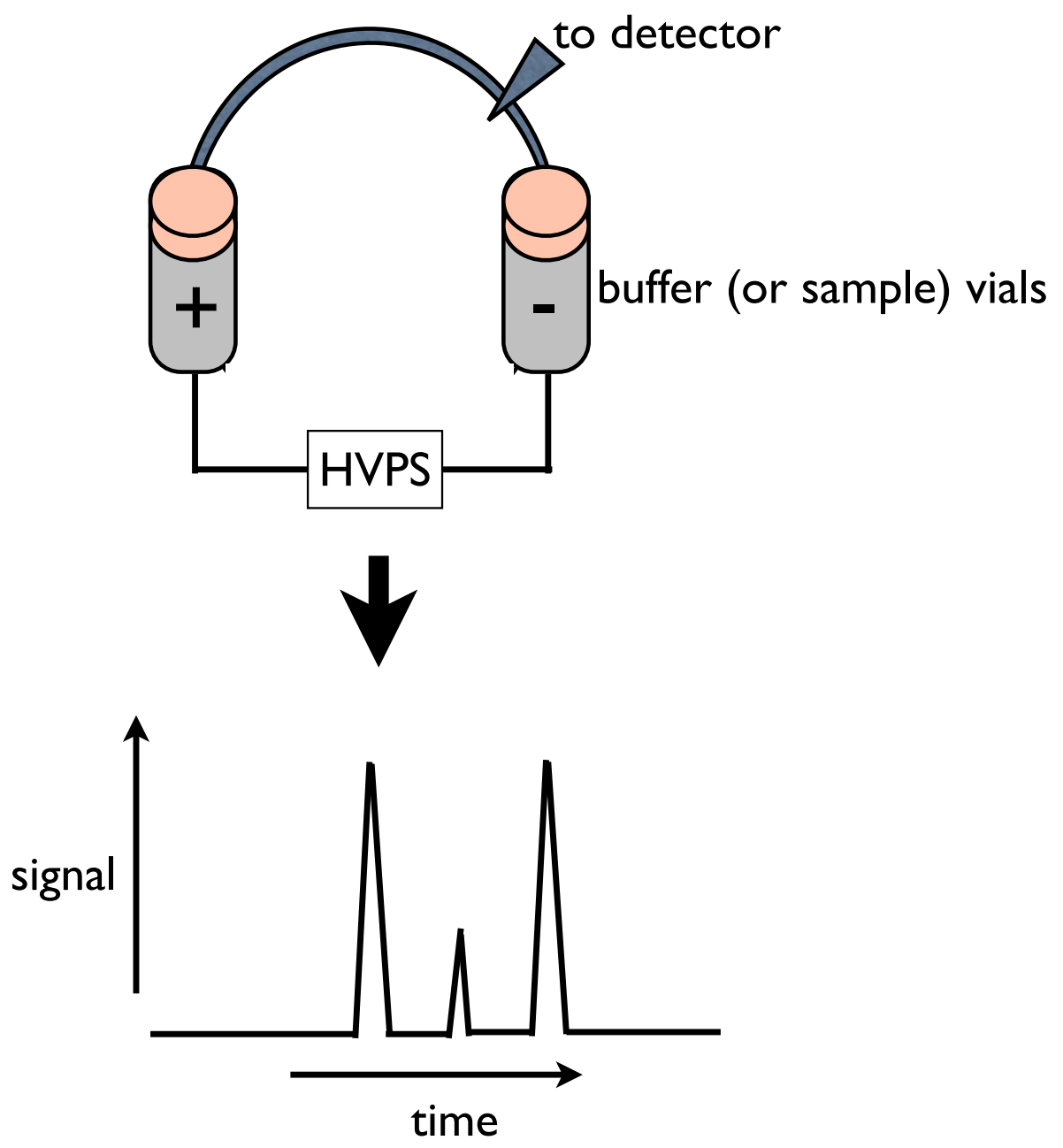

Figure 1-1: Schematic of CE instrument and Electropherogram: Figure 1 shows the basic schematic of a capillary electrophoresis instrument including a fused silica capillary held between two buffer vials attached to a high voltage power supply. Also shown is a representation of an electropherogram showing the separation of three analytes. 


\subsubsection{Electrophoretic Mobility and Electroosmotic Flow}

When a voltage is applied to the capillary, the analytes within it move as a result of their electrophoretic mobility. This mobility is direction dependent, negatively charged species will migrate toward the anode, while positively charged species will migrate toward the cathode. The velocity of this migration is dependent on the analytes' chargeto-size ratio and can be further described as

$$
\mu=q /(6 \pi \eta r) \quad(1-1)
$$

where $q$ is the net charge of the analyte, $\eta \mathrm{s}$ the viscosity of the separations media or buffer, and $\mathrm{r}$ is the hydrodynamic radius of the analyte. During separation, the various analytes within the capillary will separate based on their individual electrophoretic mobilities as discrete bands or zones. This separation method is known as capillary zone electrophoresis. During separation, molecules that are net positive, net negative, or neutral all migrate to the detection window. This indicates that there is secondary force at work within the separations capillary. This force, known as electroosmotic flow, occurs as a result of the charged nature of the fused silica capillary inner wall. The silica surface imparts charge in the form of negative silanol groups in a buffer solution. This charge attracts positive ions from the buffer solution that forms two discrete layers, known as an electronic double layer. The first, known as the Stern layer, is a thin layer of positively charged ions that lays static against the silanol groups. The second, less dense layer of positive ions is known as the Outer Helmoltz plane (OHP). Under an applied voltage, this diffuse layer will migrate toward the cathode, pulling waters of hydration with it. Due to the small inner diameters inherent to $\mathrm{CE}$, this action results in a bulk flow through the 
capillary. Electroosmotic flow, also known as EOF, provides a nonmechanical method of liquid flow through the capillary, and boasts a plug-like fluid flow profile that results in less band broadening than that of hydrodynamic flow. However, EOF is frequently a challenge to reproducibly control. EOF flow rates that are too small result in long migration times and increased time-dependent band broadening for neutral and negative species. EOF flow rates that are too fast result in analytes reaching the detector before they have adequate time to separate. The magnitude of EOF is dependent on both the $\mathrm{pH}$, and ionic strength of the separations buffer. It is common practice in capillary zone electrophoresis to include a known neutral analyte standard as a means to monitor the electroosmotic flow. A simplified schematic of how electrophoretic mobility and electroosmotic result in the separation of analytes is shown in Figure 1-2.

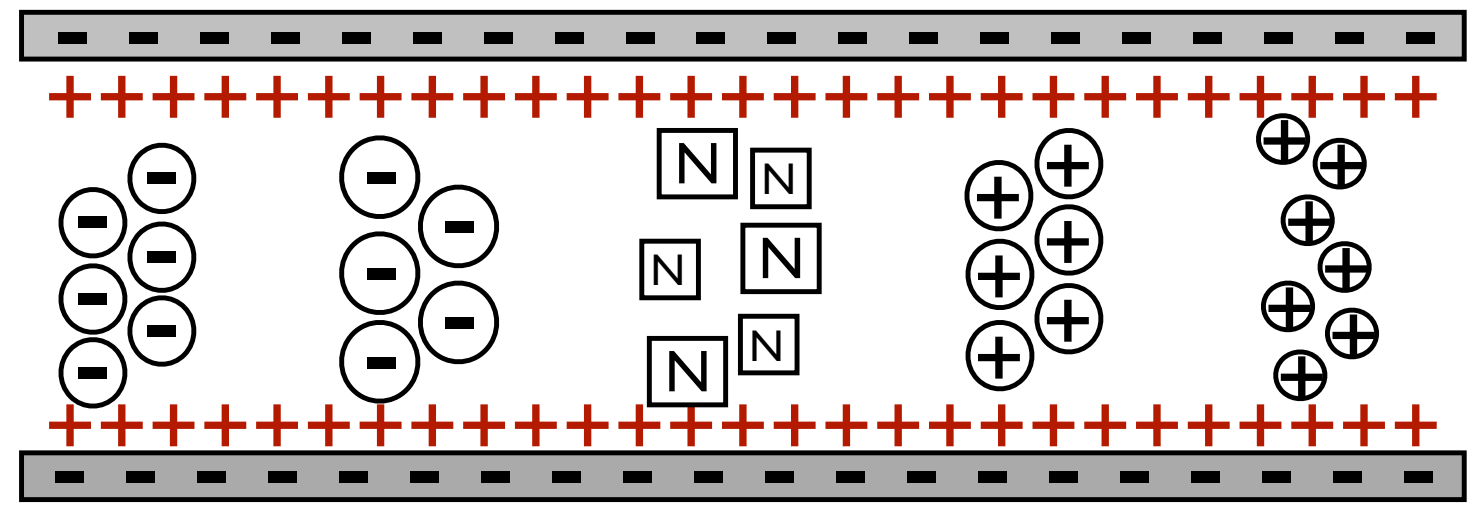

Figure 1-2 shows the migration of ions in capillary electrophoresis. An electronic double layer forms at the wall of the capillary, which is the impetus for a bulk electroosmotic flow. Analytes separate due to their individual electrophoretic mobilities, which are due to the charge and size of the analyte. 


\subsubsection{Resolution of Analytes in CE}

The simplest way to characterize the separation of two bands of analyte is to divide the difference in the migration distance $(\mathrm{x})$ by the average peak width $(\mathrm{w})$, as seen in:

$$
\mathrm{R}=2\left(\mathrm{x}_{2}-\mathrm{x}_{1}\right) /\left(\mathrm{w}_{1}+\mathrm{w}_{2}\right) \quad(1-2)
$$

In the case of capillary separations, $\mathrm{x}$ would be determined by the electrophoretic mobility of the analyte, while w would be determined by the amount of band broadening during separation. If we redefine resolution in terms of a Gaussian distribution

$$
\mathrm{R}=\Delta \mathrm{x}_{\mathrm{i}} / 4 \sigma \quad(1-3)
$$

The two peaks touch at the baseline when $\Delta \mathrm{x}=4 \sigma$ and $\mathrm{R}=1$. We can further use variance $(\sigma)$ for the definition of theoretical plate count where

$$
\mathrm{N}=\mathrm{L}^{2} / \sigma^{2} \quad(1-4)
$$

and the height equivalent of a theoretical plate, or HETP is

$$
\mathrm{HETP}=\mathrm{L} / \mathrm{N}=\sigma^{2} \text { tot }^{\prime} \mathrm{L}(1-5)
$$


These equations describe the efficiency of the separation, is a description of the analyte peak shape, and is a useful concept to relate factors of the analytical separation method. It is important to note that the total variance of the separation is due to a number of dispersive factors and can be rewritten as:

$$
\sigma_{\text {tot }}^{2}=\sigma_{\text {diff }}^{2}+\sigma^{2}{ }^{2}+\sigma_{\text {int }}^{2}+\sigma_{\text {wall }}^{2}+\sigma_{\text {other }}^{2}(1-6)
$$

These sources of variance include variances due to analyte diffusion $\left(\sigma^{2}\right.$ diff $)$ within the capillary, variance due to temperature $\left(\sigma^{2} \mathrm{~T}\right)$ due to heating as a result of current passing through the capillary, variances due to the injection of sample into the capillary $\left(\sigma^{2}\right.$ int $)$, variances due to interactions of the analyte with the capillary wall $\left(\sigma^{2}\right.$ wall $)$ and other variances $\left(\sigma^{2}\right.$ other). These other variances may include specific or nonspecific interactions of the analyte, such as interactions of the glycans to lectins or enzymes. This is further discussed in Chapters 3 and 4. Variances due to the injection of sample into the capillary will be discussed in Chapter 2 .

Increasing the migration distance the analytes must travel has been shown to increase analyte resolution. This can be accomplished by increasing the effective capillary length $[9,10]$. This effect is determined from Giddings [11] which expresses the resolution as:

$$
\mathrm{R}_{\mathrm{s}}=\left(\mathrm{N}^{1 / 2} / 4\right)(\Delta \mathrm{v} / \overline{\mathrm{v}})
$$


where $\mathrm{N}$ is the number of theoretical plates, and $(\Delta v / \bar{v})$ is the relative velocity difference between two analytes. This states that resolution can be related to theoretical plate count. Jorgenson and Lukas [6] further describe this relationship by stating that, if band broadening in CZE can be attributed only to molecular diffusion longitudinally, the plate count can be given as:

$$
\mathrm{N}=1^{2} / 2 \mathrm{Dt}
$$

where $\mathrm{D}$ is the diffusion coefficient of the analyte, 1 is the effective length of the separation, and $t$ is the migration time of the analyte through the effective length. This means that a method of improving separation efficiency is to increase the length of the separation. This effect is further explored in Chapter 2.

\subsection{Phospholipid Separations}

Because the electrophoretic mobility of an analyte is proportional to the viscosity

of the separations media, higher viscosities will result in longer separation times and better resolved analytes. Solutions of phospholipids known as bilayered micelles, or bicelles, are known to have changeable viscosities that are dependent on temperature. These phospholipids can be easily introduced into the capillary and provide superior resolution and separation efficiencies in CE separations. The phospholipid preparations 
of 1,2-dimyristoyl-sn-glycero-3-phosphocholine (DMPC) and 1,2-dihexanoyl-sn-

glycero-3-phosphocholine (DHPC) used as a separations media in this research undergo various morphologies, and thus viscosities. These morphologies are bilayered micelles (bicelles), ribbon-like micelles, and transient interconnected bilayer networks shown in Figure 1-3 [12-14].

DHPC

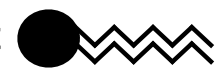

A
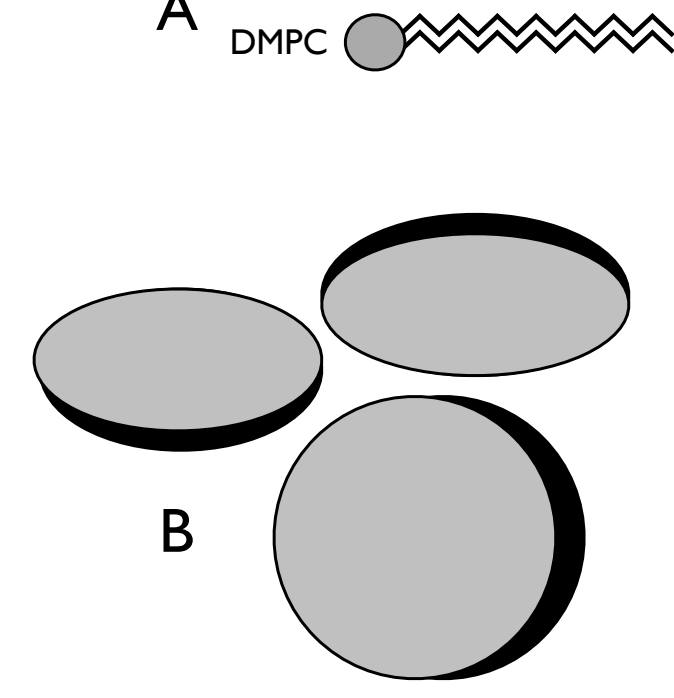

C
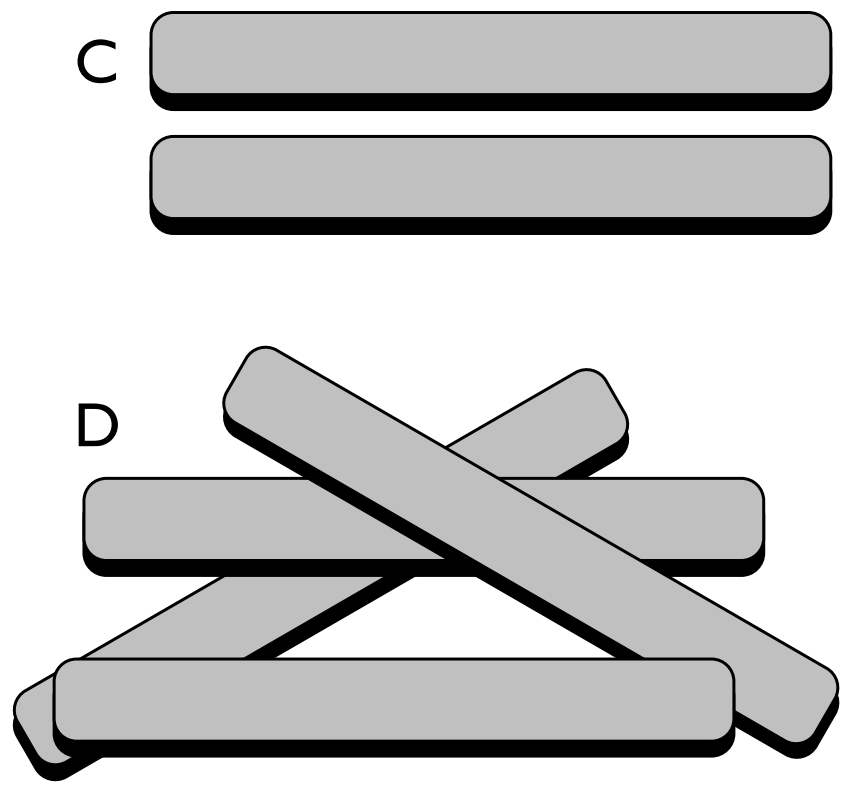

Figure 1-3 shows the phospholipids of study, and their supramolecular morphologies. Figure 3-A shows the two phosphocholine phospholipids used for these studies, short chained DHPC and long chained DMPC. Also shown are the morphologies of these lipid preparations: free floating bicelle discs, long chained ribbons, and entangled ribbons, Figure 3-B, 3-C, and 3-D respectively. Figure adapted from [12].

Bicelles are disk-like structures with a circular center of bilayered DMPC capped with a rim of DHPC (Figure 1-3-B). The radius of this disc is dependent on temperature, hydration, and $q$ value, or the concentration ratio of DMPC to DHPC. This is the primary 
structure of bicelle preparations at room temperature. At higher temperatures $\left(\sim 24{ }^{\circ} \mathrm{C}\right)$ the morphology of the bicelle transitions from disc bicelles to a ribbon-like micelle (Figure 1-3-C) [12]. This morphology results in an substantial increase in viscosity. As the temperature increases these ribbons become more entangled, and result in a further increase in viscosity (Figure 1-3-D). This phospholipid material makes an excellent additive for capillary electrophoresis, as it can be easily introduced into the capillary at low temperatures unlike the highly viscous linear polymer additives used in capillary gel electrophoresis.

\subsubsection{Phospholipid Separations}

Phospholipids have been used in a number of capillary-based separations techniques. Phospholipid preparations have been used as a coating in $\mathrm{CE}$ to suppress the electroosmotic flow and to prevent nonspecific adsorption to the capillary walls [15-18]. They have also been polymerized to immobilize proteins in capillaries and microfluidics for affinity targeting $[19,20]$, and have been used as a pseudo-stationary phase [21,22].

It is important to note that separations of glycans in phospholipid media are not due to sieving. Sieving is a common separation scheme for biopolymers such as the case of separation DNA molecules based on size [23]. Plotting the logarithm of velocity vs the logarithm of molecular mass of homologous series (Ferguson plot) and comparison the resulting slope provides information the mode of separation. Separation of glycans (linear 
or branched) were found to have same slope below and above the entanglement thresholds for the gel in use, indicating that glycans separated by capillary gel electrophoresis separate strictly on differences in charge to size ratio [24]. The same experiment was accomplished with glycan separations in phospholipid media. The data fit for glycans separated in phospholipid media was linear $(R 2=0.998)$ with slopes of $(-0.620)$ that were the same above and below the entanglement threshold of the polymer [5]. This indicates that glycans in phospholipids also are separated based on their hydrodynamic volumes through a viscous media, and not through a mechanism of sieving.

\subsection{Oligosaccharide analysis}

The analysis of carbohydrates provide unique challenges to separations scientists. Glycans affect numerous crucial biological processes and are the molecule of interest in many biochemical studies. While oligosaccharides tend to be similar in overall chemical composition, they display highly complex structures as a result of variable linkage, position, and type. Therefore glycans make excellent test molecules to assay the efficiency and resolution of a separations technique such as capillary electrophoresis. 


\subsubsection{Glycans}

Carbohydrates are among the most abundant of biological molecules, and affect numerous aspects of cellular development and biochemistry. Cellular glycosylation is essential for cell-to-cell communication and internal cellular communication. Glycans affect the folding of proteins as a post-translational modification, as well as the solubility, antigenicity, and eventual clearance of the protein from the body [25]. Glycans derived from glycoproteins are either $\mathrm{N}$ - (asparagine), or O- (serine/threonine) linked to the polypeptide sequence of the protein. The focus of this body of work is on N-liked glycans. Oligosaccharides are comprised of multiple glycan monomers, and monomers common to $\mathrm{N}$-linked glycosylation include $\mathrm{N}$-acetylglucosamine (GlcNAc), galactose (Gal), glucose (Glc), mannose (man), fucose (Fuc), and N-acetylneuraminic acid (NeuAc) (structures shown in Figure 1-4). 


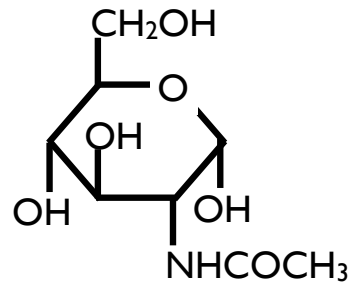

$\alpha-D-N$-acetylglucosamine (GlcNAc)

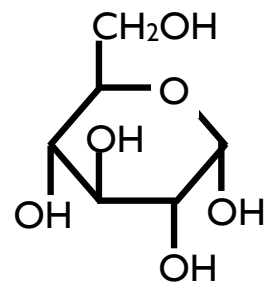

$\alpha$-D-glucose (Glc)

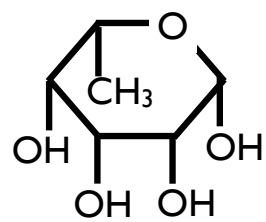

$\alpha$-D-fucose (Fuc)

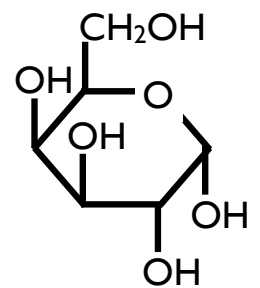

$\alpha$-D-galactose (Gal)<smiles>OCC1OC(O)C2(O)C(O)C1C2O</smiles>

$\alpha-D-m a n n o s e(M a n)$<smiles>CC(=O)NC1CC(O)CC(O)(C(=O)O)CC1(C)C(=O)O</smiles>

$\alpha-D-N-a c e t y l n e u r a m i n i c ~ a c i d ~(N e u A c)$

Figure 1-4 shows glycan monomers typical to N-type glycosylation.

$\mathrm{N}$-glycans all contain a di-GlcNAc, tri-Man core that is attached to the protein. Oligosaccharides can be connected through variable monomer linkage positions and types $(\alpha$ or $\beta$ ) but fall into common overall structure types (Figure 1-5). The overall structures of N-linked glycans can be broken into 3 broad types. These include complex type glycans, high mannose glycans, and hybrid glycans that combine characteristics of 
the two. These structures can be further modified through bisecting GlcNAc monomers, and the addition of fucose.

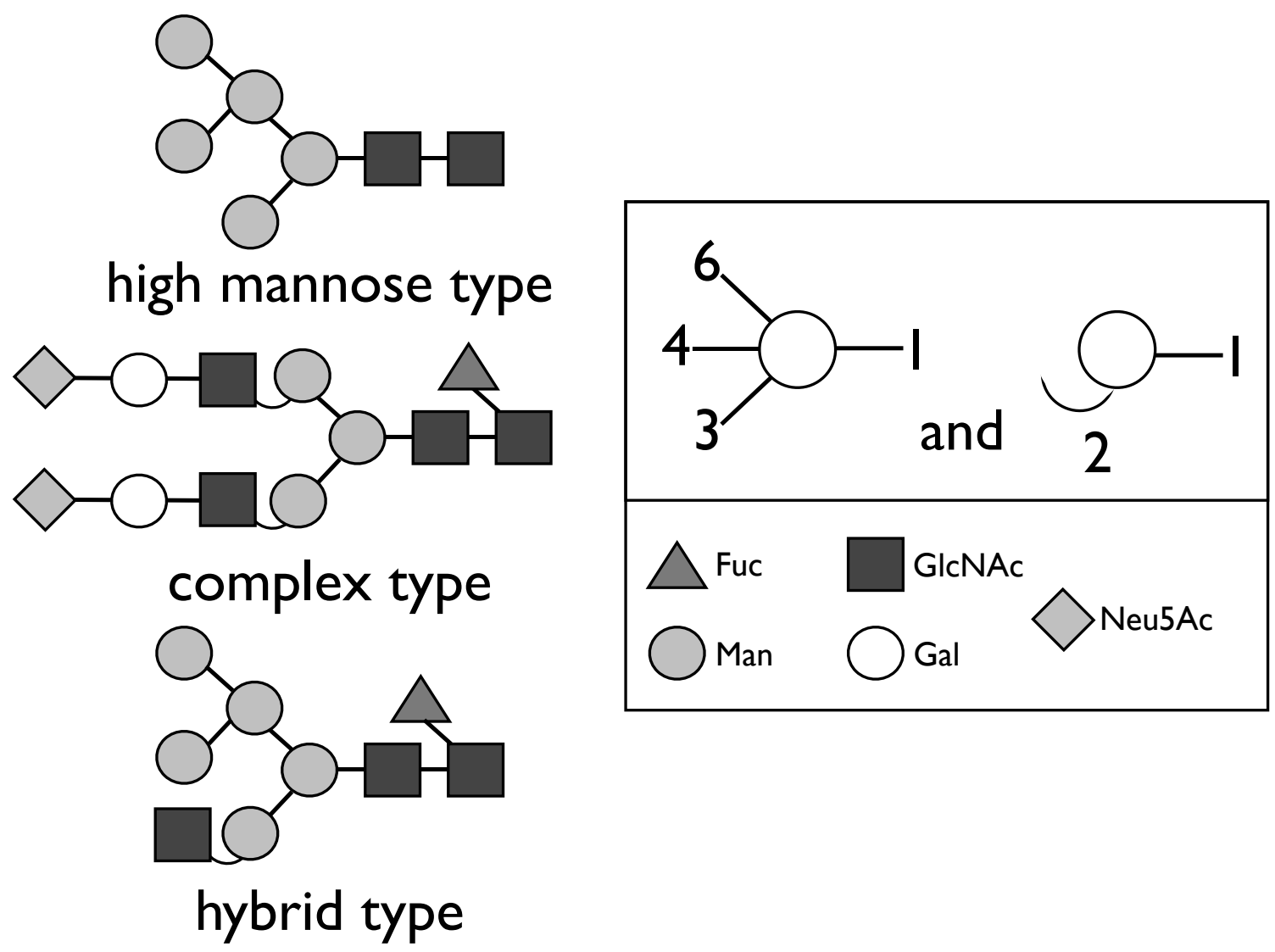

Figure 1-5 shows examples of high mannose, complex, and hybrid type glycans. Also shown is a key describing the various glycan monomers and linkages described in the text.

Both simple and complex carbohydrates tend to be similar in structures, consisting primarily of polyhydroxylated hydrocarbons that are usually very polar and nonvolatile. While carbohydrates display highly similar structures in chemical structure, the overall complexity can be extensive. This is demonstrated in the comparison of of glycan linkages to amino acid linkages. For example, while 2 identical amino acids link 
into a single dipeptide, 2 identical glucose molecules can form 11 different disacchardies. Four different hexopyranoses can produce more than 36,000 different tetrasaccharides [26]. Issues of linkage, position, and type result in great complexity of the final glycan structure.

\subsubsection{Derivatization of Glycans for CE separations}

A challenge to analyze oligosaccharides is that they are not easily detected through optical methods. Carbohydrates are not naturally chromophoric or fluorophoric and thus are not amenable to detection with UV-absorbance or laser-induced fluorescence. Additionally, glycans, which naturally contain charge only through in inclusion of sialic acid, are neutral. Labeling the glycan with a fluorescent tag often serves to provide charge to the molecule, and thus a method of electrophoretic migration through the capillary. A variety of derivatization reagents have been reported by the fluorescence detection of mono- and oligosaccharides in $\mathrm{CE}$, and include labels such as 3- (4-carboxybenzoyl)-2-quinolinecarboxaldehyde (CBQCA) [27], 8aminonaphthalene-1,3,6-trisulfonic acid (ANTS) [28], and 1-aminopyrene-3,6,8trisulfonic acid (APTS) [29]. The use of APTS for the derivatization of glycans has been well documented and is the label used for this research.

The labeling strategy for APTS is shown in Figure 1-6. The amine group from APTS attaches to the anomeric carbon of the sugar to form a reversible Schiff base. This bond attaches through reductive amination, and is further reduced to a stable bond with 
the incorporation of sodium cyanoborohydride. The APTS provides three additional negative charges to the glycan molecule. The labeling of APTS occurs in a 1:1 fashion with the sugar, proving a constant application of charge and label, and allowing for the development of quantitative analysis and for the separation of the glycan based on charge.
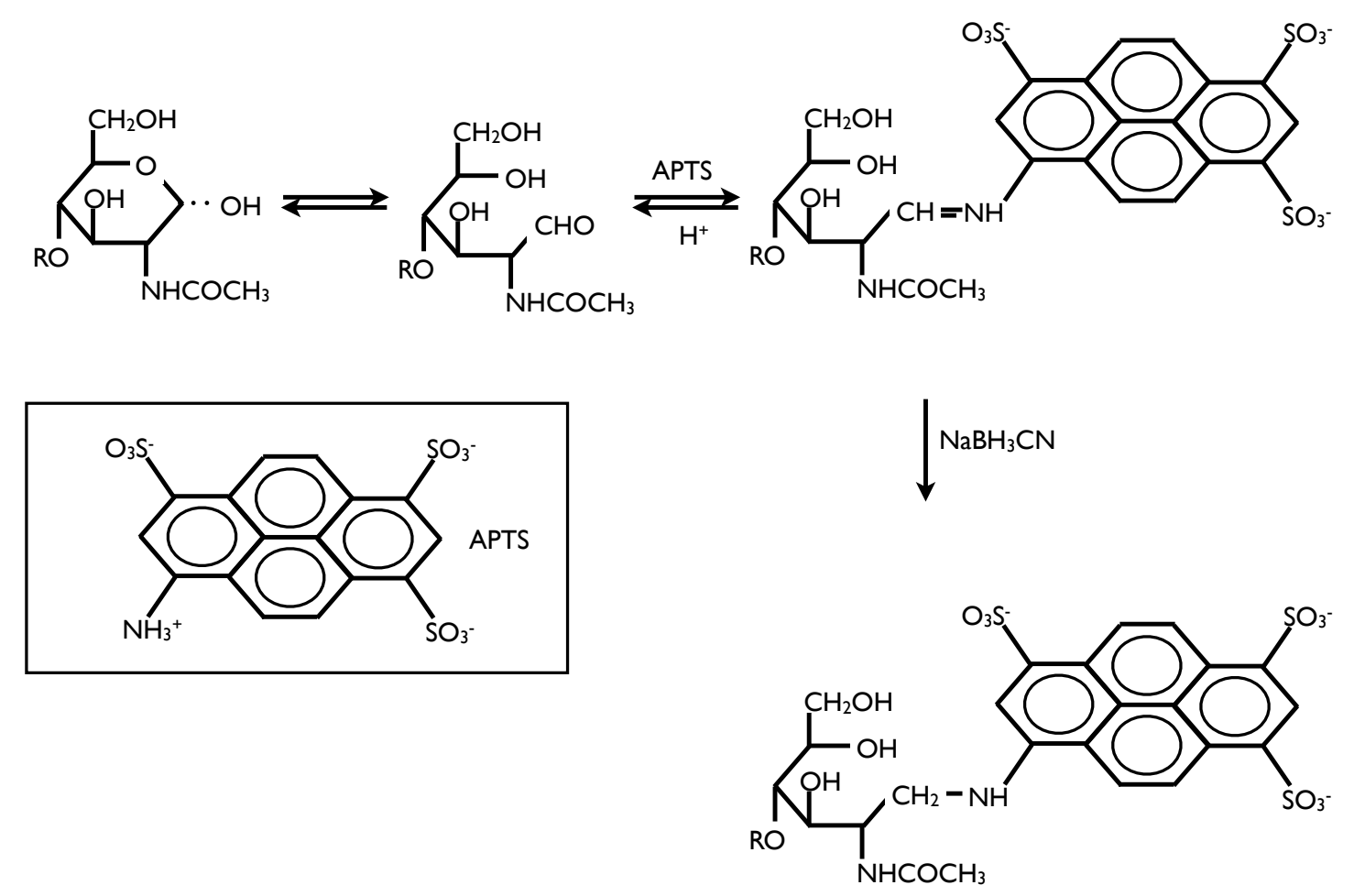

Figure 1-6 displays the reaction scheme for the derivatization of carbohydrates with APTS. 


\subsection{Bibliography}

1. Campa,C., Rossi,M., Capillary electrophoresis of neutral carbohydrates: mono-, oligosaccharides, and glycosides., Methods in Molecular Biology ., 2008. 384: p. 247-305

2. Mechref, Y.; Novotny, M. V. Miniaturized separations techniques in glycomic investigations. Journal of Chromatography B, 2006. 841: p. 65-78

3. Volpi, N.; Maccari, F.; Linhardt, R. J. Electrophoresis of complex natural polysaccharides. Electrophoresis, 2008. 29: p. 3095-3106.

4. Guttman, A.; Ulfelder, K. W. Exoglycosidase matrix-mediated sequencing of a complex glycan pool by capillary electrophoresis. Journal of Chromatography A, 1997. 781:p. 547-554.

5. Luo, R., Archer-Hartmann, S.A., Holland, L.A., Transformable Capillary Electrophoresis for Oligosaccharide Separations Using Phospholipid Additives, Analytical Chemistry, 2010. 82: p. 1228-1233

6. Jorgenson, J.W., and Lukacs, K.D., Zone electrophoresis in open-tubular glass capillaries. Analytical Chemistry, 1981. 53(8): p. 1298-1302

7. Jorgenson, J.W., and Lukacs, K.D., Capillary zone electrophoresis, Science, 1983. 222 (4621): p. 266-272

8. Kostal, V., Katzenmeyes, J., and Arriaga, E.A., Capillary electrophoresis in bioanalysis. Analytical Chemistry, 2008. 80(12): p. 4533-4550 
9. Terabe, S., Otsuka, K., Ichikawa, K., Tsuchiya, A., and Ando, T., Electrokinetic separations with micellar solutions and open-tubular capillaries, Analytical Chemistry, 1984. 56(1): p. 111-113

10. Zhao, J., Hooker, T., Jorgenson, J.W., Synchronous cyclic capillary electrophoresis using conventional capillaries: system design and preliminary results. Journal of Microcolumn Separations, 1999. 11: p. 431-437

11. Giddings, J.C., Generation of Variance, "Theoretical Plates”, resolution and peak capacity in electrophoresis and sedimentation. Separation Science, 1969. 4: p. 181-189

12. M-P, Neih, V.A., Ranghunathan, V.A, Glinka, C.J., Harroun, T.A., Pabst, G., Katsaras, J., Energetically Alignable Phase of Phospholipid "Bicelle" mixtures is a Chiral Nematic Made up of Wormlike Micelles, Langmuir, 2004. 20: p. 7893-7897

13. Rowe, B.A. Neal, S.L., Fluorescence probe study of bicelle structure as a function of temperature: Developing a practical bicelle structure model. Langmuir, 2003. 19: p. 2039-2048

14. Liu, J.P., Shirota, O., Wiesler, D., and Novotny, M., Ultrasensitive fluorometric detection of carbohydrates as derivatives in mixtures separated by capillary electrophoresis. Proceedings of the National Academy of the Sciences of the United States of America, 1991. 88(6): p. 2302-2306

15.Holland, L.A., and Leigh, A.M., Bilayered phospholipid micelles and capillary electrophoresis: A new additive for electrokinetic chromatography. Electrophoresis, 2003. 24: p. $2935-2939$ 
16.Cunliffe, J.M., Baryla, N.E., and Lucy, C.A., Phospholipid bilayer coatings for the separation of proteins in capillary electrophoresis. Analytical Chemistry, 2002. 74: p. $776-783$

17.Wang, C., and Lucy, C.A., Oligomerized phospholipid bilayers as semipermanent coatings in capillary electrophoresis. Analytical Chemistry, 2005. 77: p. 2015-2021

18. White, C.M., Luo, R., Archer-Hartmann, S.A., and Holland L.A., Electrophoretic screening of ligands under suppressed electroosmotic flow with an inert phospholipid coating. Electrophoresis, 2007. 28(17): p. 3049-3055

19. Ross, E.E., Mansfield, E., Huang, Y., and Aspinwall, C.A., In situ fabrication of three-dimensional chemical patterns in fused silica separation capillaries with polymerized phospholipids, Journal of the American Chemical Society, 2005. 127(48): p. $16756-16757$

20.Huang, B., Wu, H., Kim, S., Kobika, B.K., and Zare, R.N. Phospholipid biotinylation of polydimethylsiloxane (PDMS) for protein immobilization. Lab on a Chip, 2006. 6 (3): p. 369-373

21.Zhang, Y., Zhang, R., Hjerten, S., an Lundahl, P., Liposome capillary electrophoresis for analysis of interactions between lipid bilayers and solutes. Electrophoresis, 1995. 16(8): p. 1519-1523

22.Nilsson, C., Becker, K., Harwigsson, I., Bulow, L., Birnbaum, S., and Nilsson, S., Hydrophobic interaction capillary electrochromatography of protein mutants. Use of lipid-based crystalline nanoparticles as a pseudostationary phase. Analytical Chemistry, 2009. 81(1): p. 315-321 
23.Guttman, A., Cohen, A.S., Heiger, N.D., Karger, B.L., Analytical and micropreprative ultrahigh resolution of oligonucleotides by polyacrylamide gel high-performance capillary electrophoresis, Analytical Chemistry, 1990. 62: p. 137-141

24.Guttman, A., Cooke, N., Starr, C.M., Capillary electrophoresis separation of oligosaccharides: I. Effect of operational variables. Electrophoresis, 1994. 15: p. 1518-1522

25. Varki, A., Biological roles of oligosaccharides: all of the theories are correct. Glycobiology, 1993, 3: p.97-130

26. Landers, J.P., Handbook of capillary electrophoresis. 1994: CRC press.

27. Liu, J.P., Shirota, O., Wiesler, D., and Novotny, M., Ultrasensitive fluorometric detection of carbohydrates as derivatives in mixtures separated by capillary electrophoresis. Proceedings of the National Academy of Sciences of the United States of America, 1991. 88(6): p. 2302-2306

28.Chiesa, C., and Horvath, C., Capillary Zone electrophoresis of maltooligosaccharides derivatized with 8-aminonaphthalene-1,3,6-trisulfonic acid. Journal of Chromatography A, 1993. 645(2): p. 337-352

29.Guttman, A., and Starr, C. Capillary and slab gel electrophoresis profiling of oligosaccharides. Electrophoresis, 1995. 16(1): p. 993-997 


\section{Chapter 2}

Development of Phospholipid Assisted CE for Efficient

Glycan Separations 


\subsection{Introduction}

The separations of glycans using phospholipid additives in capillary electrophoresis was first reported by Luo et al in 2010 [1]. In this application, phospholipids served to suppress the electroosmotic flow and acted as a viscous separation media to improve analyte resolution and efficiency. This chapter covers the advancement of phospholipid separations in terms of injection optimization, capillary inner diameter, capillary length, and field strength.

\subsubsection{Phospholipids}

Phospholipids have been utilized to enhance chemical separations for studies of membrane affinity [2], lipophilicity [3], and liposome interaction [4], and as a pseudostationary phase to separation proteins [5]. Phospholipids are excellent coatings for capillary electrophoresis, as they are naturally biocompatable, and form semipermanent coatings that do not require covalent modification of the capillary, nor the presence of the phospholipid in the running buffer. The phospholipids used for the separation of glycans consist of the long chain phosphocholine 1,2-dimyristoyl-snglycero-3-phosphocholine (DMPC) and 1,2-dihexanoyl-sn-glycero-3-phosphocholine (DHPC) shown in Figure 2-1. 
<smiles>CCCCCCCCCCCCCC(=O)OC[C@H](COP(=O)([O-])OCC[N+](C)(C)C)OC(=O)CCCCCCCCCCCC</smiles>

1,2-dimyristoyl-sn-glycero-3-phosphocholine DMPC<smiles>[2H][C@@H](COC(=O)CCCCC)OC[C@H](O)OP(=O)([O-])OCC[N+](C)(C)C</smiles>

\section{1,2-dihexanoyl-sn-glycero-3-phosphocholine $\mathrm{DHPC}$}

Figure 2-1 displays the chemical structures of DMPC and DHPC, the two phospholipids used for this body of work.

Aqueous preparations of these two phospholipids are described in terms of molar ratios of $[\mathrm{DMPC}] /[\mathrm{DHPC}]$, or the $q$ value of the solution. Aqueous phospholipid preparations comprised of 1,2-dimyristoyl-sn-glycero-3-phosphocholine (DMPC) and 1,2-dihexanoyl-sn-glycero-3-phosphocholine (DHPC) display atypical temperaturedependent viscosity. At temperatures below the gel phase transition, the viscosity of an aqueous phospholipid preparation is similar to that of water. Above the gel phase transition, the viscosity increases dramatically to a maximum at $\sim 29{ }^{\circ} \mathrm{C}$. [6] The temperature-induced change in viscosity of aqueous phospholipid preparations is a function of the q-value as well as the percent hydration. The viscosity can increase with 
temperature as much as 370 -fold for $\mathrm{q}=2.5-10 \%$ phospholipid preparations and even more so when comparing preparations of different q-values [6]. This transition has practical use for capillary electrophoresis separations, as they are easily introduced into the capillary at low temperatures as an additive for chemical separations.

\subsubsection{Effects of Phospholipid Composition on Separations Performance}

To appropriately utilize phopsholipid bicelles for the separations of small molecules such as glycans, a number of parameters were characterized by Luo et al [1]. Because the morphology of the phospholipid affects its overall properties as a separations media, the effects of lipid content, composition, and temperature on the the separation were determined. The previous research in this field provided a starting point to this body of research.

\subsubsection{Utilization of Bicelle Coatings and Separations Media}

The method of sample introduction for phospholipid-mediated capillary electrophoresis separations must account for a significant temperature dependent change in viscosity of the media. Therefore, the filling of the capillary, and other hydrodynamic injections are performed for phospholipid preparations of different viscosity by injecting samples at temperatures below the gel-phase transition at which all phospholipid preparations display similar low viscosity. Following the injection, the capillary temperature is increased to a specified value and the separation proceeds. This protocol 
can increase the total analysis time by as much as 5 min but is necessary to compare open-tubular separations with phospholipid-mediated separations.

\subsubsection{Effects of Q-value, Hydration and Temperature}

Previous research compared three different ratios of $[\mathrm{DMPC}] /[\mathrm{DHPC}]$, or $q$ values. Q-values of $\mathrm{q}=1.5,2.0$, and 2.5 were compared at equivalent percent hydration (5\%). Separations of branched glycans were conducted using these three solutions at various temperatures ranging from 21 to $35^{\circ} \mathrm{C}$. The migration reproducibility varied with the $\mathrm{q}$ value, with $\mathrm{q}$ values of 2.5 providing the best reproducibility. While there was no discernible trend in the theoretical plate count or resolution of glycans with these three $5 \%$, phospholipid preparations, $\mathrm{q}=2.5$ phospholipid preparations were used to provide the reproducibilities needed for more precise analysis.

$\mathrm{Q}=2.5$ phospholipids at 5, 10, and $15 \%$ preparations were also compared at various temperatures $\left(21\right.$ to $\left.35^{\circ} \mathrm{C}\right)$ in terms of separation efficiency and resolution. Q 2.5, $10 \%$ preparations provided overall better separations than the other two percent hydrations. A separation of the branched glycans taken from bovine asialofetuin showed that, for a $40.2 \mathrm{~cm}$ capillary (30.2 $\mathrm{cm}$ effective length) with a $50 \mu \mathrm{m}$ i.d, theoretical plate counts as high as 240,000 could be obtained. These maximum efficiencies, and the maximum resolutions were obtained at $25{ }^{\circ} \mathrm{C}$. Therefore this report utilized phospholipid additives that were $\mathrm{q}=2.5,5 \%$ hydration and were used for separations at $25^{\circ} \mathrm{C}$, and were also used for the studies in this body of work. 


\subsubsection{Sample Introduction}

The method of sample introduction a the capillary must account for the significant change in viscosity following change in temperature to the phospholipid separations media. This viscosity can result in inconsistent injections if a suitable protocol for the electrokinetic introduction of sample into the capillary is not used. Luo et al first reported the use of a small aqueous plug of buffer into the phospholipid before and after the electrokinetic injection of the glycan [1]. Electrokinetic sample introduction is also frequently employed in capillary gel electrophoresis, where a small aqueous plug is hydrodynamically injected into the capillary before electrokinetically injecting the analyte. Inclusion of this pre-plug was shown to improve sample introduction [1,7]. A small plug of buffer following the electrokinetic injection was also shown to reduce peak tailing [8] and thus was also incorporated .The protocol utilizes an aqueous pre-plug of MOPS into the phospholipid material before and after the analyte is electrokinetically injected. These pre and post plugs improve the reproducibility of peak area and greatly reduces peak asymmetry. 


\subsection{Experimental}

\subsubsection{Chemicals and Materials}

Reagents were obtained from a variety of manufacturers. Sigma Aldrich (St. Louis, MO, USA) was the source for asialofetuin from fetal calf serum, 3-(N-morpholino)propanesulfonic acid (MOPS), calcium chloride dihydrate, maltooligosaccharide standards, sodium chloride, and sodium hydroxide. Methanol and $\alpha 1$-acid glycoprotein (AGP) were purchased from EMD Biosciences (La Jolla, CA). Ethanol was obtained from AAPER Alcohol (Shelbyville, KY). 1,2-dimyristoyl-sn-glycero-3-phosphocholine (DMPC) and 1,2-dihexanoyl-sn-glycero-3-phosphocholine (DHPC) were obtained from Avanti Polar Lipids (Alabaster, AL). 1-aminopyrene-3,6,8-trisulfonic acid (APTS) was purchased from Biotium (Hayward, CA). Sodium cyanoborohydride $\left(\mathrm{NaCNBH}_{3}\right)$ was acquired from Strem Chemicals (Newburyport, MA). Triethylamine, acetonitrile, and citric acid were acquired from Fisher Scientific (Pittsburgh, PA). An Elga Purelab ultra water system (Lowell, MA) was used to provide deionized water.

\subsubsection{Glycan Labeling and Preparation}

Glycans derived from glycoproteins (Rnase B, asialofetuin, and $\alpha$-acid glycoprotein) were prepared as follows. Glycans were removed from protein sources using a PNGase F kit using protocol based on the kit from the manufacturer. Briefly the protein is denatured using a solution containing sodium dodecyl sulfate (SDS), dithiothreitol (DTT) and 
heating at $95{ }^{\circ} \mathrm{C}$ for 10 minutes. The nonionic surfactant NP-40 is then added to the solution to prevent the DTT from denaturing the enzyme PNGase F, which immediately added afterward. This reaction was incubated at $37^{\circ} \mathrm{C}$ overnight, rather than the 2 hours suggested by the protocol. The next day, a $3 \mathrm{X}$ volume of ice-cold ethanol was added to precipitate the protein. The solution was centrifuged at $4{ }^{\circ} \mathrm{C}$ at $10000 \mathrm{rpm}$ for 10 minutes. The liquid fraction containing cleaved glycans was dried using a Savant SpeedVac concentrator (ThermoScientific, Waltham, MA). The dried glycans, or dried glycan standards were reconstituted in $1 \mu \mathrm{L}$ of a $0.2 \mathrm{M}$ solution of APTS dissolved in 1.2 M citric acid, along with $1 \mu \mathrm{L}$ of $1 \mathrm{M} \mathrm{NaCNBH}_{3}$ in deionized water. The solution was thoroughly mixed before being incubated overnight at $37{ }^{\circ} \mathrm{C}$. The reaction was stopped with the addition of $100 \mu \mathrm{L}$ of deionized water. If needed, the sialic acid was removed by adjusting the $\mathrm{pH}$ of the glycan solution to 6 with sodium hydroxide then incubating it overnight with neuraminidase. If necessary, a $10 \mathrm{kDa}$ molecular weight cut off filter (Sartiorius, Stonehouse, UK) was used to remove the neuraminidase followed by removal of excess APTS by a Discovery DPA-6S solid phase extraction cartridge (50 mg packing, Supelco, Bellefonte, PA). A flush of 95:5 (v/v) acetonitrile:water was used to prepare the cartridge prior to use. APTS was eluted from the extraction cartridge with a solution containing 95:5 (v/v) acetonitrile:water containing 50mM trimethylamine. An aqueous solution of 50mM triethylamine was used to elute the retained glycans from the cartridge. The glycan solution was evaporated to dryness and the reconstituted in $100 \mu \mathrm{L}$ deionized water and stored at $-20^{\circ} \mathrm{C}$. 


\subsubsection{Phospholipid Preparation}

Preparations of phospholipids were comprised of 5\%, [DMPC $] /[\mathrm{DHPC}](\mathrm{q}$ value) $=0.5$ were used for coating of the capillary, which serves to suppress the electroosmotic flow, and to passivate the surface from nonspecific interactions. Another phospholipid preparation of a $10 \%, q=2.5$, phospholipid solution was used for the separation media, due to the thermally-switchable gel-like viscosity of the material. These phospholipids were prepared by weighing out the appropriate masses of dry DMPC and DHPC, then adding $100 \mathrm{mM}$ aqueous MOPS buffered to $\mathrm{pH}$ 7. After the solution was thoroughly mixed, the preparation was subjected to a minimum of three freeze-thaw cycles and centrifuged for 10,000 rpm for ten minutes. The phospholipid preparation was stored at $-20^{\circ} \mathrm{C}$, and was thawed and vacuum degassed prior to use.

\subsubsection{Capillary Electrophoresis}

Separations were performed using a P/ACE MDQ Capillary electrophoresis system (Beckman Coulter, Fullerton, CA) equipped with laser induced fluorescence detection (air cooled argon ion laser, $\lambda_{\mathrm{ex}}=488 \mathrm{~nm}, \lambda_{\mathrm{em}}=520 \mathrm{~nm}$ ). The fused silica separation capillary had a $25 \mu \mathrm{m}$ internal diameter and a $360 \mu \mathrm{m}$ outer diameter (Polymicro Technologies, Phoenix, AZ) with an effective length of $50.0 \mathrm{~cm}$ and a total length of $60.2 \mathrm{~cm}$. Capillaries were subject to the following flushing sequence daily: $1 \mathrm{M}$ $\mathrm{NaOH}$ for 30 minutes at $170 \mathrm{kPa}(25 \mathrm{psi})$, deionized water for 15 minutes at $170 \mathrm{kPa}$ (25 
psi), methanol for 15 minutes at $170 \mathrm{kPa}(25 \mathrm{psi})$, and 15 minutes of water at $170 \mathrm{kPa}(25$ psi). Following this flushing sequence, the capillary was passivated with a phospholipid coating with a $5 \%, \mathrm{q}=0.5$ phospholipid preparation containing $1.25 \mathrm{mM}$ calcium. This semi-permanent coating was applied for 20 minutes at $170 \mathrm{kPa}$ ( $25 \mathrm{psi}$ ) followed by a 2 minute MOPS flush at $170 \mathrm{kPa}$ ( $25 \mathrm{psi})$ to remove excess phospholipid and from the capillary. A brief pre-coat was applied prior to each run using the following protocol at $170 \mathrm{kPa}(25 \mathrm{psi})$ with the capillary held at $19^{\circ} \mathrm{C}: \mathrm{q}=0.5,5 \%$ phospholipids for 3 minutes, MOPS for 2 minutes, and $\mathrm{q}=2.5,10 \%$ phospholipids for 3 minutes. If enzyme was being used in-capillary, an additional 3 minute $170 \mathrm{kPa}$ (25 psi) MOPS flush was performed in the reverse direction before this sequence, to expel any enzymes from the capillary, and to prevent fouling of the capillary. When the room temperature was higher than $22{ }^{\circ} \mathrm{C}$, a portable air conditioner was used to provide ambient thermal control. Injections into the capillary were carried out in three steps. First, a plug a MOPS was injected into the phospholipid filled capillary $(7 \mathrm{sec}$, at $6.9 \mathrm{kPa})$ at $19{ }^{\circ} \mathrm{C}$. The capillary temperature was then heated to $25^{\circ} \mathrm{C}$, resulting in the viscosity of the $\mathrm{q}=2.510 \%$ phospholipid filling to increase to a gel-like consistency. The glycan is then electrokinetically injected into the capillary. Finally a post-plug of MOPS was pressure injected ( $5 \mathrm{sec}, 3 \mathrm{kPa}$ ). Separations were carried out at $400 \mathrm{~V} / \mathrm{cm}$ under reversed polarity. Data collection and analysis were performed using 32 Karat Software version 5.0 (Beckman Coulter). Theoretical plates were calculated using 32 Karat Software using the "USP plates" criterion. 


\subsection{Results and Discussion}

The results provided in this section have been peer-reviewed and published in reference [9].

\subsubsection{Effects of Capillary Inner Diameter}

Previous experiments utilizing phospholipid additives were accomplished with a $50 \mu \mathrm{m}$ i.d., $30.2 \mathrm{~cm}$ effective length capillary [1], but should be compatible with varying capillary inner diameters, including $25 \mu \mathrm{m}$ i.d.s. The advantages of utilizing a smaller i.d. capillary include reduced consumption of phospholipid additives as well as incorporated proteins. This advantage is explained further in Chapters 3 and 4 of this document. Reducing the i.d. of the capillary also results in a reduction of the separation current. The majority of separations reported in this research were accomplished in a 25 $\mu \mathrm{m}$ inner diameter. While separations with 75 and $100 \mu \mathrm{m}$ i.d capillaries are feasible, they were not pursued.

\subsubsection{Optimization of Injection}

This protocol utilizes an aqueous pre-plug of MOPS into the phospholipid material before and after the analyte is electrokinetically injected. The protocol was originally reported by Luo et al. [1] for a $50 \mu \mathrm{m}$ i.d., $30.2 \mathrm{~cm}$ effective length capillary, but was further optimized for a $25 \mu \mathrm{m}$ i.d capillary. Experiments were conducted to determine optimum pre and post-plug sizes, as well as the effects of injection size on separation efficiency and area reproducibility. 
The injection of a small plug of buffer prior to the electrokinetic injection of sample creates an ion depleted zone for the negatively charged glycans to inject into [7]. To determine if the volume of the buffer pre plug affects the plate count, two different plug sizes were compared for a $10 \mathrm{kV} 3 \mathrm{sec}$ injection of high mannose glycans from RNase B in a $30.2 \mathrm{~cm}$ capillary. The results of these separations are shown in Table 2-2. They reveal no statistical difference until the plug size was less than $3 \mathrm{kPa}(0.5 \mathrm{psi}) 7 \mathrm{sec}$. Under these conditions the oligosaccharides could no longer be reproducibly injected. Therefore injections were accomplished with a $6.9 \mathrm{kPa}(1 \mathrm{psi}) 7 \mathrm{sec}$, unless otherwise noted.

\begin{tabular}{|c|c|c|}
\hline Table 2-1: & nparis & re-plug S \\
\hline Plug size & Plates & Area \\
\hline 10psi $7 \mathrm{sec}$ & 370,000 & 4600 \\
\hline 1psi $7 \mathrm{sec}$ & 420,000 & 4300 \\
\hline $0.5 p s i 5 \mathrm{sec}$ & 370,000 & 4800 \\
\hline $\begin{array}{l}\text { Mannose } 6 \text { (from } \\
50.2 \mathrm{~cm} \text {, sample } \\
\text { BGE }=100 \mathrm{mM} M \mathrm{MC} \\
\text { permission from } \\
\text { Society. }\end{array}$ & $\begin{array}{l}\text { ase B), } n=1 \\
\text { ted for } 10 \mathrm{kV} \\
\mathrm{pH} 7 \text {. This c } \\
\text { Copyright } 20\end{array}$ & $\begin{array}{l}.2 \mathrm{~cm}, \mathrm{Lt}= \\
\text { app }=400 \mathrm{~V} / \mathrm{cm} \text {, } \\
\text { reproduced with } \\
\text { can Chemical }\end{array}$ \\
\hline
\end{tabular}

Table 2-2: Comparison of Two Pre plug Sizes

Plug size Time (RSD\%) Area (RSD\%) Plates (RSD\%) $3 \mathrm{kPa}(0.5 \mathrm{psi}) 7 \mathrm{sec} 6.95(1 \%) \quad 92,000(20 \%) \quad 78,000(4 \%)$ $6.9 \mathrm{kPa}(1 \mathrm{psi}) 7 \mathrm{sec} \quad 6.85(1 \%) \quad 91,000(20 \%) \quad 81,000(5 \%)$ Mannose 6 (from RNase B), $n=3$, Leff $=20.2 \mathrm{~cm}, \mathrm{~L}_{\mathrm{t}}=30.2 \mathrm{~cm}$, sample injected for $10 \mathrm{kV} 3 \mathrm{sec}, \mathrm{Eapp}=400 \mathrm{~V} / \mathrm{cm}, \mathrm{BGE}=100 \mathrm{mM}$ MOPS pH 7 . Time is in minutes. This data was reproduced with permission from [9]. Copyright 2011 American Chemical Society. 
The injection of a small plug of MOPS after the electrokinetic injection in the 50 $\mu \mathrm{m}$ i.d. capillary prevents peak tailing [1], as a result of carryover of analyte [8]. No statistical difference in area or plate count was obtained with the inclusion of a postinjection plug (as shown in Table 2-3). However, because the inclusion of a small postinjection plug did not increase the analysis time, and does prevent long-term contamination of the separation buffer vials, a $(3 \mathrm{kPa}(0.5 \mathrm{psi}) 5 \mathrm{sec})$ plug was used.

\section{Table 2-3. Effect of Post plug size}

\begin{tabular}{llll} 
Post Plug & Time (RSD) & Area (RSD) & Plates (N) \\
wait & $13.2(1 \%)$ & $49,000(20 \%)$ & $520,000(4 \%)$ \\
0.5psi 5s + wait & $13.1(1 \%)$ & $43,000(7 \%)$ & $520,000(2 \%)$ \\
1psi 7s + wait & $13.1(1 \%)$ & $44,000(20 \%)$ & $530,000(3 \%)$ \\
5psi 5s + wait & $13.1(1 \%)$ & $45,000(20 \%)$ & $530,000(5 \%)$ \\
\hline
\end{tabular}

Mal 5 (from Maltoses), $n=3$, Leff $=50.2 \mathrm{~cm}, \mathrm{Lt}=60.2 \mathrm{~cm}$, sample injected for $10 \mathrm{kV} 3$ $\mathrm{sec}, \mathrm{Eapp}=400 \mathrm{~V} / \mathrm{cm}, \mathrm{BGE}=100 \mathrm{mM}$ MOPS $\mathrm{pH}$ 7. This data was reproduced with permission from [9]. Copyright 2011 American Chemical Society.

The time of the electrokinetic injection affects separation efficiency, as the peak broadening associated with sample introduction is related to the analyte injection band size [10-12]. Therefore, the highest efficiency separations are obtained with the smallest possible injection volumes. However, the ramp time for applied voltage affects the peak area reproducibility. This is demonstrated in Table 2-4 using the glycans derived the RNase B, which compares three injections of varying injection voltage but identical duration. As the injection voltage is increased, the width of injection band increases. This 
reduces the plate count, as the area increases. The highest plate count was obtained for a $2 \mathrm{kV} 9 \mathrm{sec}$ injection. However, the area reproducibility of injections performed at $2 \mathrm{kV} 9$ sec had a relative standard deviation of $20 \%$.

\begin{tabular}{|c|c|c|}
\hline Injection & Area (RSD) & Plates (N) \\
\hline $2 \mathrm{kV} 9 \mathrm{sec}$ & $34,000(20 \%)$ & $97,000(3 \%)$ \\
\hline $4 \mathrm{kV} 9 \mathrm{sec}$ & $89,000(5 \%)$ & $76,000(5 \%)$ \\
\hline $6 \mathrm{kV} 9 \mathrm{sec}$ & $133,000(5 \%)$ & $48,000(3 \%)$ \\
\hline
\end{tabular}

Mannose 6 (from RNase B), $n=5$, Leff $=20.2 \mathrm{~cm}, \mathrm{Lt}=30.2 \mathrm{~cm}$, other conditions as described in Table 1. This data was reproduced with permission from [9]. Copyright 2011 American Chemical Society.

The trade-off between precision and plate count is further demonstrated in Table 2-5. If the user requires highly efficient separations, an injection of $10 \mathrm{kV} 3 \mathrm{sec}$ may be used. However, if quantitative data is required, a $4 \mathrm{kV} 5 \mathrm{sec}$ injection will result in a reduced plate count, but area reproducibilities of $6 \%$.

Table 2-5. Effect of Injection Size on Precision and Plate Count

\begin{tabular}{|c|c|c|c|}
\hline Injection & Time (RSD) & Area(RSD) & Plates (N) \\
\hline $10 \mathrm{kV} 3 \mathrm{sec}$ & $15.1(0.1 \%)$ & $16,000(10 \%)$ & $537,000(2 \%)$ \\
\hline $4 \mathrm{kV} 5 \mathrm{sec}$ & $14.7(1 \%)$ & $28,000(6 \%)$ & $485,000(6 \%)$ \\
\hline
\end{tabular}




\subsubsection{Effects of Capillary Length on Efficiency}

To characterize the effects of capillary length on the separation efficiency, branched glycans taken from RNase B (Table 2-6) and linear maltooligosaccharides (Table 2-7) were separated in capillaries with varying effective lengths. The total capillary length varied from 30.2 to $60.2 \mathrm{~cm}$, which the effective capillary length varying from 10.2 to $50 \mathrm{~cm}$. Separations of the glycans were injected for $10 \mathrm{kV} 3 \mathrm{sec}$ and separated at an applied voltage of $400 \mathrm{~V} / \mathrm{cm}$. When the effective capillary length was increased, the corresponding plate count also increased. This trend was equivalent for both the branched and linear glycans. When the total length of the capillary was kept constant, but the effective length was changed, the higher effective separation length resulted in a higher theoretical plate count. This was accomplished by performing separations on a capillary with a total length of $60.2 \mathrm{~cm}$, but introducing sample from either end of the capillary, providing an effective length of either 10.2 or $50.0 \mathrm{~cm}$. Interestingly, the gains in efficiency as a function of increasing effective length are not linear. This can be seen in both Tables 2-6 and 2-7 where the plates per meter also increase with increasing effective capillary length. Based on this data, the optimum separation length was determined to be with a 50.0 effective, $60.2 \mathrm{~cm}$ total capillary length, which provided theoretical plate counts of more than a half a million plates 


\begin{tabular}{|c|c|c|c|}
\hline$L_{\text {eff }}(\mathrm{cm})$ & Time (RSD) & Plates (RSD) & Plates per meter $(\mathrm{N} / \mathrm{m})$ \\
\hline 10 & $3.11(1 \%)$ & $32,000(3 \%)$ & 320,000 \\
\hline 20 & $6.05(0.2 \%)$ & $133,000(2 \%)$ & 665,000 \\
\hline 30 & $8.88(0.7 \%)$ & $234,000(3 \%)$ & 780,000 \\
\hline 40 & $12.14(0.4 \%)$ & $378,000(1 \%)$ & 945,000 \\
\hline 50 & $15.1(0.1 \%)$ & $530,000(2 \%)$ & $1,060,000$ \\
\hline
\end{tabular}

Mannose 6 (from RNase B), $n=5$, sample injected for $10 \mathrm{kV} 3 \mathrm{sec}$. The applied voltage was $400 \mathrm{~V} / \mathrm{cm}$. The anodic/cathodic reservoir contained $100 \mathrm{mM}$ MOPS buffered at $\mathrm{pH}=7$, and the capillary was filled with $10 \% \mathrm{q}=2.5$ phospholipid as described in the text. RSD = relative standard deviation. This data was reproduced with permission from [9]. Copyright 2011 American Chemical Society.

Table 7. Effect of Length on Separation Efficiency (linear glycan)

\begin{tabular}{lrrr}
\hline Leff $(\mathrm{cm})$ & Time $(\mathrm{RSD})$ & \multicolumn{1}{c}{ Plates $(\mathrm{N})$} & Plates per meter $(\mathrm{N} / \mathrm{m})$ \\
10 & $2.74(0.7 \%)$ & $44,000(5 \%)$ & 440,000 \\
20 & $5.41(0.2 \%)$ & $149,000(1 \%)$ & 745,000 \\
30 & $7.85(0.1 \%)$ & $247,000(2 \%)$ & 823,000 \\
40 & $10.75(0.01 \%)$ & $370,000(3 \%)$ & 930,000 \\
50 & $13.38(0.2 \%)$ & $536,000(1 \%)$ & $1,070,000$
\end{tabular}

Maltose 5 (from linear maltoses), $n=5$, sample injected for $10 \mathrm{kV} 3 \mathrm{sec}$. The applied voltage was $400 \mathrm{~V} / \mathrm{cm}$. The anodic/cathodic reservoir contained $100 \mathrm{mM}$ MOPS buffered at $\mathrm{pH}=7$, and the capillary was filled with $10 \% \mathrm{q}=2.5$ phospholipid as described in the text. RSD = relative standard deviation. This data was reproduced with permission from [9]. Copyright 2011 American Chemical Society.

\subsubsection{Effects of Electric Field Strength on Efficiency}

Separation efficiency is increased in CE when the applied voltage is as high as possible without inducing band broadening due to Joule heating. The risk of Joule heating is especially relevant to the use of phospholipid additives due to the temperature dependent viscosity of the media. Therefore, the highest applied field strength that does 
not lead to Joule heating will provide the best efficiency. Because the maximum applied voltage for the Beckman $\mathrm{P} / \mathrm{ACE}$ MDQ capillary electrophoresis instrumentation is limited to $30 \mathrm{kV}$, a shorter capillary $(40.2 \mathrm{~cm}, 25 \mu \mathrm{m})$ was utilized to provide a wide range of field strengths. A plot of plate height versus the electric field strength is shown in Figure 2-2. The field strengths range from 100 to $600 \mathrm{~V} / \mathrm{cm}$. and were based on the $\mathrm{n}=3$ separation efficiencies of maltopentaose. The lowest plate heights were obtained at field strengths between $350 \mathrm{~V} / \mathrm{cm}$ and $450 \mathrm{~V} / \mathrm{cm}$. This information is consistent with the separation suffering from longitudinal band broadening at field strengths at field strengths below $350 \mathrm{~V} / \mathrm{cm}$, and Joule heating effects at field strengths above $450 \mathrm{~V} / \mathrm{cm}$. Therefore all glycan separations were performed at an effective field strength of $400 \mathrm{~V} /$ $\mathrm{cm}$. 


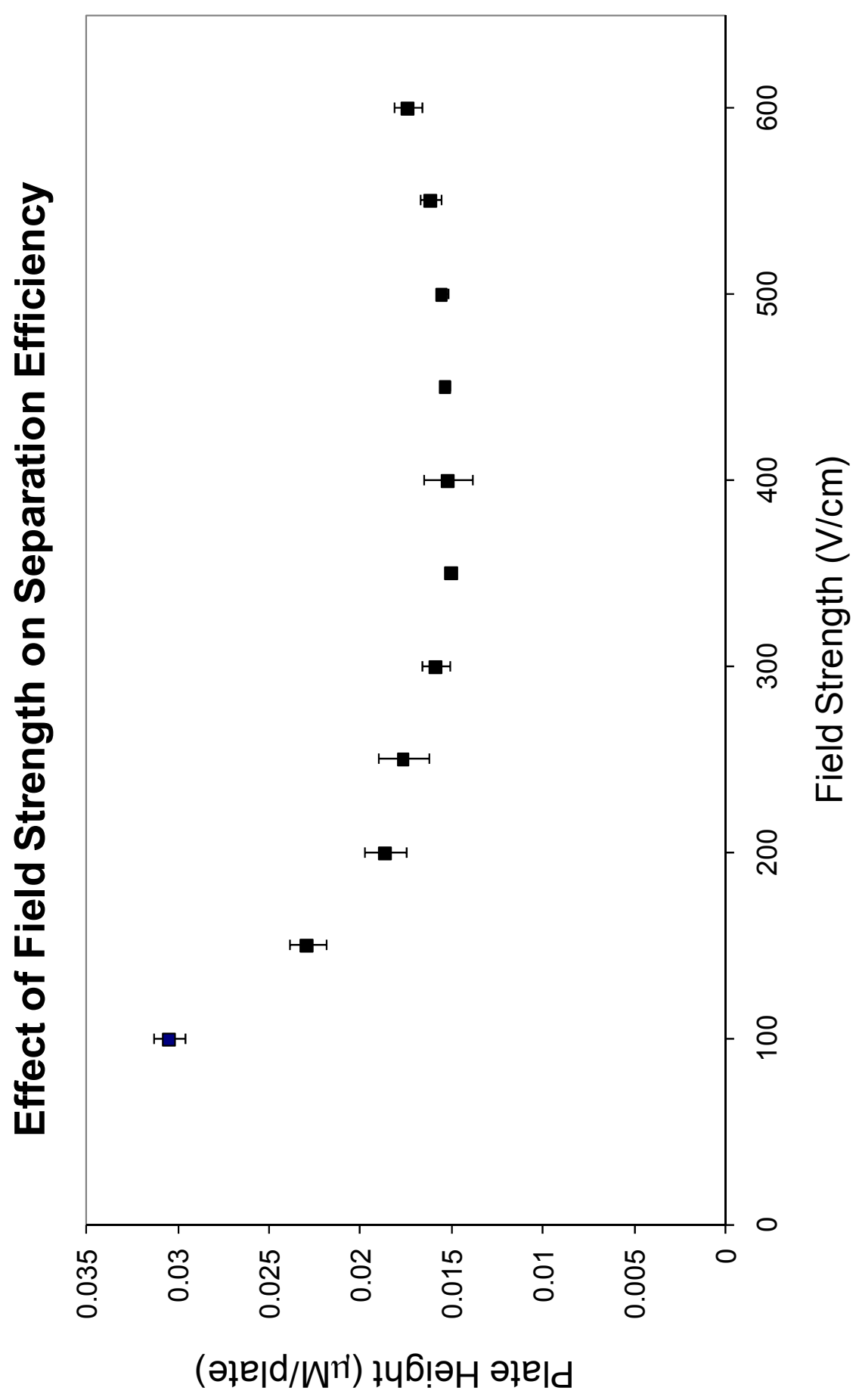

Figure 2-2 displays a plot of separation efficiency as a function of applied electric field. Each plotted data point is determined from three electrophoretic separations of maltopentaose. This data was reproduced with permission from [9]. Copyright 2011 American Chemical Society. 


\subsubsection{Limits of Detection}

The limit of detection of this method was estimated for a $10 \mathrm{kV} 3 \mathrm{sec}$ injection using the linear maltooligosaccharide, maltopentaose. This oligosaccharide was labeled with APTS as the limiting reagent. Assuming the labeling efficiency was $100 \%$, a 300 femtomolar sample of maltopenaose was electrokinetically injected to the separation capillary. This separation yielded a signal to noise $(\mathrm{S} / \mathrm{N})$ ratio of 60 , and thus a limit of detection of 15 femtomolar.

\subsection{Conclusions}

This chapter demonstrates the further development of efficient separations for capillary electrophoresis with phospholipid-additives. These separations are accomplished without any covalent modification of the capillary, and can be accomplished in a variety of capillary inner diameters. This i.d. compatibility is critical because modified capillaries smaller than $50 \mu \mathrm{m}$ i.d. are not easily obtained commercially. As a $25 \mu \mathrm{m}$ i.d. provided a reduction in reagent consumption and separation current, it was chosen for continued studies of . The highest separations efficiencies were obtained in capillaries with the longest effective separation length. 


\subsection{Bibliography}

1. Luo, R., Archer-Hartmann, S.A., Holland, L.A., Transformable Capillary Electrophoresis for Oligosaccharide Separations Using Phospholipid Additives, Analytical Chemistry, 2010. 82: p. 1228-1233

2. Holland, L.A., and Leigh, A.M., Bilayered phospholipid micelles and capillary electrophoresis: A new additive for electrokinetic chromatography. Electrophoresis, 2003. 24: p. 2935-2939

3. Mills, J.O., Holland, L.A., Membrane-mediated capillary electrophoresis: Interaction of cationic peptides with bicelles. Electrophoresis, 2004. 25, 1237-1242

4. Zhang, Y., Zhang, R., Hjerten, S., an Lundahl, P., Liposome capillary electrophoresis for analysis of interactions between lipid bilayers and solutes. Electrophoresis, 1995. 16(8): p. $1519-1523$

5. Nilsson, C., Becker, K., Harwigsson, I., Bulow, L., Birnbaum, S., and Nilsson, S., Hydrophobic interaction capillary electrochromatography of protein mutants. Use of lipid-based crystalline nanoparticles as a pseudostationary phase. Analytical Chemistry, 2009. 81(1): p. 315-321

6. Pappas, T.J., Holland, L.A., Fluid steering in a microfluidic chip by means of thermally responsive phospholipids. Sensors and Actuators B: Chemical, 2008. 128: p. 427-434

7. Guttman, A.; Schwartz, H. E. , Artifacts related to sample introduction in capillary gel electrophoresis affecting separation performance and quantitation. Analytical Chemistry, 1995. 67: p. 2279-2283. 
8. Lux, J. A.; Yin, H.-F.; Schomburg, G. Construction, evaluation and analytical operation of a modular capillary electrophoresis instrument. Chromatographia, 1990. 30: p. $7-15$.

9. Archer-Hartmann, S.A., Sargent, L.M., Lowry, D.T., Holland, L.A., Microscale Exoglycosidases Processing and Lectin Capture of Glycans with Phospholipid Assisted Capillary Electrophoresis Separations, Analytical Chemistry, 2011. 83: p. 2740-2747

10.Jorgenson, J.W., and Lukacs, K.D., Zone electrophoresis in open-tubular glass capillaries. Analytical Chemistry, 1981. 53(8): p. 1298-1302

11. Zhao, J., Hooker, T., Jorgenson, J.W., Synchronous cyclic capillary electrophoresis using conventional capillaries: system design and preliminary results. Journal of Microcolumn Separations, 1999. 11: p. 431-437

12.Giddings, J.C., Generation of Variance, "Theoretical Plates", resolution and peak capacity in electrophoresis and sedimentation. Separation Science, 1969. 4: p. 181-189 


\section{Chapter 3}

\section{Optimization of In-Capillary Interactions of Glycans to \\ Lectins and Enzymes}




\subsection{Introduction}

Carbohydrates are vital to cellular biological processes where they play key roles such as cell-cell recognition, cell-matrix recognition, and cellular regulation [1]. However, the determination of the structural characteristics of glycoproteins is nontrivial, due in part because of the wide variability of glycosylation and the prevalence of isomeration. Additionally, a small changes in the glycan structure can significantly influence the biological activity of the glycoprotein. This is especially true for glycoproteins manufactured for therapeutic purposes, where changes in glycosylation may dramatically affect the overall pharmacological efficacy of the glycoprotein. Carbohydrate-specific proteins such as lectins and exoglycosidase enzymes have been shown to be effective methods of oligosaccharide characterization. By incorporating these proteins into the separations capillary, glycans introduced into it with the targeted structural features will be bound or enzymatically cleaved. This results in changes to the electropherogram by removing (for lectins) or shifting (for enzymes) the peak. This chapter describes a means to incorporate lectins and enzymes into a phospholipid-filled capillary to rapidly characterize and sequence glycan samples. The work described in this chapter has been published in [2][3]. 


\subsubsection{Lectins}

Lectins are plant and animal isolated proteins that bind to carbohydrates with high affinity. Lectins are of non-immune origin and have no catalytic activity and thus are unique from antibodies and enzymes in this regard [4]. The cellular functionalities of lectins vary and have been implicated in cellular recognition [5], the recognition of cellular hosts by viruses [6], cell growth and differentiation [7], as well as number of other functions. The highly specific nature of lectins for a particular glycan characteristic, makes it useful for a number of biochemical applications. These applications include blood typing, glycan analysis, preparative scale isolation of glycoconjugates, as well as studies that focus on cellular agglutination and cellular separation and identification. The binding affinities of lectins $\left(10^{2}-10^{6} \mathrm{M}^{-1}\right)$ are not as strong as that of carbohydrate-binding antibodies $\left(10^{4}-10^{8} \mathrm{M}^{-1}\right)$, which provides a distinct advantage [8]. Unlike immunoaffinity interactions that may require harsh conditions to trigger release after binding, the conditions for release of a glycoconjugate from a lectin is comparatively mild, allowing for the release of intact glycoprotein or whole cell. Lectins are commercially available, and are produced from a number of naturally derived sources. 


\subsubsection{Mass Spectrometry}

Mass spectrometry is a powerful tool that has been extensively used in the study of glycans and glycoconjugates, and providing a basis for the structural characterization of the glycan structure. Both matrix-assisted laser desorption/ionization (MALDI) and electrospray ionization offer unique advantages for the analysis of glycans [9]. However, determining glycan sequence with each method also has number of challenges. These include difficulties in elucidating the correct linkage of residues, and an inability to distinguish isomers. As a result, interpretation of these spectra often must be overcome with complicated analyses, often by requiring sophisticated computational methods of bond linkage determination $[10,11]$. Challenges in ionization and detection are often due to the presence of additional negative charges, such as through the addition of sialyated species [12]. To provide better ionization for MS analysis, they must be derivatized through methods such as permethylation prior to analysis. The method of ionization can result in increased spectra complexity. Electrospray ionization spectra often are complicated by the appearance of different charge states, ion suppression, and adduct formations, while MALDI ionization requires derivatization prior to analysis to prevent fragmentation, and to facilitate quantitative analysis [13]. Due to the complexity of most biological glycan samples, both methods often require analytical separations prior to ionization and analysis. While ESI methods can be readily coupled online to chemical separations methods such as CE and HPLC, MALDI methods must be coupled off-line. 
The difficulties in determining linkage, and in distinguishing between isobaric glycan isoforms have led to the enzymatic cleavage of these glycans prior to analysis. Mass spectrometry sequencing following enzymatic treatment has been utilized for both ESI coupled to ion trap $[14,15]$ and MALDI coupled to time-of-flight mass analysis [16].

\subsubsection{Exoglycosidase Enzymes}

Exoglycosidase enzymes are glycosidic hydrolase enzymes that selectively cleave the terminal residues of glycans. In addition to monomer specificity, these enzymes can also be both position and linkage specific. Exoglycosidases are readily available through a number of commercial sources. While the use of these enzymes for benchtop analyses have been well documented, these reactions face a number of obstacles. The incubation times required for glycan hydrolysis in free solution can be lengthy, and the amounts of glycan and enzyme required per analysis can be cost prohibitive. Reaction products must be analytically separated from the unreacted original substrate. Furthermore, errors related to sample handling can affect the overall performance of the final method. Therefore ideal methods that utilize exoglycosidases for glycan analysis should use low amounts of glycan and enzymes, be low volume, and should be integrated into the methods of separation to provide reduced sample handling and losses due to sample transfer. 


\subsection{Experimental}

\subsubsection{Chemicals and Materials:}

Reagents were obtained from a variety of manufacturers. Sigma Aldrich (St. Louis, MO, USA) was the source for asialofetuin from fetal calf serum, 3-(Nmorpholino)-propanesulfonic acid (MOPS), calcium chloride dihydrate, maltooligosaccharide standards, sodium chloride, and sodium hydroxide. Methanol and al-acid glycoprotein (AGP) were purchased from EMD Biosciences (La Jolla, CA). Ethanol was obtained from AAPER Alcohol (Shelbyville, KY). 1,2-dimyristoyl-snglycero-3-phosphocholine (DMPC) and 1,2-dihexanoyl-sn-glycero-3-phosphocholine (DHPC) were obtained from Avanti Polar Lipids (Alabaster, AL). 1-aminopyrene-3,6,8trisulfonic acid (APTS) was purchased from Biotium (Hayward, CA). Sodium cyanoborohydride $\left(\mathrm{NaCNBH}_{3}\right)$ was acquired from Strem Chemicals (Newburyport, MA). Triethylamine, acetonitrile, and citric acid were acquired from Fisher Scientific (Pittsburgh, PA). Ribonuclease B (Rnase B), $\alpha 1-2,3$ mannosidase, $\beta 1-4$ galactosidase, neuraminiase, $\beta$ - $N$-acetylglucosaminidase, and a peptide $\mathrm{N}$-glycosidase (PNGase F) kit, were obtained from New England Biolabs (Ipswich, MA). A G7 10X reaction solution composed of $0.5 \mathrm{M}$ sodium phosphate buffered at $\mathrm{pH} 7.5$, a glycoprotein denaturing solution containing 5\% sodium dodecyl sulfate (SDS), and 0.4 dithiothreitol (DTT), and $10 \%$ solution of nonionic surfactant NP-40 were included in the PNGase F kit. A G1 10X reaction solution composed of $0.5 \mathrm{M}$ sodium citrate buffered at $\mathrm{pH} 6$ was provided in the 
neuraminidase kit. An Elga Purelab ultra water system (Lowell, MA) was used to provide deionized water.

\subsubsection{Preparation and Derivatization of Glycan Standards}

Glycans derived from glycoproteins (Rnase B, asialofetuin, and $\alpha$-acid glycoprotein) were prepared as follows. Glycans were removed from protein sources using a PNGase F kit using a protocol based on the kit from the manufacturer. Briefly the protein is denatured using a solution containing SDS and DTT and heating at $95^{\circ} \mathrm{C}$ for 10 minutes. The nonionic surfactant NP-40 is then added to the solution to prevent the DTT from denaturing the enzyme PNGase F, which immediately added afterward. This reaction was incubated at $37^{\circ} \mathrm{C}$ overnight, rather than the 2 hours suggested by the protocol. The next day, a $3 \mathrm{X}$ volume of ice-cold ethanol was added to precipitate the protein. The solution was centrifuged at $4^{\circ} \mathrm{C}$ at $10000 \mathrm{rpm}$ for 10 minutes. The liquid fraction containing cleaved glycans was dried using a Savant SpeedVac concentrator (ThermoScientific, Waltham, MA). The dried glycans, or dried glycan standards were reconstituted in $1 \mu \mathrm{L}$ of a $0.2 \mathrm{M}$ solution of APTS dissolved in $1.2 \mathrm{M}$ citric acid, along with $1 \mu \mathrm{L}$ of $1 \mathrm{M} \mathrm{NaCNBH}_{3}$ in deionized water. The solution was thoroughly mixed before being incubated overnight at $37^{\circ} \mathrm{C} .100 \mu \mathrm{L}$ of deionized water was used to stop the reaction. If needed, the sialic acid was removed by adjusting the $\mathrm{pH}$ of the glycan solution to 6 with sodium hydroxide then incubating it overnight with neuraminidase. If necessary, a 10kDa molecular weight cut off filter (Sartiorius, Stonehouse, UK) was used to remove the neuraminidase followed by removal of excess APTS by a Discovery 
DPA-6S solid phase extraction cartridge (50mg packing, Supelco, Bellefonte, PA). A flush of 95:5 $(\mathrm{v} / \mathrm{v})$ acetonitrile:water was used to prepare the cartridge prior to use. APTS was eluted from the extraction cartridge with a solution containing 95:5 (v/v) acetonitrile:water containing $50 \mathrm{mM}$ triethylamine. An aqueous solution of $50 \mathrm{mM}$ triethylamine was used to elute the retained glycans from the cartridge. The glycan solution was evaporated to dryness and the reconstituted in $100 \mu \mathrm{L}$ deionized water and stored at $-20^{\circ} \mathrm{C}$.

\subsubsection{Preparation of Phospholipid Additive}

Preparations of phospholipids were comprised of 5\%, [DMPC]/[DHPC] (q value) $=0.5$ were used for coating of the capillary, which serves to suppress the electroosmotic flow, and to passivate the surface from nonspecific interactions. Another phospholipid preparation of a $10 \%, q=2.5$, phospholipid solution was used for the separation media, due to it's thermally-switchable gel-like viscosity. These phospholipids were prepared by weighing out the appropriate masses of dry DMPC and DHPC, then adding $100 \mathrm{mM}$ aqueous MOPS buffered to $\mathrm{pH}$ 7. After the solution was thoroughly mixed, the preparation was subjected to a minimum of three freeze-thaw cycles and centrifuged for $10,000 \mathrm{rpm}$ for ten minutes. The phospholipid preparation was stored at $-20^{\circ} \mathrm{C}$, and was thawed and vacuum degassed prior to use. 


\subsubsection{Capillary Electrophoresis}

Separations were performed using a P/ACE MDQ Capillary electrophoresis system (Beckman Coulter, Fullerton, CA, USA) equipped with laser induced fluorescence detection (air cooled argon ion laser, $\lambda_{\mathrm{ex}}=488 \mathrm{~nm}, \lambda_{\mathrm{em}}=520 \mathrm{~nm}$ ). The fused silica separation capillary had a $25 \mu \mathrm{m}$ internal diameter and a $360 \mu \mathrm{m}$ outer diameter (Polymicro Technologies, Phoenix, AZ, USA) with an effective length of 50.0 $\mathrm{cm}$ and a total length of $60.2 \mathrm{~cm}$. Capillaries were subject to the following flushing sequence daily: $1 \mathrm{M} \mathrm{NaOH}$ for 30 minutes at $170 \mathrm{kPa}$ (25 psi), deionized water for 15 minutes at $170 \mathrm{kPa}(25 \mathrm{psi})$, methanol for 15 minutes at $170 \mathrm{kPa}(25 \mathrm{psi})$, and 15 minutes of water at $170 \mathrm{kPa}$ (25 psi). Following this flushing sequence, the capillary was passivated with a phospholipid coating with a $5 \%, q=0.5$ phospholipid preparation containing $1.25 \mathrm{mM}$ calcium. This semi-permanent coating was applied for 20 minutes at $170 \mathrm{kPa}$ (25 psi) followed by a 2 minute MOPS flush at 170kPa (25psi) to remove excess phospholipid and from the capillary. A brief pre-coat was applied prior to each run using the following protocol at $170 \mathrm{kPa}(25 \mathrm{psi})$ with the capillary held at $19^{\circ} \mathrm{C}: \mathrm{q}=0.5,5 \%$ phospholipids for 3 minutes, MOPS for 2 minutes, and $\mathrm{q}=2.5,10 \%$ phospholipids for 3 minutes. If enzyme was being used in-capillary, an additional 3 minute $170 \mathrm{kPa}$ (25 psi) MOPS flush was performed in the reverse direction before this sequence, to expel any enzymes from the capillary, and to prevent fouling of the capillary. When the room temperature was higher than $22^{\circ} \mathrm{C}$, a portable air conditioner was used to provide ambient thermal control. Injections into the capillary were carried out in three steps. First, a plug a MOPS was injected into the phospholipid filled capillary $(7 \mathrm{~s}$, at $6.9 \mathrm{kPa})$ at $19^{\circ} \mathrm{C}$. The 
capillary temperature was then heated to $25^{\circ} \mathrm{C}$, resulting in the viscosity of the $\mathrm{q}=2.5$ $10 \%$ phospholipid filling to increase to a gel-like consistency. The glycan is then electrokinetically injected into the capillary. Finally a post-plug of MOPS was pressure injected $(5 \mathrm{~s}, 3 \mathrm{kPa})$. Separations were carried out at $400 \mathrm{~V} / \mathrm{cm}$ under reversed polarity. Data collection and analysis were performed using 32 Karat Software version 5.0 (Beckman Coulter).

\subsubsection{Enzymatic Reactions}

Enzymatic reactions were either conducted in a bench-top reaction, or in capillary. Benchtop reactions of enzyme were conducted at small volume $(<100 \mu \mathrm{L})$ in $\sim 0.2 \mathrm{~mL}$ polypropylene tubes in the buffers and conditions suggested by manufacturers. All incubations, unless otherwise noted, were completed at $37^{\circ} \mathrm{C}$ overnight. Enzymatic reactions completed in-capillary were accomplished by injecting a small plug of the enzyme solution into the capillary at $19^{\circ} \mathrm{C}$, prior to increasing the temperature of the capillary to $25^{\circ} \mathrm{C}$. Glycans were injected into the capillary at this elevated temperature, and electrokinetically moved at a low voltage into the enzyme plug prior to incubation and separation, as noted in the text.

\subsection{Results and Discussion}

The results in this section have been peer reviewed and published in references [2] and [3]. 


\subsubsection{Methods of Glycan Identification using Standards}

Glycan standards can be used to test the performance of an analytical method. Standards may also be used to confirm the identity of a glycan of interest. In this work, both the glycan to be analyzed and the standard glycan are labeled with the fluorescent tag, APTS. Migration times of the two are then either compared, or the standard is added to the glycan sample to assign peak composition. Glycan standards can be purchased commercially, or can be derived from common glycoproteins. Examples of glycoproteins well-charaterized in literature and thus used as standards are the high mannose glycans from ribonuclease B (RNase B), as well as the complex-type glycans from bovine serum fetuin and $\alpha$-acid glycoprotein (AGP). Figure 3-1 displays a separation of glycan standards used in some of the studies completed for this work. These glycans include the linear maltose oligosacchardies (G4, G5, G6, and G7) that were purchased, glycans (Man5, Man6, Man7, Man8, Man9) taken from Ribonuclease B, and branched di, tri, and tetraantennary complex-type glycans from the protein $\alpha$-acid glycoprotein (AI, AII, AIII, AIV, and AV). Sialic acid from complex-type glycans was commonly removed prior to analysis as sialyation drastically increases the complexity by adding additional charge and thus variation electropherogram. The Figure 3-1 glycans provide 14 standard glycans all with different glycoform structural types and serve well as inexpensive methods of structural confirmation. Due to the high separation efficiencies described in Chapter 2, these glycans can be efficiently separated from each other, and with very small variances in migration time, making migration-based identification a feasible method. 


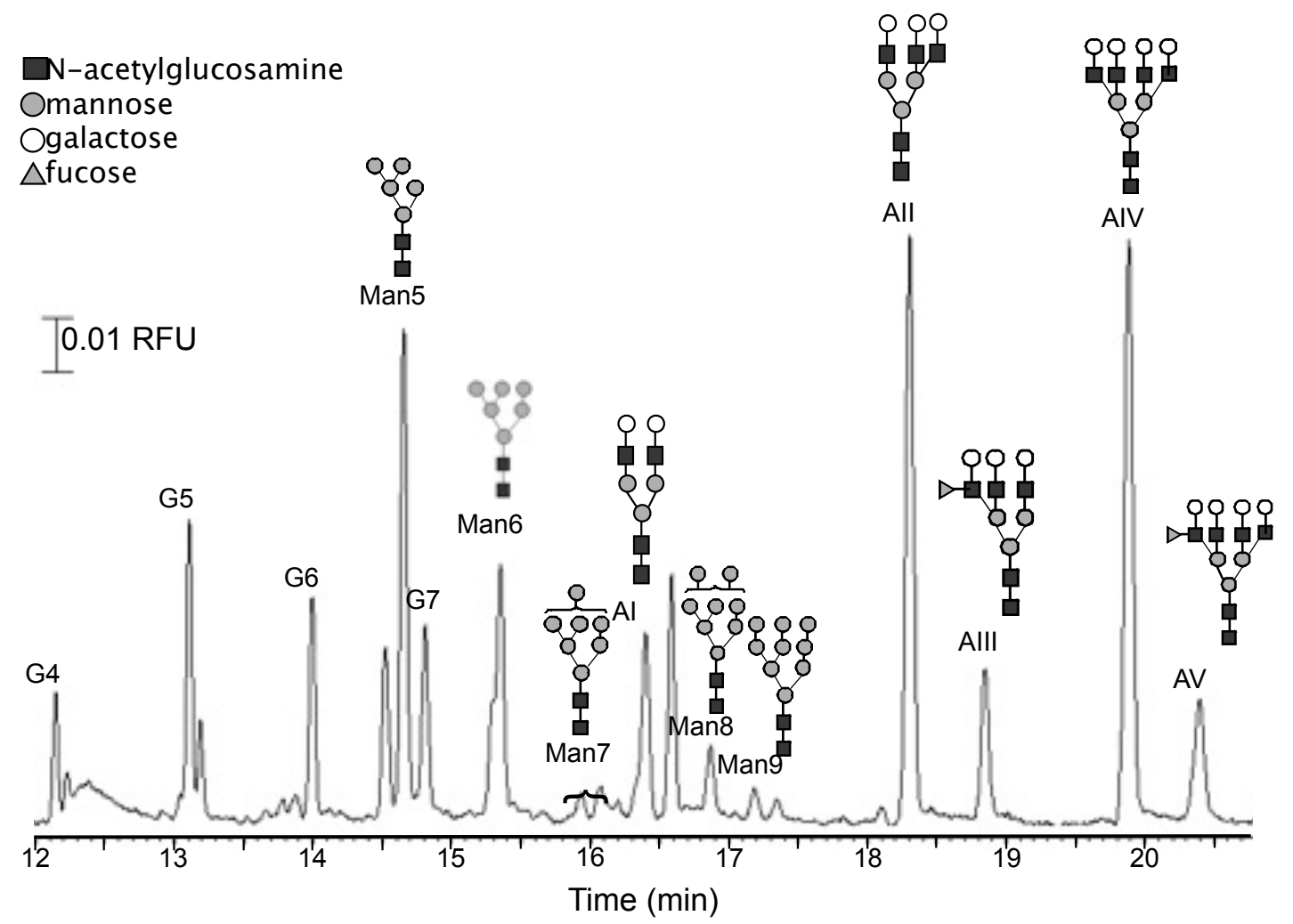

Figure 3-1 displays an electropherogram of glycan standards used by the Holland group. Glycans include those from linear maltooligosaccharides as well as branched glycans from glycoproteins Rnase B and AGP. This figure was reproduced with permission from [3]. Copyright 2011 American Chemical Society.

While the use of glycan standards is a frequently used approach for peak identification, it suffers from two major drawbacks. The first drawback is that, simply, the needed glycan standard may not be available to the user through a commercial or glycoprotein source. The second is due to the increased cost that comes from purchasing, each particular glycan standard that is of interest. Obtaining and labeling each standard can be costly and commercial availability of such standards is often a major challenge to this method of identification. While glycan standards can be obtained from glycoprotein 
sources, the increased time and cost in deglycosylating, labeling, and purifying these glycans can be prohibitive, and the number of glycoproteins that are well characterized is few.

\subsubsection{Utilization of Lectins and Enzymes for Glycan Characterization}

An alternative method of elucidating structure of a glycan of interest is through the use of highly specific proteins, such as lectins and enzymes. These proteins will selectively bind or enzymatically cleave only the glycans that have the targeted characteristic. This method has been frequently used on the bench-top for down-stream analysis using separations techniques such as HPLC and CE, and mass spectrometry. However, this method is hindered by the amounts of enzyme or lectin consumed per analysis, as well as the lengthy incubation times that are a result of free-solution reactions. Incorporating these proteins within the capillary allows for the reaction volume to be reduced, and for the incubation times to be reduced by increasing the ratios of enzyme to glycan per analysis.

In-capillary analyses were performed using a commercially available, automated capillary electrophoresis system (Beckman P/ACE MDQ). This system is equipped with temperature-programmable storage for samples and reagents. Although the practical volume limitations of the Beckman P/ACE MDQ are $20 \mu \mathrm{L}$, the actual amount of lectin injected into the capillary is in the nanoliter range per analysis. A $1.5 \mathrm{psi}, 15 \mathrm{sec}$ injection into a $25 \mu \mathrm{m}$ inner diameter, $60 \mathrm{~cm}$ capillary is only $2 \mathrm{~nL}$. In the $25 \mu \mathrm{m}$ i.d. capillary this plug is only $\sim 0.5 \mathrm{~cm}$ long and is less than $1 \%$ of the length of the total capillary. An 
extensive flush in the reverse direction is used prior to each analysis to prevent contamination from run to run. Additionally, it is common practice to complete a "blank" reaction in-between lectin or enzyme reactions to ensure this.

\subsubsection{In-Capillary Reactions of Glycans to Lectins}

The process of in-capillary incorporation and interaction with glycan is depicted conceptually in Figure 3-2. Prior to analysis the capillary is prepared by briefly coating, flushing, then filling the the capillary phospholipid at $19^{\circ} \mathrm{C}$. At this temperature, the viscosity of the phospholipid is similar to that of water, and a small plug of lectin may be hydrodynamically injected into capillary. This lectin plug is bracketed by two small plugs of separation buffer to prevent the cross-contamination of the lectin with any of the other vials. The temperature of the capillary is then increased to $25^{\circ} \mathrm{C}$, resulting in the increased viscosity of the phospholipid and the entrapment of the protein lectin within the capillary. Because the phospholipid material is biocompatible, this entrapment procedure serves to immobilize the protein without denaturing it. At this increased temperature, the glycans are injected into the capillary and separated under reversed polarity (usually $400 \mathrm{~V} / \mathrm{cm}$ ). The glycans are separated in the absence (top figure) and presence (bottom figure) of lectin. When lectin is incorporated into the separations capillary, glycans specific for the lectin are bound, and therefore do not migrate to the detection window. Thus the incorporation of lectins into the capillary is quick method to discern structural characteristics and can even be used to simplify complex electropherograms by selectively removing groups of glycans from analysis. 

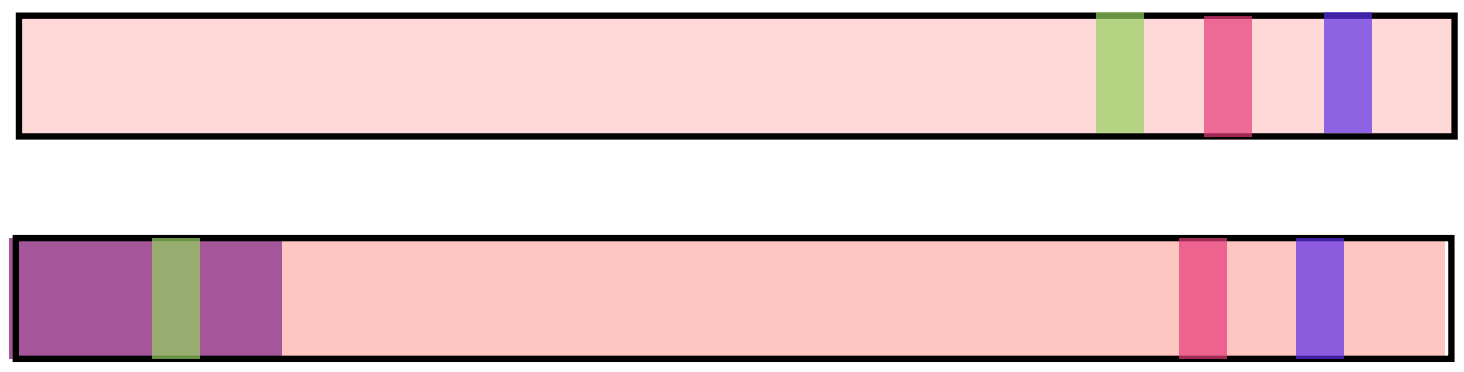

\section{lectin plug}

Figure 3-2 displays a schematic of how plugs of lectins can be incorporated into a separations capillary. The top figure shows how glycans (colored bands) would separate in a capillary with no modifications. The bottom figure shows how glycans would separate in a capillary with a plug of lectin specific for a single (green) glycan. As the glycans are separated, and pass through the plug, the species with the chosen characteristic are bound to the lectin and do not migrate.

\subsubsection{Concanavalin A}

Concanavalin A (ConA) is a lectin derived from Canavalia ensiformis (jack-bean) that is specific for glucose and mannose resides. It has been used in a number of studies for the analysis of mannose-rich glycans, including methods of capillary affinity electrophoresis [17] and lectin-arrays [18,19].

A small plug (1psi $7 \mathrm{sec})$ of $1 \mathrm{mg} / \mathrm{mL}(\sim 9 \mu \mathrm{M})$ Concanavalin A in $\mathrm{pH} 6,2-(\mathrm{N}-$ morpholino)ethanesulfonic acid (MES) was used for the in-capillary analysis of high mannose glycans from the standard glycans also shown in Figure 3-1. The glycan was separated through the capillary as normal, with no incubation or wait steps. Figure 3-3 shows this electropherogram (top trace), as well as an electropherogram of the same 
glycans through a capillary containing only a buffer blank (pH 6 MES)(bottom trace). No incubations were necessary for the binding of these glycans to the lectin. Concanavalin A selects for mannose, and highly-branched mannose, and therefore bound to the highmannose glycans from Rnase B (Man5, Man6, Man7, Man8, and Man9). It is interesting to note that, despite the relative abundance of these glycans, a high specificity of the lectin to branch mannose is obtained. This is especially true for the branched mannose Man5 in comparison to the linear heptamaltose, G7. While the relative concentration of Man5 is high in comparison to G7, the linear glycan unaffected by the lectin. The diantennary complex-type glycan AI from $\alpha$-acid glycoprotein does respond to ConA, but could be completely removed from the separation with higher concentrations of ConA. This is because ConA will bind to the Man3 core the glycan. [17]. 


\section{+ Concanavalin A}

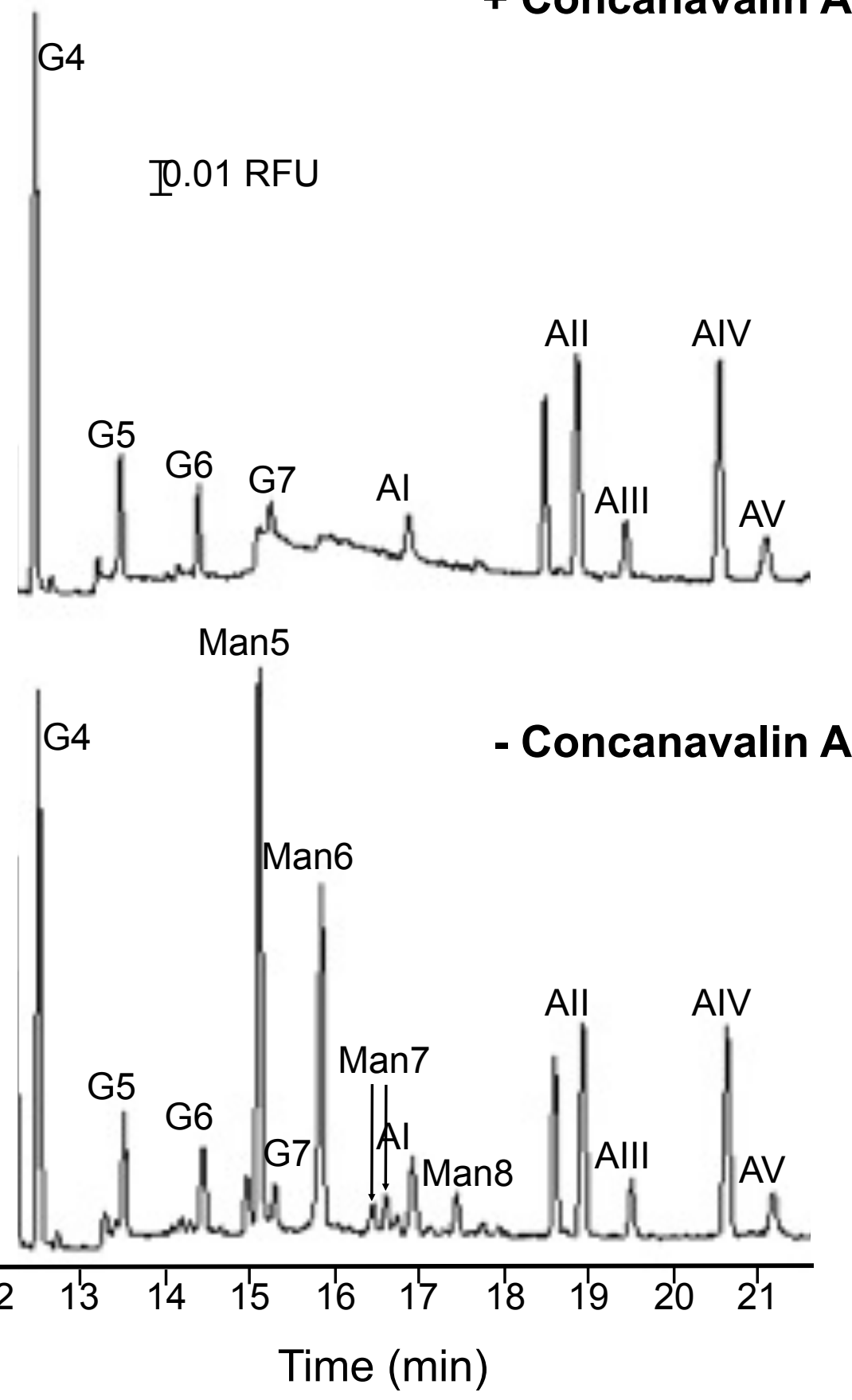

Figure 3-3 displays an electropherogram of glycan standards (high mannose glycans from RNase B, complex-type glycans from AGP, and linear maltoses) separated in a capillary containing either a buffer blank, or $1 \mathrm{mg} / \mathrm{mL}$ Concanavalin A. Separations were completed in a $60.2 \mathrm{~cm}, 25 \mathrm{~m}$. i.d. capillary at a field strength of $400 \mathrm{~V} / \mathrm{cm}$. This figure was reproduced with permission from [3]. Copyright 2011 American Chemical Society. 


\subsubsection{Use of Enzymes for In-Capillary Analysis}

The phospholipid media can be utilized to incorporate proteins into the capillary without subsequent covalent modification or denaturation. This makes this media especially useful for the incorporation of bio-active proteins such as exoglycosidase enzymes. These enzymes exhibit great sensitivity to both residue types (e.g. mannose, galactose), linkage position (e.g. 1-3, 1-4), and linkage type (e.g. $\alpha, \beta)$. Exoglycosidases are well characterized and commercially available through a number of sources. Unlike the use of lectins in-capillary, the selected glycan is not retained in the protein plug inside of the capillary. Because the exoglycosidase removes terminal glycan residues, the rest of the glycan is still fluorescently tagged, but now smaller in size. This results in a change of electrophoretic mobility, and thus the migration. In this analysis method, the glycans with the desired characteristics will be identified by a shift in the migration time. This is demonstrated conceptually in Figure 3-4. 

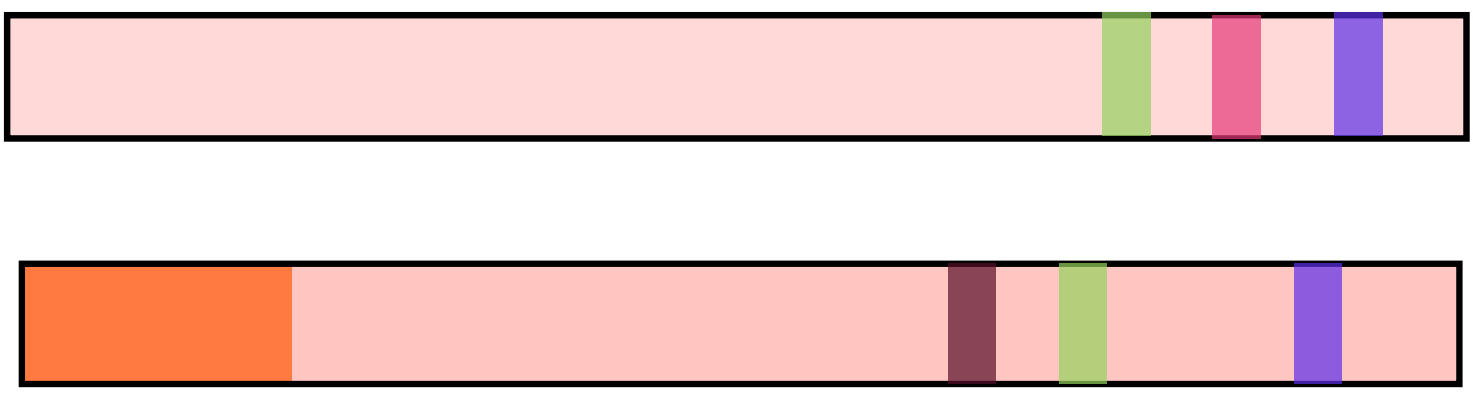

\section{enzyme plug}

Figure 3-4 displays a schematic of how plugs of enzymes can be incorporated into a separations capillary. The top figure shows how glycans (colored bands) would separate in a capillary with no modifications. The bottom figure shows how glycans would separate in a capillary with a plug of enzyme specific for a single (pink) glycan. Following incubation, this glycan is truncated by the enzyme, and therefore migrates at a different velocity.

The process of positioning, incubating, then separating the glycan is part of a three-step process. The enzyme is introduced into the capillary using the same methods as lectin introduction mentioned previously, and immobilized within the capillary at $25^{\circ} \mathrm{C}$ by the highly viscous phospholipids. The glycan is then injected into the capillary and moved into the enzyme plug with a brief electrokinetic "push" at low voltage (10kV 30 sec). The glycans are incubated in the enzyme plug for a specified amount of time, and the reaction products are separated and detected in the capillary. A benefit of using incapillary exoglycosidase reactions over bench-top free solution reactions is that the reaction volume is small $(\sim 2 \mathrm{~nL})$. Although commercial exoglycosidase kits require 1 hour of incubation time, none of the in-capillary incubations presented in these studies were longer than 20 minutes. Additionally, because the incubation step in the capillary is 
part of the program, a series of experiments with varying incubation times can be performed with the same sets of enzyme and glycan. This includes the monitoring of both the disappearance of substrate, the appearance of product, and the appearance of intermediate products, if possible (Figure 3-5).

\section{$0,5,10$, or 15 minute incubation in capillary}

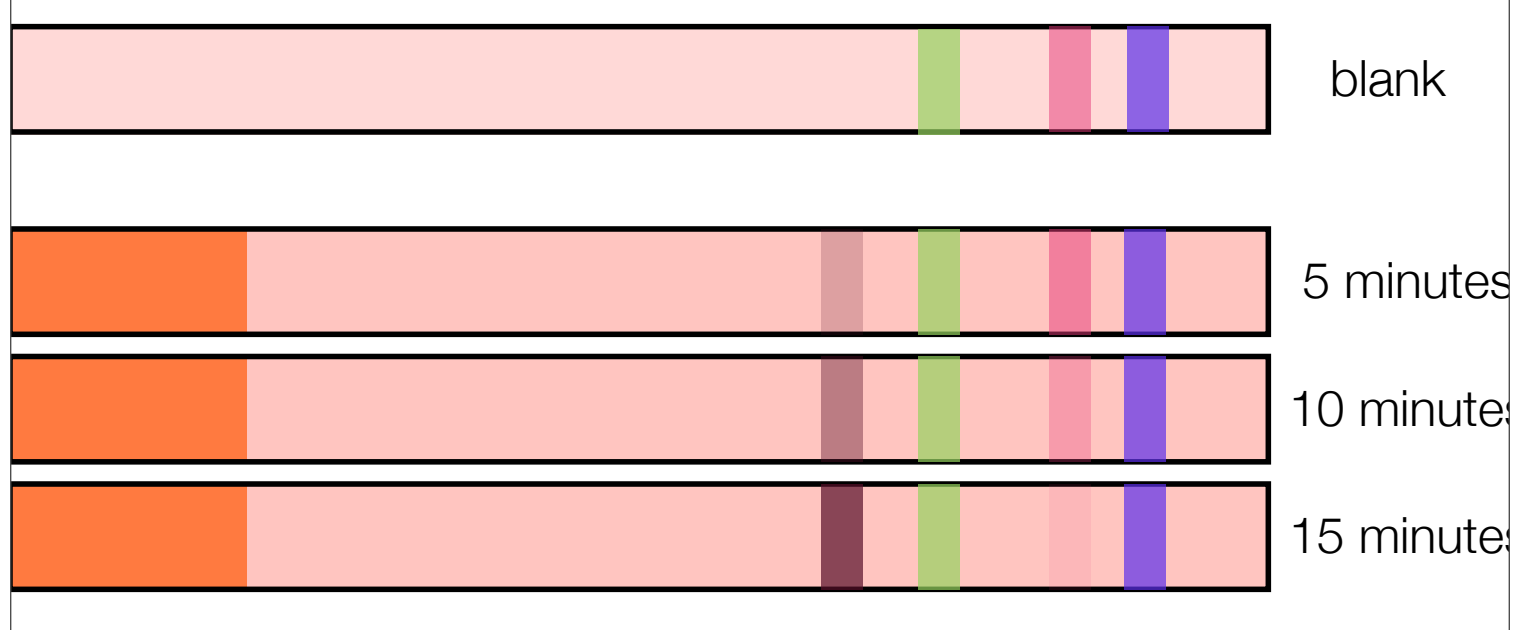

Figure 3-5 displays a schematic of how in-capillary plugs of enzymes can be utilized to monitor the formation of glycan enzymatic products. The top figure shows how glycans (colored bands) would separate in a capillary with no modifications. The other figures demonstrate the progressive depletion of the original glycan, and the accumulation of the glycan products.

\subsubsection{Mannosidase}

High-mannose glycans are of interest in a number of fields of study; for example high-mannose glycans have been linked as biomarkers for a number of health-related issues such as breast cancer [20]. To investigate high mannose glycans, the enzyme a1-2,3 mannosidase was used for in-capillary studies. This enzyme selectively cleaves 
a1-2 and a1-3 mannopyranosyl residues that are commonly found on high-mannose residues, and would eventually result in a final product consisting of a trimannose core with a number of $\alpha 1-6$ mannoses residues attached. Because these linkages are specific for high-mannose and high-mannose hybrid glycans, this enzyme can be used to confirm structure along with the lectin concanavalin A.

Figure 3-6 demonstrates how this enzyme can be used as a method to distinguish unresolved glycans. High mannose glycans from Rnase B, as well as linear maltooligosaccharides were separated in a $40 \mathrm{~cm}, 50 \mu \mathrm{m}$ inner diameter capillary coated and filled with phospholipid. In Figure 3-6-A, the glycan peaks for Man5 and heptamaltose have overlapped and thus are indistinguishable. By separating these glycans after increasing incubation times in-capillary, the peak corresponding to mannose 5 decreases in area, revealing the identity of the peak. The linear maltoses are not cleaved by this enzyme and migrate with the same electrophoretic velocity as those separated in the capillary in the absence of enzyme. The product peak, which is believed to be from the cleavage of the $\alpha 1-3$ mannose residue attached directly to the trimannose core, forms almost completely after 15 minutes, rather than the 1 hour required for the protocols provided by the manufacturer. The $20 \mu \mathrm{L}$ samples of both glycan and enzyme may be used for multiple reactions, and under different incubation conditions. 


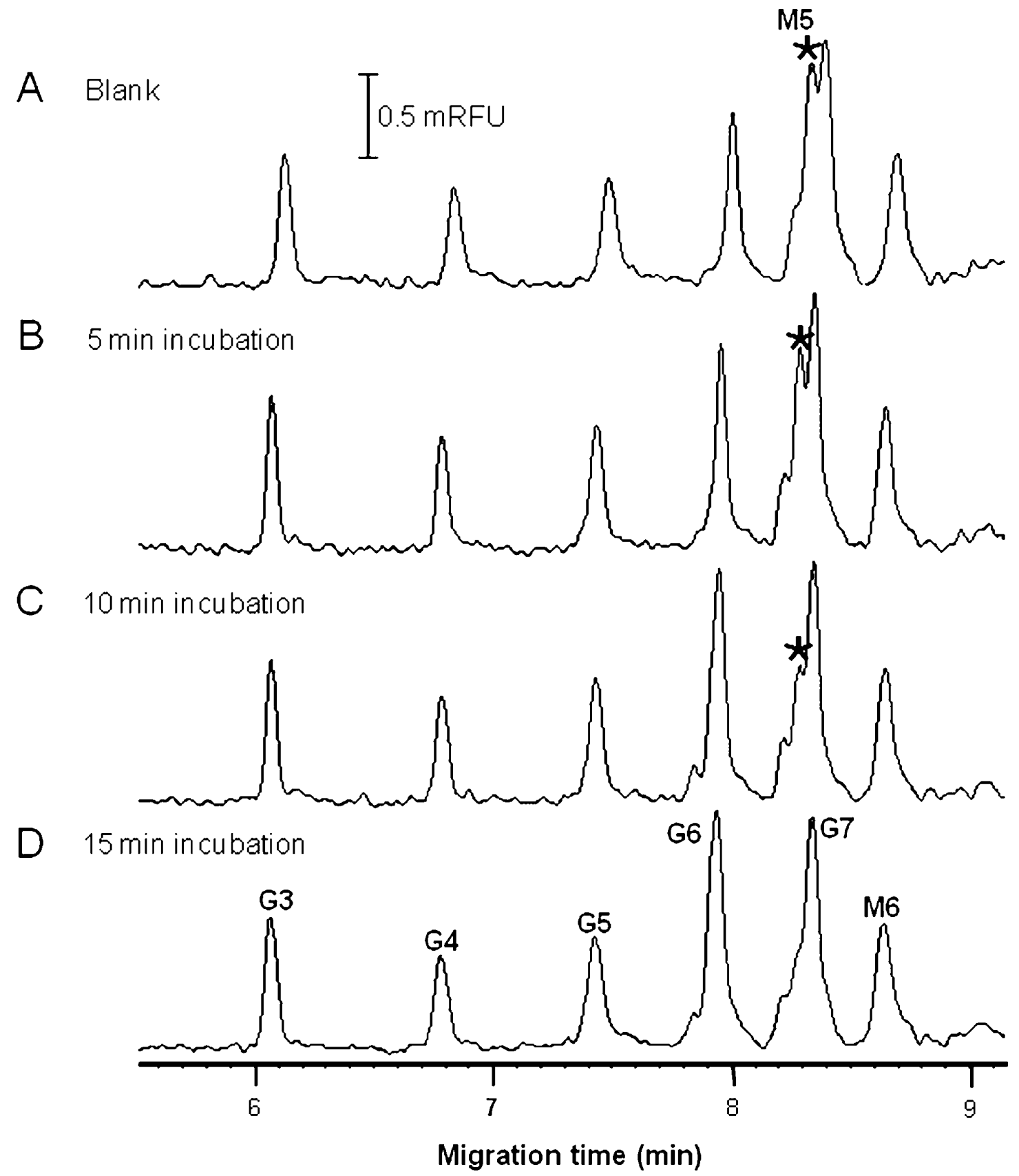

Figure 3-6 demonstrates how the enzyme $\alpha 1-2,3$ mannosidase can be used for incapillary analysis of glycan samples. A sample containing high-mannose sugars from Rnase $B$ and linear maltoses was separated following various incubation times in a plug of $\alpha 1-2,3$ mannosidase, resulting in the progressive cleavage of the Mannose 5 glycan, and the formation of its reaction product, which overlaps with the G6 peak. This figure was reproduced with permission from [2]. Copyright 2010 American Chemical Society. 


\subsection{Galactosidase}

Galactose is one of the most common glycan residues in complex-type glycosylation, making it an important feature analyze. In addition to a number of general $\beta$-galactosidase enzymes, positionally specific galactosidase enzymes are readily available including those that target $\beta 1-3, \beta 1-4, \beta 1-3,4,6$, and $\beta 1-3,6$ linkages. $\beta 1-4$ Linked galactose, a common terminal residue found in complex-type glycans, was the target of an on-line reaction using the enzyme $\beta 1-4$ galactosidases. This enzyme was used to probe a solution of complex-type glycans from asialofetuin, a desialated version of bovine fetuin (Figure 3-7). Asialofetuin has three glycan structures, diantennary and triantennary structures that are identical to that as glycan from AGP (AI and AII), as well as a isoform of AII known as FII. FII has an identical structure to that of AII, with the exception that one of the glactose residues is attached with a $\beta 1-3$ rather than $\beta 1-4$ linkage. This small change in overall glycan structures makes the resolution of these two isoforms difficult for most separations methods and speaks to the ability of phospholipid additives for high resolution and efficiency separations. Figure 3-7 also demonstrates how, with different incubation times, the progressive disappearance of the substrate and appearance of product peaks can be monitored using the same initial samples of enzyme and glycan. 


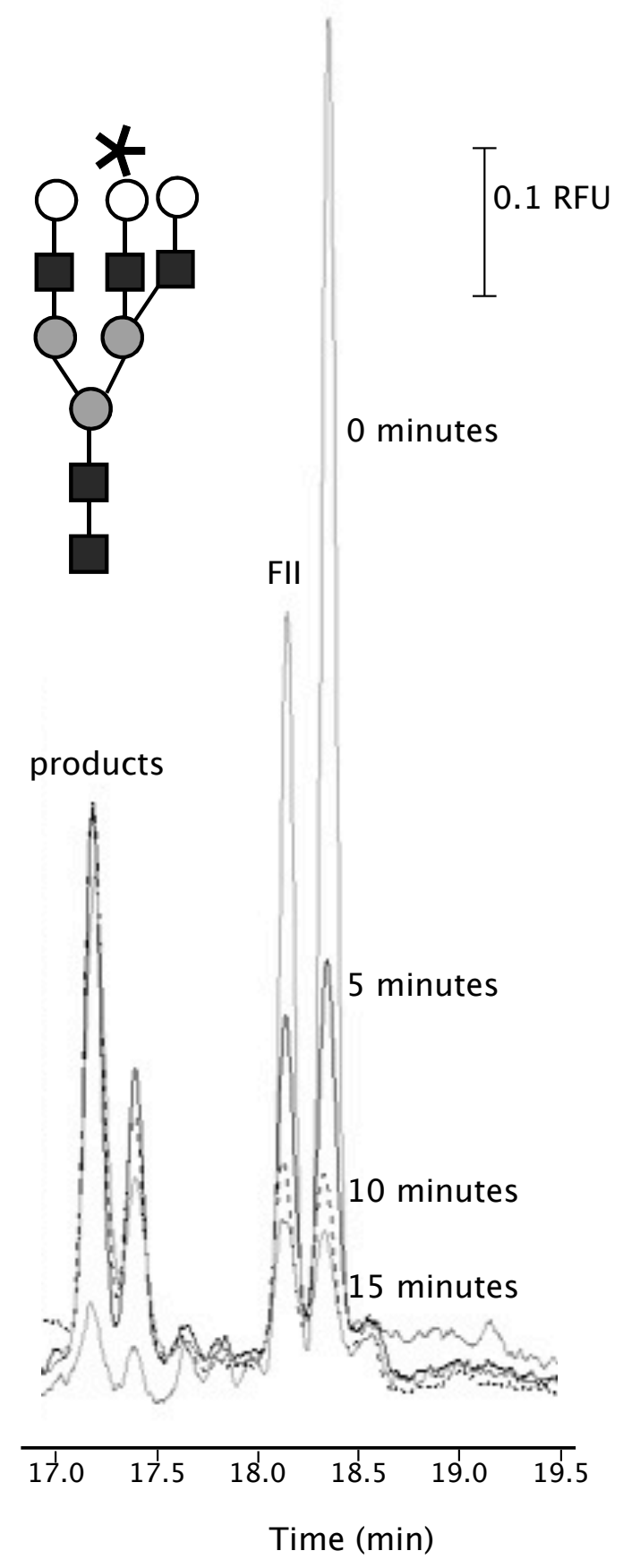

Figure 3-7 demonstrates how the enzyme $\beta 1-4$ galactosidase can be used for incapillary analysis of glycan samples. A sample containing complex-type glycans from bovine asialofetuin was separated following various incubation times in a plug of $\beta 1-4$ galactosidase, resulting in the progressive cleavage of the $\beta 1-4$ galactose monomers from the All and FII glycans, and the formation of its reaction product. This figure was reproduced with permission from [4]. Copyright 2011 American Chemical Society. 


\subsubsection{Neuraminidase}

The existence of sialic acid can greatly complicate the separation and identification of glycans for a number of analytical methods including liquid chromatography and mass spectrometry. Sialic acid residues provide additional negative charge to the glycan. Sialic acids are also thermally labile and can detach following application of heat and acid. Often, the sialic acid content may analysis to analysis. Mass spectrometric methods of analysis often require methylation and derivatization of sialic acids to prevent their detachment prior to analysis. The affect of sialic acids are demonstrated in Figure 3-10-A, where glycans from $\alpha$ acid glycoprotein (AGP) are separated without prior removal of the sialic acid. Although there are only 5 major forms from AGP, the number of variable forms from sialic acid results in the number of peaks in the electropherogram. Therefore, it is common practice to remove sialic acids from glycans prior to analysis, by incubating the glycan solution with the enzyme neuraminidase. By incorporating this enzyme in-capillary, a simpler electropherogram can be obtained without extended incubation times.

Neuraminidase cleaves terminal sialic residues rapidly. On-line incubation times of 5 minutes or less are sufficient to remove all sialic acid. The desialylation of AGP shown in Figure 3-10-B was completed after a 5 minute incubation. Neuraminidase can also be incorporated with other enzymes as a discrete plug, or as part of an "enzyme cocktail" plug, where the enzyme is mixed with another prior to injection. 


\subsubsection{Multiple enzyme Methods}

Exoglycosidase enzymes selectively target the terminal residues of a glycan. Therefore multiple enzymes can be used in combination to systematically determine the full structure of the glycan. In a bench-top analysis, this is accomplished by sequentially treating the glycan with multiple enzymes, sequentially. The first enzyme is added, reacted, and the products are analyzed, then the sample is interacted with the second enzyme and so on. By scaling this model to the microscale, numerous experiments may be conducted using a single glycan samples and pristine solutions of enzymes, with the enzymatic reaction being completed within the capillary.

\subsubsection{Off-line sequencing model: AGP}

Enzymes can be utilized in combination to progressively clip away layers of residues, revealing the overall structure of the total glycan. This process is demonstrated for a single glycan (AV) in Figure 3-8. To discern the structure of this glycan, exoglycosidases are systematically applied to the glycan to remove each outer layer of residues with analysis in between each step. If CE is utilized for these analysis steps, the cleaved glycan will respond to by a different migration time, as the electrophoretic mobility has changed in response to the truncated glycan. With the exception of desialation, which removes additional negative charge in addition to the residue, all of these cleavage steps result in an increased electrophoretic mobility and thus a shorter migration time. A greater migration shift can reveal the number of residues that have been removed during each step. 


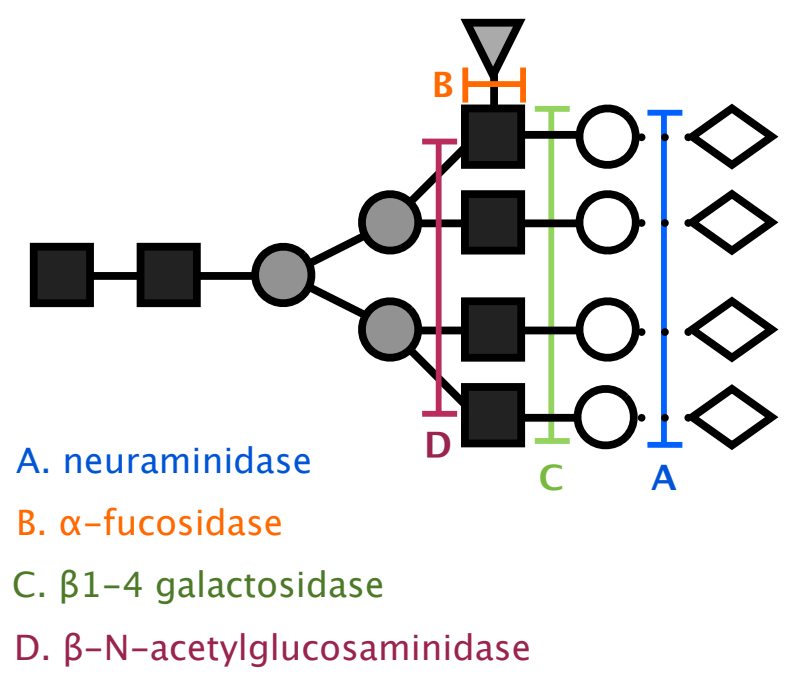

Figure 3-8 demonstrates how multiple enzymes can be used in conjunction to determine the sequence of a complex glycan. The complex-type glycan shown (AV from AGP) has sialic acid, galactose, acetylglucosamine, and fucose glycan residues all attached to it's mannose core. By using a number of enzymes in conjunction with each other the structure of the original glycoform can be deduced.

To demonstrate how these enzymes can used to sequence glycans derived from a glycoprotein, a multi-step enzymatic reaction on the bench-top was conducted using the carbohydrates derived from $\alpha$ acid glycoprotein (AGP). The original, sialylated glycans are shown in Figure 3-9-A. When this glycan sample is modified with the enzyme neuraminidase the negatively charged sialic acid residues are removed, resulting in a reduced charge to size ratio and a longer migration time. Because this source of variable charge is removed, the five major glycoforms of AGP are shown in the resulting electropherogram, Figure 3-9-B. This glycan solution is then reacted with $\alpha$ fucosidase, with the resulting electropherogram shown in Figure 3-9-C. This affects the two glycans containing fucose (AIII and AV) and the reaction products collapses into the AII and AIV 
glycans. The sample is then reacted with $\beta 1-4$ galactosidase with the results shown in Figure 3-9-D. All of the galactose in AGP are removed, resulting in dramatic migration shifts in the three remaining peaks. The resulting solution is then reacted with $\beta-N-$ acetylglucosaminidase with the results shown in Figure 3-9-E. This reaction results in a single product, as all glycans have been cleaved down to the common, N-glycan trimannose core. The peak labeled with an asterisk $(*)$ is a byproduct of the APTS labeling reaction and was used in this experiment as a migration time standard. 


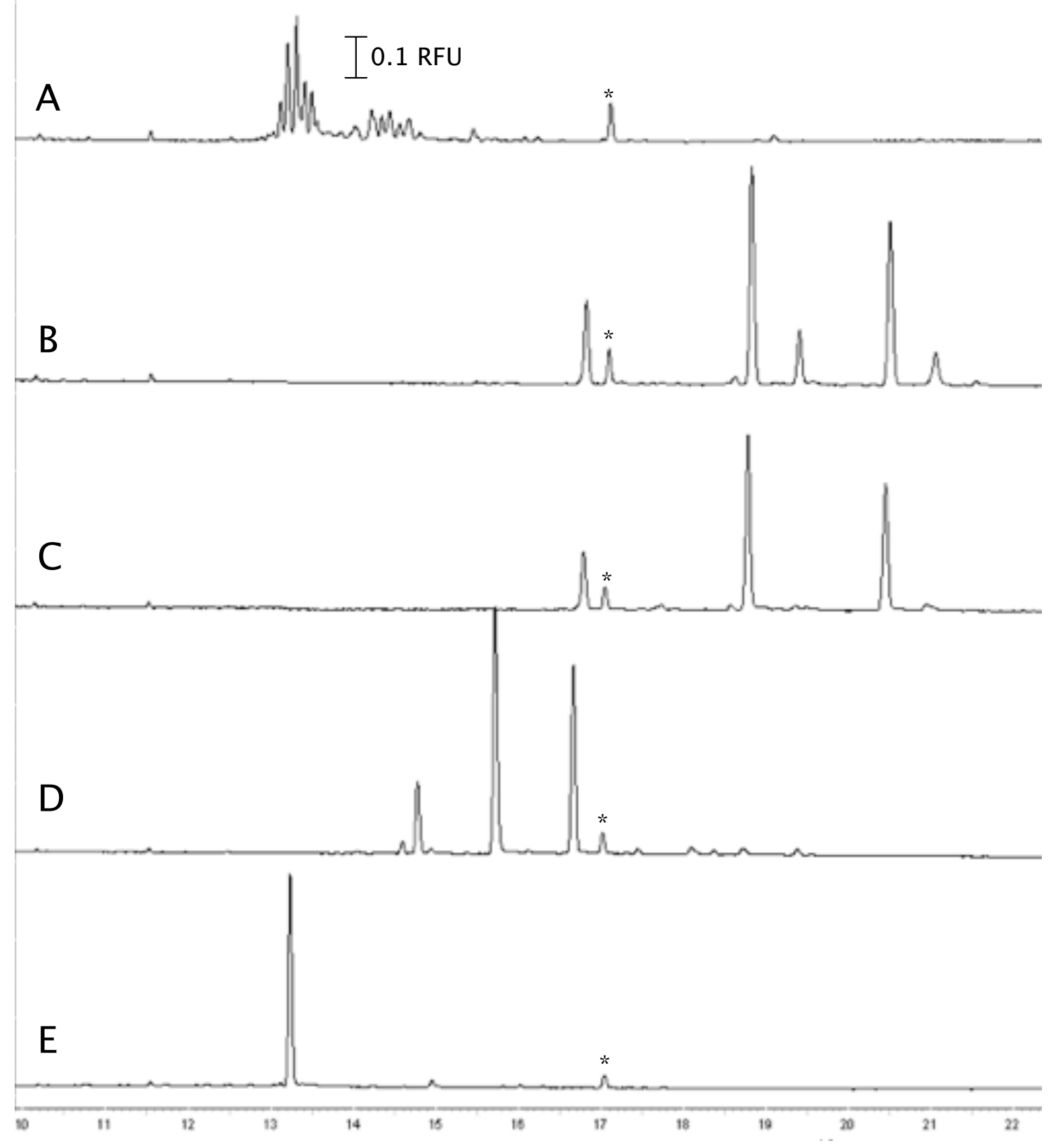

Figure 3-9 demonstrates how multiple enzymes can be used in conjunction to determine the sequence of a complex glycan. Glycans derived from AGP were progressively treated with the exoglycosidases neuraminidase, $\alpha$ fucosidase, $\beta 1-4$ galactosidase, and $\beta-\mathrm{N}$-acetylglucosaminidase. These reactions progressively clip away successive layers of glycans until that all that remains is the trimannose core (shown in Figure 9-E) 


\subsubsection{In-Capillary Sequential Enzymatic Reactions:}

The use of multiple enzymes that target only the terminal glycan residues can be used to glean structural information. However, this approach requires significant amounts of enzyme and sample The increased time to perform all of these bench-top enzymatic reactions is also a disadvantage. By incorporating these enzymes into the capillary, these sequential analyses can be completed without utilizing the entire glycan sample or consuming significant volumes of enzyme. A glycan sample can be used for numerous analysis without affecting the original sample. Because the interaction with protein occurs in the separation capillary, no sample cleanup following the enzymatic reaction is necessary.

To demonstrate how multiple-enzyme plugs inside of the capillary can be utilized to discern structure, the two enzymes neuraminidase and $\beta 1-4$ galactosidase were use separately and together to probe solutions of glycans from AGP. Prior to injection of the glycan into the capillary two discrete plugs are pressure injected into the capillary, separated by a small plug of of buffer. The glycan is injected into the capillary then electrokinetically moved onto the first plug of enzyme and incubated. The glycan is then electrokinetically moved onto the second plug, incubated, then separated through the capillary. The resulting electropherograms are shown in Figure 3-10. The first trace shows a separation of glycans from AGP through a capillary that contains no enzyme only blanks consisting of $\mathrm{pH} 6$ citrate buffer. The many sialyated glycans can be seen by this electropherogram. These sugars were incubated for 5 minutes in a small plug of the enzyme Neuraminidase prior to the separation step. The five major desialylated. 
glycoforms as seen in Figure 3-10-B. To determine the galactose content of these five glycoforms, the final trace demonstrates the use of two enzymes. In this electropherogram, glycans are injected and moved onto a plug of neuraminidsae, incubated for 5 minutes, then moved onto a plug of $\beta 1-4$ galactosidase, incubated for 10 minutes, then separated through the rest of the capillary. As can be seen in figure 3-10-C, all of the glycans have been shown to be affected by the enzyme, by both the reduction in peak area, as well as by the formation of product peaks. 

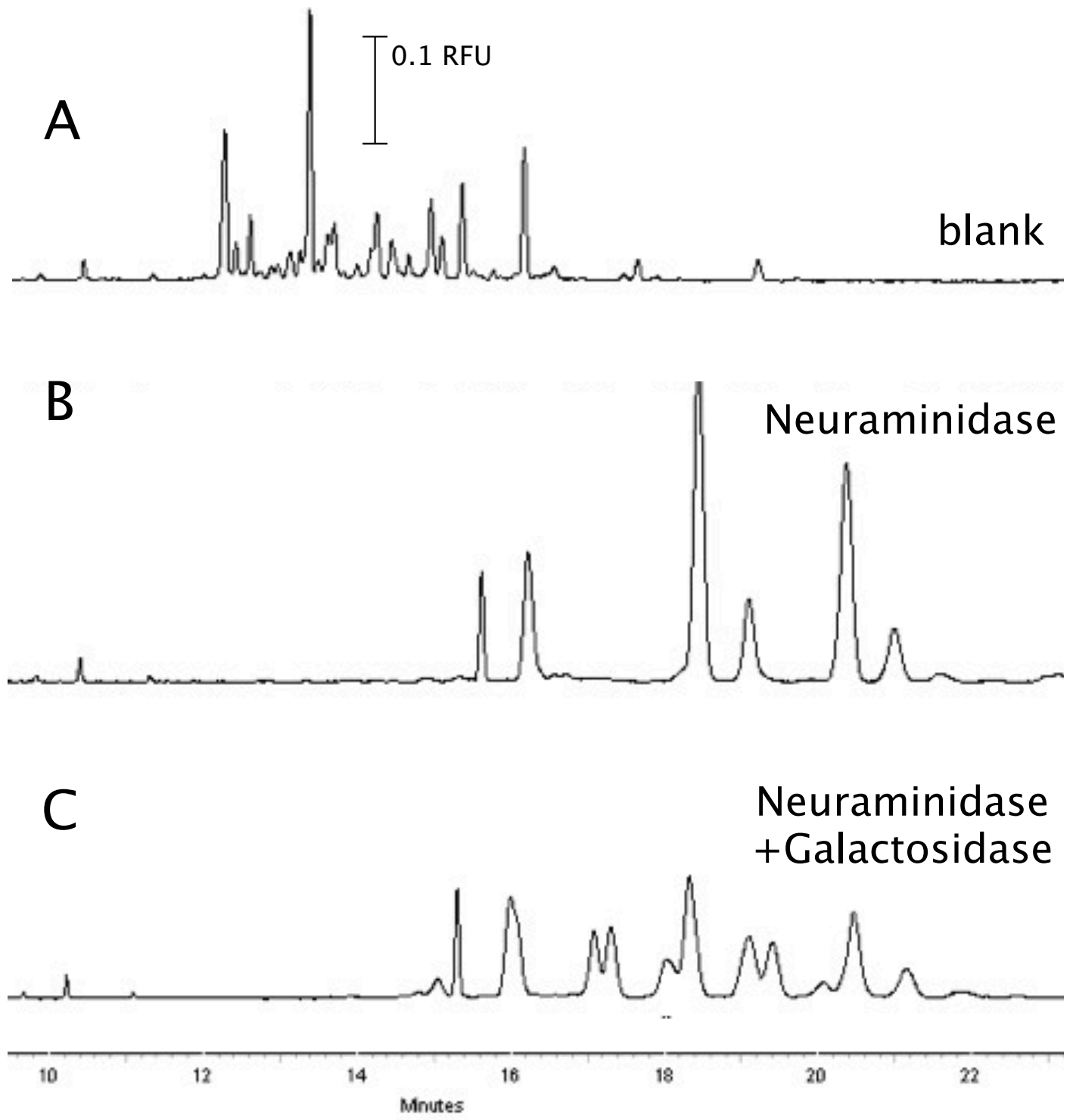

Figure 3-10 demonstrates how multiple enzymes with a separation capillary to sequentially remove terminal glycan residues, determining the overall structure of the glycan. Figure 10-A demonstrates an electrophoretic separation of glycans from AGP, that are sialyated. These highly complex glycans are greatly simplified when they are enzymatically treated with the enzyme Neuraminidase in-capillary for 5 minutes. (Figure 10-B). When the glycans are are injected then injected for 5 , then 10 minutes in Neuraminidase and $\beta 1-4$ galactosidase respectively, it can be noted that all major isoform glycans react. This indicates that all major isoforms of AGP contain sialic acid and $\beta 1-4$ galactose 


\subsection{Conclusions}

The incorporation of glycan-specific proteins such as lectins and enzymes is a useful approach to elucidate glycan structure and composition. Phospholipid additives support the incorporation of protein-based selection agents without the need for covalent modification. This method has been shown to be effective in a variety of capillary inner diameters. Utilization of an in-capillary approach to lectin capture and enzymatic cleavage has a number of advantages of bench-top analyses including reduced reaction times, reduced consumption of reagents, and the utilization of a single sample of glycans for a multitude of analyses. The lectin concanavalin A, as well as the enzymes $\alpha 1-2,3$ mannosidase, neuraminidase, and $\beta 1-4$ galactosidase were all used to demonstrate how in-capillary interactions can be used to probe solutions of glycans. 


\subsection{Bibliography}

1. Varki, A., Biological roles of oligosaccharides: all of the theories are correct, Glycobiology, 1993. 3: p. 97-130

2. Luo, R., Archer-Hartmann, S.A., Holland, L.A., Transformable Capillary Electrophoresis for Oligosaccharide Separations Using Phospholipid Additives, Analytical Chemistry, 2010. 82: p. 1228-1233

3. Archer-Hartmann, S.A., Sargent, L.M., Lowry, D.T., Holland, L.A., Microscale Exoglycosidases Processing and Lectin Capture of Glycans with Phospholipid Assisted Capillary Electrophoresis Separations, Analytical Chemistry, 2011. 83: p. 2740-2747

4. Rami, P.G., Bachhawat, K., Reddy, G.B., Oscarson, S., Surolia, A., Isothermal Titration Calorimetric Studies on the Binding of Deoxytrimannoside Derivatives with Artocarpin: Implications for a Deep-Seated Combining Site in Lectins. Biochemistry, 2000. 39: p 10755-10760

5. McEver, R.P., Moore, K.L., Cummings, R.D., Leukocyte trafficking mediated by selectin-carbohydrate interactions. Journal of Biological Chemistry, 1995. 270: p11025-11028

6. Suguna, K., Surolia, A., Vijayan, M., Perspectives in structural biology. Hyderabad: universities Press, (1999), 367-79

7. Vijayan M., Chandra, N., Lectins. Current Opinion in Structural Biology, 1999. 9: p707-714

8. Satish, P.R., Surolia, A., Exploiting lectin affinity chromatography in clinical diagnosis. Journal of Biochemical and Biophysical Methods, 2001. 49: p625-640 
9. Zaia, J., Mass spectrometry and glycomics. OMiCS: A Journal of Integrative Biology, 2010. 14: p401-418

10.Sheng, Q., Mechref Y., Li, Y., Novotny, M.V., Tang, H., A computational approach to chacterizing bond linkages of glycan isomers using matrix-assisted laser desorption ionization mass spectrometry. Rapid Communications in Mass Spectrometry, 2008. 22: p3561-3569

11.Tang, H., Mechref, Y., Novotny, M., Automated interpretation of MS/MS spectra of oligosaccharides. Bioinformatics, 2005. 21: pi431-i439

12.Mechref, Y., Kang, P., Novotny, M.V., Differentiating structural isomers of sialyated glycans by matrix-assisted laser desorption/ionization time-of-flight tandem mass spectrometry. Rapid Communications in Mass Spectrometry, 2006. 20: p1381-1389

13.Orlando, R., (2010) Functional Glycomics, Methods in Molecular Glycomics . Chapter 3 Quantitative Glycomics, 31-49

14.Segu, Z., Hussein, A., Novotny, M.V., Mechref, Y. Assigning N-Glycosylation Sites of Glyproteins Using LC/MSMS in Conjunction with Endo-M/Exoglycosidase Mixture. Journal of Proteome Research, 2010. 9: p. 3598-3607

15.Alley, W.R., Jr., Madera, M., Mechref, Y., Novotony, M.V., Chip-based reversedphase Liquid Chromatography-Mass Spectrometry of Permethylated N-linked glycans: A potential Methodology for cancer-biomarker Discovery. Analytical Chemistry, 2010. 82: p5095-5106

16.Alley, W.R., Jr., Madera, M., Mechref, Y., Novotony, M.V., Chip-based reversedphase Liquid Chromatography-Mass Spectrometry of Permethylated N-linked glycans: 
A potential Methodology for cancer-biomarker Discovery. Analytical Chemistry, 2010. 82: p5095-5106

17.Hong, M., Cassely, A., Mechref, Y., Novotny, M.W., Sugar-lectin interactions investigated through affinity capillary electrophoresis. Journal of Chromatography B: Biomedial Sciences and Applications, 2010. 752: p207-216

18.Hsu, K.L. Pilobello, K.T., and Mahal, L.K., Analyzing the dynamic bacterial glycome with a lectin microarray approach. Nature Chemical Biology, 2006. 2: p153-157

19.Harvey, D.J. Matrix-assisted laser desorption/ionization mass spectrometry of carbohydrates. Mass Spectrometry Reviews 1999. 18: p349-450

20.de Leoz, M.L. A., Young, L. J.T., An, H.J., Kronewitter, S.R., Kim, J., Miyamoto, S., Borowsky, A.D., Chew, H.K., Lebrilla, C.B., High mannose glycans are elevated during breast cancer progression. Molecular and Cellular Proteomics, 2011. 10: p.1-9 


\title{
Chapter 4
}

\section{Applications of Method to Biological Samples: MCF7}

\author{
and Trastuzumab
}




\subsection{Introduction:}

Glycosylation exists as one of the primary post-translational modifications of proteins, and has extensive biological implications. Glycosylation also plays a vital role in the functionality of these proteins, as changes in the glycan structure can result in altered protein structure and changes in cellular signaling. This is especially important in the search for biomarkers of disease and the development of biological therapeutics such as IgG antibodies. This chapter covers how phospholipid-assisted capillary electrophoresis can be utilized to efficiency separate and analyze glycans, as well as to characterize these two samples by incorporating lectins and exoglycosidase enzymes into the capillary. Cancerous tissues have been known to display abherrent glycosylation [1]. Therefore the method was used to analyze the total glycan content from immortalized breast cancer cell line MCF7. This data has been published in reference [2]. This method was also applied to analysis of glycans from the therapeutic antibody Trastuzumab (Herceptin $\left.{ }^{\circledR}\right)$, a monoclonal antibody whose glycosylation has been well characterized [3]. This data has been published in reference [4].

\subsubsection{Glycomics and Clinical Biomarker Research}

The total glycan content of a cellular sample can host a diverse variety of oligosaccharides. Glycoproteins in eurkaryotic systems occur in all cellular compartments where they are attached to linked to peptides through serine or threonine (O-linked), or asparagine (N-linked) residues [5]. Glycans can also be attached to lipids, such as the glycosphingosine, ceramide [6]. Unlike other protein modifications such as 
phosphorylation, acetylation, or methylation, glycosylation poses a challenge to analysis due to extensive variation in glycan monomer composition, linkage between monomers, and overall placement. Further adding to the difficulty in studying glycan structure and function it should be noted that, unlike nucleic acids and proteins, glycans are not linked back to the genome, but result from the numerous and coordinated actions of highly specific glycosyltransferases that can change based on numerous localized conditions [7]. These events result in highly variable solutions of glycoforms, made of very slight alterations in the actual glycan structure.

\subsubsection{MCF-7}

Protein glycosylation is one of the primary post-translational modifications, and results in extensive biological implications. Changes in the glycosylation of proteins has been shown to change as a result of malignant transformation, making glycosylation alteration a common feature of disease such as cancer [8]. MCF-7, which stands for Michigan Cancer Foundation Line 7, was established in Detroit in 1973, and is the most commonly used breast cancer cell line in the world [9]. As of 2003, this line has been cited in literature more than 5700 times [10]. As this line is well-documented, it is frequently used as a model line to characterize advances in instrumentation in methodology in proteomic studies. Because glycosylation has such a profound effect on cellular biology, monitoring of cellular glycosylation is vital in in-vitro cellular studies. 


\subsubsection{Therapeutical Biologics and Antibodies}

Total revenues of antibody-based therapeutics generated about 20 billion USD in 2007 [11]. Sale growth forecasts for antibody therapeutics are 14\% (vs $0.6 \%$ for small molecule- based therapeutics). Antibody-based therapeutics have a relatively high success rate from clinical to the licensure $(25-29 \%$ for antibodies vs only $11 \%$ for small-molecule drugs) [12] It was reported by Reichert in 2008 that a total of $205 \mathrm{mAbs}$ were in clinical trials. It was also estimated that from 1988 to $2006,17 \%$ of all humanized mAb candidates that reached clinical trials were eventually approved by the FDA (as opposed to only $11 \%$ of small molecule drugs) [13].

Biosimilar antibodies are "generic" (it is important to use the term "generic" cautiously because generic versions of off-patent small-molecule drugs are exact copies of the original drugs) versions of an original drug, that contain the same amino acid sequence but are produced from different clones and manufacturing processes. These molecules may have different glycosylation patterns as well as other micro-variants that may affect quality, safety, and potency. Bio-better antibodies target the same validated epitope but have been engineered to have improved properties. One of the most popular methods to do this is through changes in the glycosylation. [12]

\subsubsection{Antibody Structure and the Effects of glycosylation}

IgG antibodies are comprised of two heavy and two light chains held together by covalent and non-covalent bonds to form three independent protein moieties connected at a flexible linker known as the hinge region (Figure 4-1). The two Fab fragments serve as 
the antigen-binding regions of the antibody, while the third Fc fragment, along with the site of glycosylation, at asparagine at position 297, plays a major role in the communication and interaction with the immune system and cell surfaces [14]. The glycan is attached to the amino acid prior to the secondary, tertiary, and quaternary structure is formed, and is a major factor in the overall structure of the protein. Following the folding steps of the antibody, the glycan undergoes a number of glycan trimming and addition steps[15] . The basic structure of this N-linked glycan is that of a core structure comprising $\mathrm{N}$-acetylglucosamine and mannose, with a variable region at the ends [16]. The type of glycosylation from $\operatorname{IgG}$ antibodies can vary widely; although there is very little sialyation $(<10 \%)$, antibody heterogeneity can result in a potential of up to 128 different glycoforms [17]. Utility of the the antibody as a therapeutic is through several possible functions. The primary function is the use of the antigen binding regions to bind a specific target, halting the pathway that it would be involved with. However, a number of other effects of antibodies are being engineered, including extensions of biological half-life and effector functions, such as antibody-dependent cell-mediated cytotoxicity (ADCC). Extending an antibody's half-life provides a number of benefits, including an improved bioavailability and reduced amount or frequency of dosing [14]. These methods may be used to improve the efficacy of the drug or decrease the cost of treatment to the patient. Many biotherapeutics utilize effector functions such as antibody dependent cellmediated cytotoxicity (ADCC) or complement dependent cytotoxicity (CDC) as a major part of the drugs mechanism in the body. These modes of targeting cells for active lysing by the immune system is a potent method therapy for a number of diseases. When this 
method of alteration is considered; however, the antibody is often engineered to shorten the biological half-life, so that patient does not suffer from undue toxicity [14]. Current efforts are underway to enhance these effects by engineering the glycan structure. Methods to alter antibody glycosylation include changes in the cell culture production such as the choice of cell line, nutrient availability, amount of dissolved oxygen or ammonia, $\mathrm{pH}$, culture viability, growth phase, and temperature [15]. Host cell lines, such as Chinese hamster ovary $(\mathrm{CHO})$ have been selected to express antibodies with altered glycosylation such as increased amounts of bisecting $\mathrm{N}$-acetylglucosamine or reduced amounts of fucose which serves to increase ADCC activity [18]. It is therefore necessary for both the manufacturer, as well as regulatory agencies, to profile and monitor the structural characteristics of these glycans. 


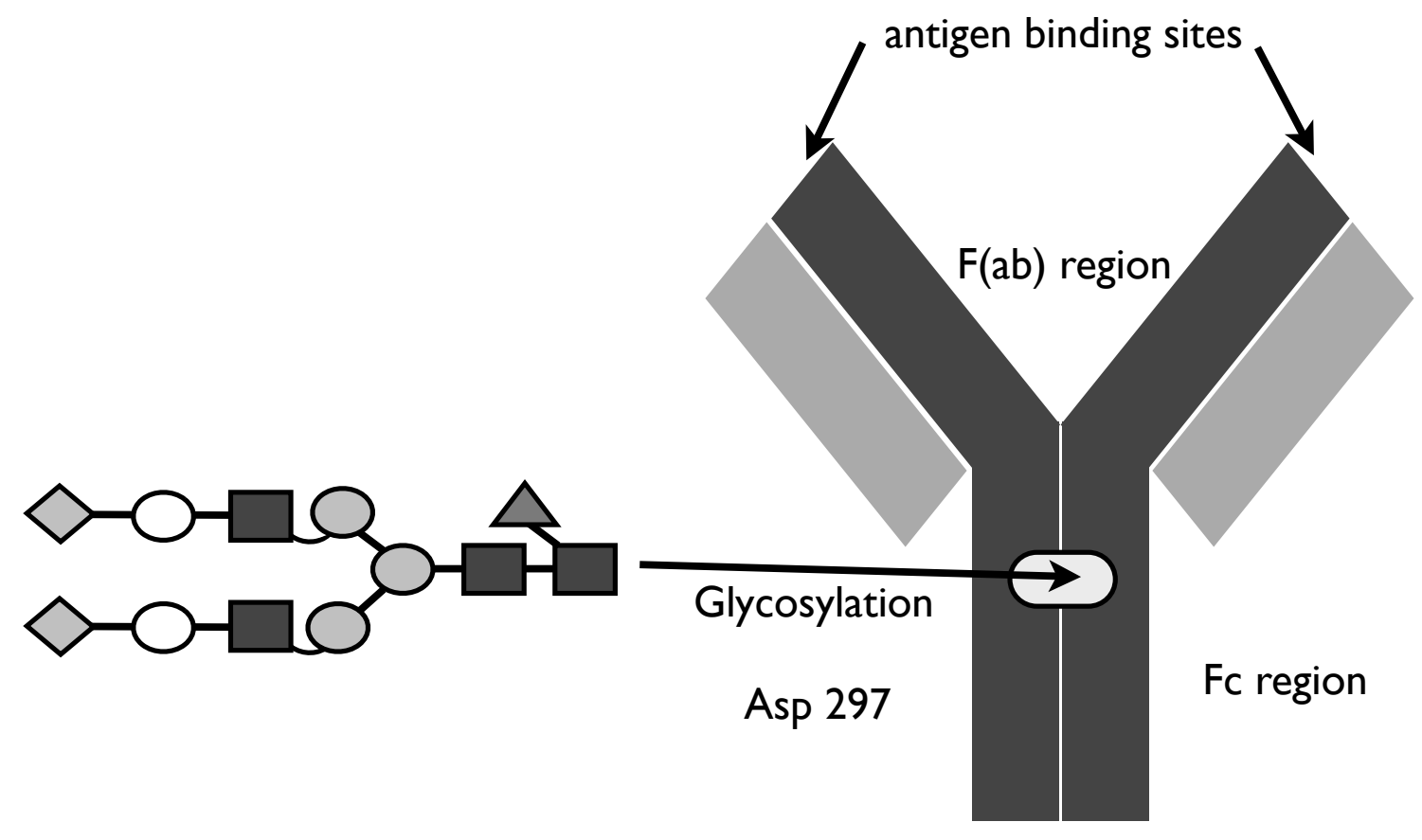

Figure 4-1 Figure 4-1 shows a general depiction of a whole IgG antibody and a general depiction of the glycosylation found N-linked to asparagine at position 297.

\subsubsection{Trastuzumab (Herceptin)}

The human epidermal growth factor receptor family of of four receptors (HER1, HER2, HER3, and HER4, also known as ErbB) are tyrosine kinase receptors that normally regulate cell growth and survival. These receptors have an extracellular domain for ligand binding, a transmembrane segment, and with the exception of HER3, an intracellular tyrosine kinase domain [19]. The extracellular domain of HER2 is unique in this family because unlike the other three HER receptors, HER2 can adopt a conformation that permits dimerization when there is a lack of ligand [20]. This binding activates signal-transduction cascades of these receptors that promote cellular 
proliferation, survival, as well as mobility and invasiveness [21]. The over expression of HER 2 has been observed in the 20 to $30 \%$ of breast cancer that has been classified as the most aggressive and with the worst prognosis. [22,23].

Trastuzumab (Herceptin $®$ ) is a recombinant monoclonal humanized IgG antibody that contains two antigen-binding sites specific to the extracellular domain of the HER2 receptor, effectively blocking the receptor for ligand binding or dimerization. This prevents activation of the intracellular tyrosine kinase, and the cascade of events resulting in unchecked cellular growth [24]. Trastuzumab was produced by Genentech and was approved for the treatment of patients with HER2 over expressed metastatic breast cancer by the Food and Drug Administration (FDA) in 1998. Trastuzumab has been shown effective when used in conjunction with standard chemotherapy, and has been shown to extend the time to disease's progression, increase response rates, and result in a longer median survival rate [25]. Trastuzumab is rarely prescribed as a standalone treatment, and is beneficial for only a small percentage of patients (only approximately $20 \%$ ) when it is not combined with a secondary treatment such as cisplatin chemotherapy [26]. As possible mechanisms of resistance are being investigated [27] a number of alternative therapeutics focusing on the same targets have been developed. Trastuzumab's effectiveness has been shown to improve with the removal of fucose from the existing glycan structure. Removal of fucose has been shown to greatly enhance ADCC, and thus the effectiveness of the drug to target cancerous cells. A recently study showed that defucosylated trastuzumab doubled the survival time in 
comparison to fucosylated trastuzumab in preclinical models of HER2 overexpressed breast cancer [28].

\subsubsection{Quality by Testing vs Quality by Design}

The historical approach toward the approval of pharmaceutical products involved the identification of the process parameters at each stage of development that have critical influence on product quality, then testing the end product to validate the process. This process, known as Quality by Testing has a number of important disadvantages, including the fact that any change in the manufacturing process requires validation, discouraging companies from changes, improvements, or optimization of the manufacturing process. The major regulation bodies in the United States and Europe (USFDA and EMEA) now encourage the incorporation of Quality by Design into the production pipeline. Quality by Design involves the understanding and utilization of indepth knowledge of the product and mechanisms at every of production. Quality by Design concepts include a definition of the desired performances (clinical or in vivo), identification of critical quality attributes and the process parameters that affect these attributes, and sets of analyses during processing for the dynamic control of manufacturing to ensure that the defined product performances are achieved [29]. Because glycosylation is responsible for the considerable variability of mAb products, rapid, efficient analyses of glycosylation is vital to this industry. 


\subsection{Experimental}

\subsubsection{Chemicals and Materials:}

Reagents were obtained from a variety of manufacturers. Sigma Aldrich (St. Louis, MO, USA) was the source for asialofetuin from fetal calf serum, 3-(Nmorpholino)-propanesulfonic acid (MOPS), calcium chloride dihydrate, sodium chloride, maltooligosaccharide standards and sodium hydroxide. Methanol and $\alpha 1$-acid glycoprotein (AGP) were purchased from EMD Biosciences (La Jolla, CA). Ethanol was obtained from AAPER Alcohol (Shelbyville, KY). 1,2-dimyristoyl-sn-glycero-3phosphocholine (DMPC) and 1,2-dihexanoyl-sn-glycero-3-phosphocholine (DHPC) were obtained from Avanti Polar Lipids (Alabaster, AL). 1-aminopyrene-3,6,8-trisulfonic acid (APTS) was purchased from Biotium (Hayward, CA). Sodium cyanoborohydride $\left(\mathrm{NaCNBH}_{3}\right)$ was acquired from Strem Chemicals (Newburyport, MA). Triethylamine, acetonitrile, and citric acid were acquired from Fisher Scientific (Pittsburgh, PA). Fetal bovine serum was obtained from Thermo Scientific (Rockford, IL). Trastuzumab was obtained from Genentech (San Francisco, CA, USA). Ribonuclease B (Rnase B), $\alpha 1-2,3$ mannosidase, $\beta 1-4$ galactosidase, neuraminiase, $\beta$ - $N$-Acetylglucosaminidase, and a peptide N-glycosidase (PNGase F) kit, were obtained from New England Biolabs (Ipswich, MA). A G7 10X reaction solution composed of $0.5 \mathrm{M}$ sodium phosphate buffered at $\mathrm{pH} 7.5$, a glycoprotein denaturing solution containing 5\% sodium dodecyl sulfate (SDS), and 0.4 dithriothreitol (DTT), and 10\% solution of nonionic surfactant NP-40 were included in the PNGase F kit. A G1 10X reaction solution composed of $0.5 \mathrm{M}$ 
sodium citrate buffered at $\mathrm{pH} 6$ was provided in the neuraminidase kit. An Elga Purelab ultra water system (Lowell, MA) was used to provide deionized water.

\subsubsection{Culture of MCF7 Cells and Protein Isolations}

MCF7 cells (ATCC, Manassas, VA) were cultured by David Lowrey and Linda Sargent at the National Institute for Occupational Safety and Health (Morgantown, WV). Cells were cultured with Dulbecco's Modified Eagle Medium (Invitrogen, Carlsbad, CA) supplemented with $10 \%$ fetal bovine serum. The total protein was isolated from approximately $10 \times 10^{6}$ MCF7 cells in a $\mathrm{T} 75$ flask. Two $\mathrm{mg} / \mathrm{mL}$ of total protein was isolated when the cells were approximately $70 \%$ confluent. The protein was extracted in 50mM Tris- $\mathrm{HCl}, 1 \%$ Triton, $1.5 \mathrm{mM} \mathrm{MgCl} 2,150 \mathrm{mM} \mathrm{NaCl}$, and protease inhibitors. An $83 \mu \mathrm{g}$ sample of the isolated protein fraction taken from the MCF7 cells was labeled with APTS as described.

\subsubsection{Preparation and Derivatization of Glycans from MCF7 and Trastazumab}

Glycans derived from glycoproteins (Branched glycan standards, glycans from MCF7, and glycans from Trastuzumab) were prepared as follows. Glycans were removed from protein sources using a PNGase F kit using a protocol based on the kit from the manufacturer. Briefly the protein is denatured using a solution containing SDS and DTT and heating at $95^{\circ} \mathrm{C}$ for 10 minutes. The nonionic surfactant $\mathrm{NP}-40$ is then added to the solution to prevent the DTT from denaturing the enzyme PNGase F, which immediately added afterward. This reaction was incubated at $37^{\circ} \mathrm{C}$ overnight, rather than the 2 hours 
suggested by the protocol. The next day, a $3 \mathrm{X}$ volume of ice-cold ethanol was added to precipitate the protein. The solution was centrifuged at $4^{\circ} \mathrm{C}$ at $10000 \mathrm{rpm}$ for 10 minutes. The liquid fraction containing cleaved glycans was dried using a Savant SpeedVac concentrator (ThermoScientific, Waltham, MA). The dried glycans were reconstituted in $1 \mu \mathrm{L}$ of a $0.2 \mathrm{M}$ solution of APTS dissolved in $1.2 \mathrm{M}$ citric acid, along with $1 \mu \mathrm{L}$ of $1 \mathrm{M}$ $\mathrm{NaCNBH}_{3}$ in deionized water. The solution was thoroughly mixed before being incubated overnight at $37^{\circ} \mathrm{C} .100 \mu \mathrm{L}$ of deionized water was used to stop the reaction. If needed, the sialic acid was removed by adjusting the $\mathrm{pH}$ of the glycan solution to 6 with sodium hydroxide then incubating it overnight with neuraminidase. If necessary, a $10 \mathrm{kDa}$ molecular weight cut off filter (Sartiorius, Stonehouse, UK) was used to remove the neuraminidase followed by removal of excess APTS by a Discovery DPA-6S solid phase extraction cartridge (50 mg packing, Supelco, Bellefonte, PA). A flush of 95:5 (v/v) acetonitrile:water was used to prepare the cartridge prior to use. APTS was eluted from the extraction cartridge with a solution containing 95:5 (v/v) acetonitrile:water containing $50 \mathrm{mM}$ trimethylamine. An aqueous solution of $50 \mathrm{mM}$ triethylamine was used to elute the retained glycans from the cartridge. The glycan solution was evaporated to dryness and the reconstituted in $100 \mu \mathrm{L}$ deionized water and stored at $-20^{\circ} \mathrm{C}$. Following labeling of the MCF7 glycans with APTS, a 1kDa molecular weight cutoff filter (MWCO) was used to remove APTS labeled- small molecules, such as monosaccharides. Prior to deglycoyslation and labeling of Trastuzumab, a $10 \mathrm{kDa}$ MWCO filter was used to remove trehalose and other stabilizes from the protein antibody. 


\subsubsection{Preparation of Phospholipid Additive}

Preparations of phospholipids were comprised of $5 \%$, [DMPC]/[DHPC] (q value) $=0.5$ were used for coating of the capillary, which serves to suppress the electroosmotic flow, and to passivate the surface from nonspecific interactions. Another phospholipid preparation of a $10 \%, \mathrm{q}=2.5$, phospholipid solution was used for the separation media, due to it's thermally-switchable gel-like viscosity. These phospholipids were prepared by weighing out the appropriate masses of dry DMPC and DHPC, then adding $100 \mathrm{mM}$ aqueous MOPS buffered to $\mathrm{pH}$ 7. After the solution was thoroughly mixed, the preparation was subjected to a minimum of three freeze-thaw cycles and centrifuged for $10,000 \mathrm{rpm}$ for ten minutes. The phospholipid preparation was stored at $-20{ }^{\circ} \mathrm{C}$, and was thawed and vacuum degassed prior to use.

\subsubsection{Capillary Electrophoresis}

Separations were performed using a P/ACE MDQ Capillary electrophoresis system (Beckman Coulter, Fullerton, CA, USA) equipped with laser induced fluorescence detection (air cooled argon ion laser, $\lambda \mathrm{ex}=488 \mathrm{~nm}, \lambda \mathrm{em}=520 \mathrm{~nm}$ ). The fused silica separation capillary had a $25 \mu \mathrm{m}$ internal diameter and a $360 \mu \mathrm{m}$ outer diameter (Polymicro Technologies, Phoenix, AZ, USA) with an effective length of 50.0 $\mathrm{cm}$ and a total length of $60.2 \mathrm{~cm}$. Capillaries were subject to the following flushing sequence daily: $1 \mathrm{M} \mathrm{NaOH}$ for 30 minutes at $170 \mathrm{kPa}$ (25 psi), deionized water for 15 minutes at $170 \mathrm{kPa}(25 \mathrm{psi})$, methanol for 15 minutes at $170 \mathrm{kPa}(25 \mathrm{psi})$, and 15 minutes of water at $170 \mathrm{kPa}(25 \mathrm{psi})$. Following this flushing sequence, the capillary was 
passivated with a phospholipid coating with a $5 \%, \mathrm{q}=0.5$ phospholipid preparation containing $1.25 \mathrm{mM}$ calcium. This semi-permanent coating was applied for 20 minutes at $170 \mathrm{kPa}(25 \mathrm{psi})$ followed by a 2 minute MOPS flush at $170 \mathrm{kPa}$ (25 psi) to remove excess phospholipid and from the capillary. A brief pre-coat was applied prior to each run using the following protocol at $170 \mathrm{kPa}(25 \mathrm{psi})$ with the capillary held at $19^{\circ} \mathrm{C}: \mathrm{q}=$ $0.5,5 \%$ phospholipids for 3 minutes, MOPS for 2 minutes, and $\mathrm{q}=2.5,10 \%$ phospholipids for 3 minutes. If enzyme was being used in-capillary, an additional 3 minute $170 \mathrm{kPa}(25 \mathrm{psi}) \mathrm{MOPS}$ flush was performed in the reverse direction before this sequence, to expel any enzymes from the capillary, and to prevent fouling of the capillary. When the room temperature was higher than $22^{\circ} \mathrm{C}$, a portable air conditioner was used to provide ambient thermal control. Injections into the capillary were carried out in three steps. First, a plug a MOPS was injected into the phospholipid filled capillary ( $7 \mathrm{sec}$, at $6.9 \mathrm{kPa}$ ) at $19{ }^{\circ} \mathrm{C}$. The capillary temperature was then heated to $25^{\circ} \mathrm{C}$, resulting in the viscosity of the $\mathrm{q}=2.510 \%$ phospholipid filling to increase to a gel-like consistency. The glycan is then electrokinetically injected into the capillary. Finally a post-plug of MOPS was pressure injected (5 sec, $3 \mathrm{kPa}$ ). Separations were carried out at $400 \mathrm{~V} / \mathrm{cm}$ under reversed polarity. Data collection and analysis were performed using 32 Karat Software version 5.0 (Beckman Coulter).

\subsection{Results and Discussion}

Chapter 3 discussed how glycan-specific lectins and enzymes may be used to analyze solutions of glycans for structural characterization. In this chapter, these methods 
of analysis are used on two different biological samples, demonstrating two different types of analyses.

In-capillary interactions may be used to probe and simplify highly complex samples of unknown glycans, such as those taken from the protein fraction of cellular samples. N-linked glycans from the immortalized human breast carcinoma cell line MCF7 were analyzed with capillary electrophoresis. This highly complex sample was probed with lectins and enzymes to discern the overall characteristics, providing an analysis method that can be used monitor changes in the overall glycan composition. These changes may act as biological "clues" to reveal changes that are relevant to cancer. This method was also used on glycans with the uncharacterized low abundance glycans from the therapeutic antibody Trastuzumab, to discern the amount of glycans containing sialic acid.

The incorporation of enzymes into capillary may also be used to target and determine the sequence of specific glycans. Various exoglycosidase enzymes are used in combination to systematically cleave terminal residues, revealing the sequence of the overall glycan structure. This method provides a rapid, low-tech method of determining sequence without the use of sophisticated instrumentation, such as mass spectrometry. This method is used to sequence the major isoform glycans taken from the therapeutic antibody Trastuzumab. 


\subsubsection{Separation of Glycans from MCF7 Cells and Identification with Glycan}

\section{Standards}

Glycans from the immortalized breast cancer cell line, MCF7, were labeled with APTS and separated using phospholipid-assisted capillary electrophoresis. The use of phospholipid additives as an easily incorporated, gel-like separations media provides superior separations efficiencies. These glycans were separated with efficiencies as high as 640000 theoretical plates. The excellent separations efficiencies as a result of the phospholipid materials allow for superior resolutions of high abundance glycans, as well as the detection and separations of low abundance glycans, as seen in Figures 2 and 3. Two of the low abundance peaks (as seen in Figure 3) were identified with the glycan standards mannose 5 and mannose 6.

\subsubsection{Analysis of MCF7 with Concanavalin A}

Phospholipids provide excellent media for the incorporation of proteins such as lectins and enzymes. Because phospholipids are naturally the components of cellular membranes, phospholipids are inherently biocompatable and do not result in denaturation. Alternative methods of protein incorporation for analysis usually involve a method of conjugation such as biotin-streptavidin or covalent modification of the protein, which can result in denaturation of the protein and/or modification of the binding or reaction pockets of the protein. These may reduce subsequent protein binding or enzymatic activity. The methods of conjugation often utilize buffers, ionic strengths, and pHs that can further damage the enzyme, and require lengthy cleanup steps prior to 
utilization. In contrast, using the temperature-dependent viscosity of the phospholipid to immobilize the enzyme within the capillary is achieved without modifications to the protein or phospholipid.

The lectin concanavalin A was used to reduce the complexity of the electropherogram of glycans taken from MCF7 cells. Analyses with off- or on-line of incubations of concanavalin A select for mannose-rich glycans that bind with high specificity, especially to glycans such as mannose 5 and mannose 6 . The electropherogram shown below displays the major and minor glycans from MCF7. Glycans that responded to concanavalin A and thus had these structural characteristics are shown. The coefficient of variation of peak area was less than $10 \%$. Therefore the criterion for peaks that responded to enzyme or lectin was chosen to be $15 \%$. Any peak that responded by more than $15 \%$ was denoted in Figures $4-2$ and 4-3. Mannose composition of the MCF7 glycans were primarily identified from using an off-line incubation with concanavalin A. These experiments showed that the majority of glycans taken from the MCF7 cell line are structurally high in mannose, a characteristic that is supported in other literature sources [29]. The analyte peak identified as mannose 5 by glycan standards did not respond to concanavalin A. This may be because of the low abundance of this peak and competing higher affinity of other mannose-rich species. Additionally others have reported that lectins may display unusual interactions that do not obey predicted epitope binding [30]. 


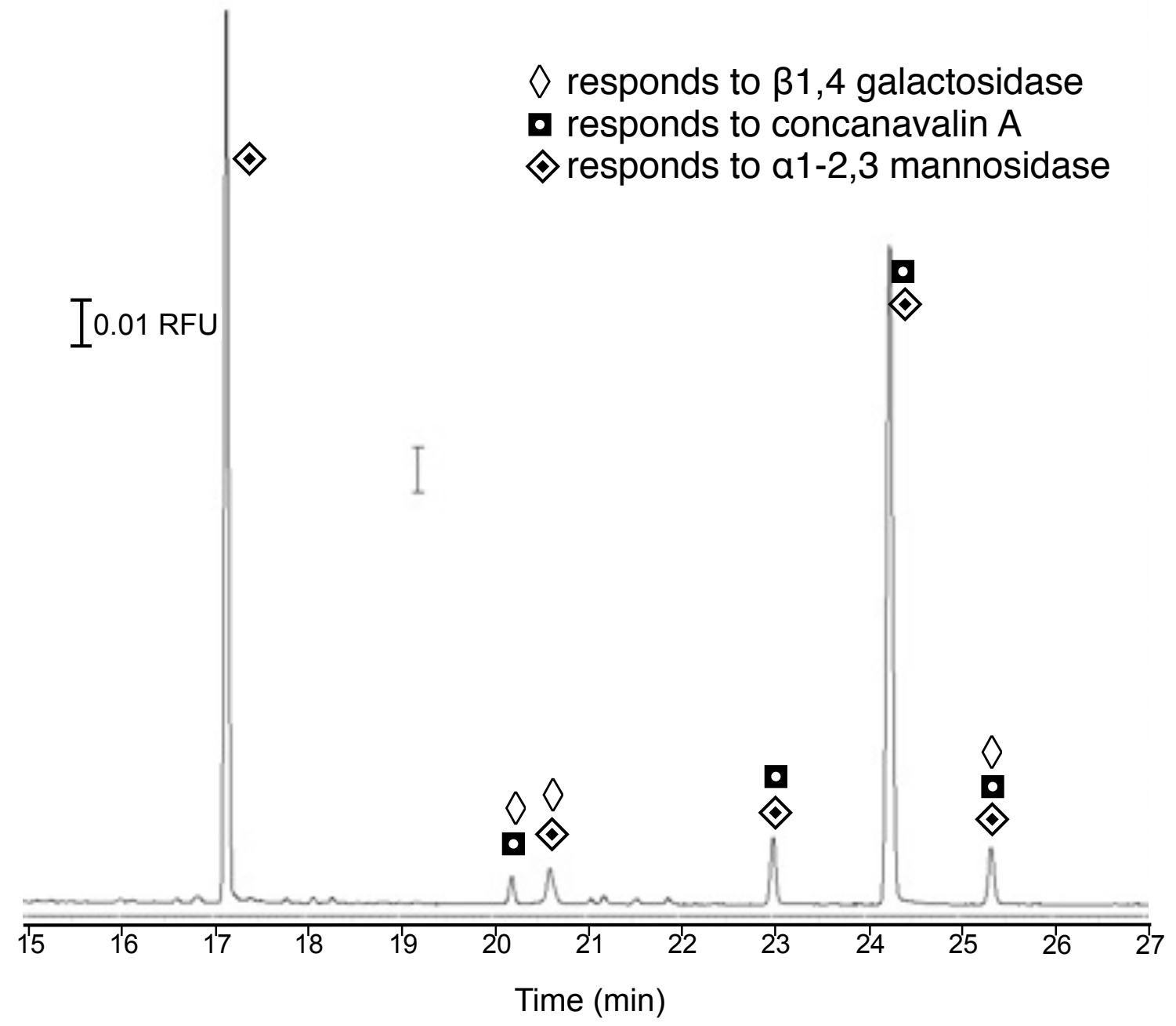

Figure 4-2 is the electropherogram of the labeled glycan fraction derived from MCF7 cells. Glycan composition is interrogated using the enzymes $\beta 1-4$ galactosidase, $\alpha 1-2,3$ mannosidase, or the lectin concanavalin A.This figure was reproduced with permission from [2]. Copyright 2011 American Chemical Society.

\subsubsection{Analysis of MCF7 with galactosidase, mannosidase}

The enzymes $\alpha 1-2,3$ mannosidase and $\beta 1-4$ galactosidase were used for incapillary interactions with the MCF7 glycans. The enzyme $\alpha 1-2,3$ mannosidase cleaves terminal $\alpha 1-2$ or $\alpha 1-3$ mannose residues and can be used along with the lectin concanavalin A to confirm the characteristics of a high-mannose glycan. The enzyme 
$\beta 1-4$ galactosidase selectively cleaves terminal $\beta 1-4$ galactose residues and is an indicator of branched glycan species.

$\diamond$ responds to $\beta 1,4$ galactosidase

- responds to concanavalin $A$ $\diamond$ responds to a1-2,3 mannosidase

I0.01 RFU
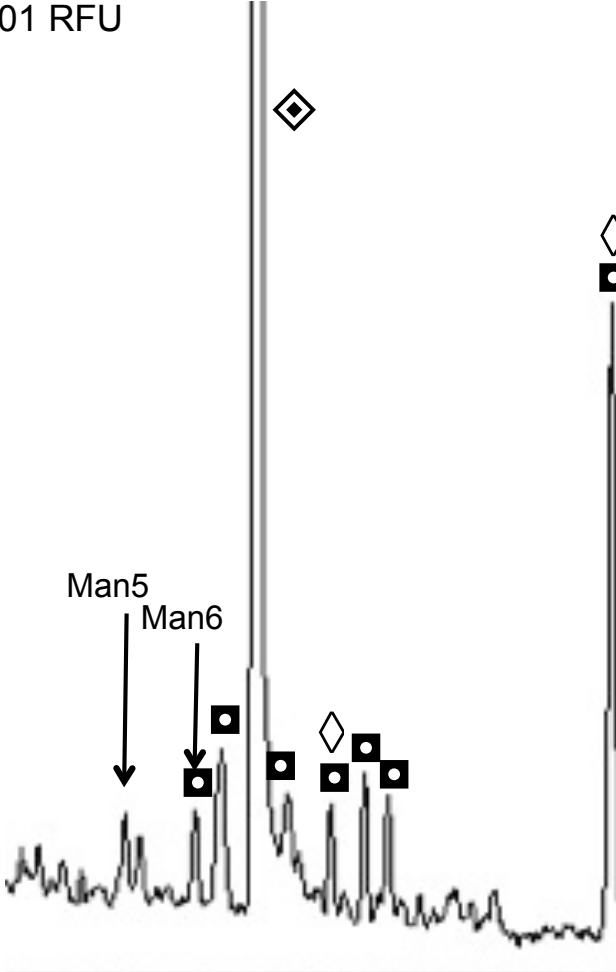

15

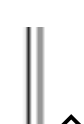




\subsubsection{Identification of the major glycans from Trastuzumab}

Glycosylation of the humanized immunoglobulin IgG1, Trastuzumab is primarily fucosylated N-linked biantennary complex glycans [17,31]. The major glycans from Trastuzumab are shown in Figure 4-4. These glycans have been confirmed through a number of literature sources and comprise $99 \%$ of the major glycans from the antibody.

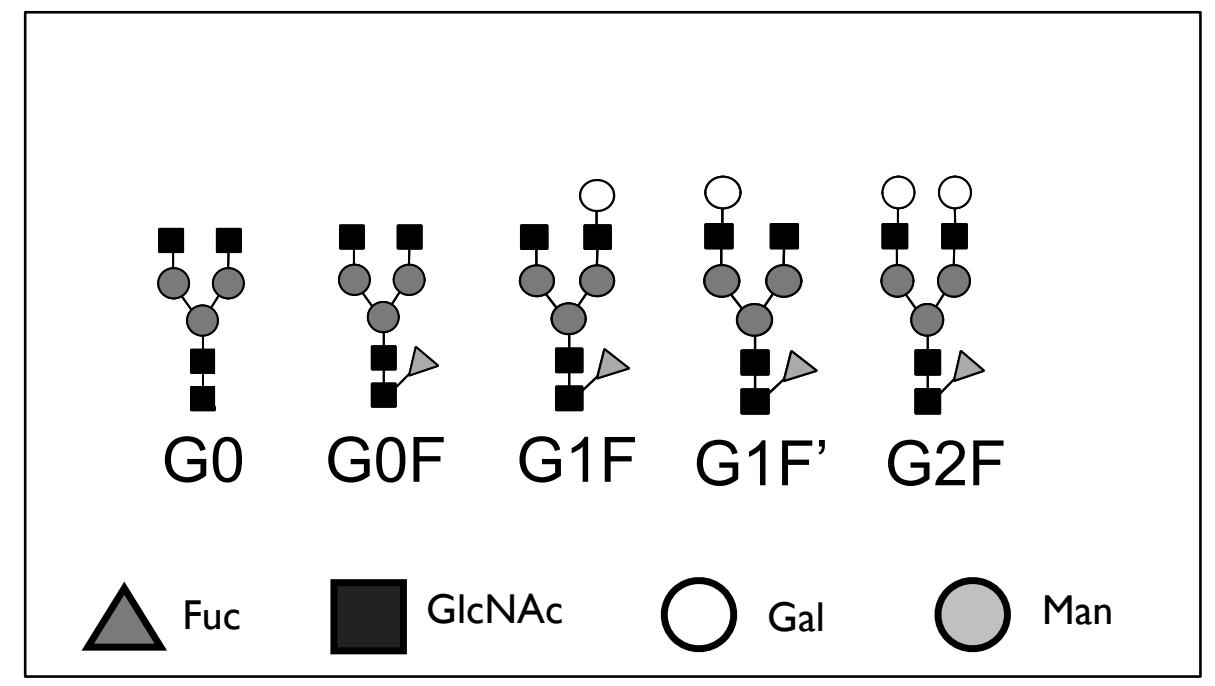

Figure 4-4 displays the highest abundance structures characterized for Trastuzumab (Herceptin ${ }^{\circledR}$ ), as well as the naming used for this study.

\subsubsection{Separations of glycans from Trastuzumab}

Glycans from Trastuzumab were labeled with APTS and separated using conditions previously reported. The results are shown in Figure 4-5. A $60.2 \mathrm{~cm}, 25 \mu \mathrm{m}$ inner diameter capillary was coated with Q $0.55 \%$ phospholipid, rinsed with MOPS, then filled with Q2.5 $10 \%$ phospholipid. Glycans were injected, then separated using a field strength of $400 \mathrm{~V} / \mathrm{cm}$. The major abundance glycans from Trastuzumab had separation efficiencies ranging from 410,000 plates $(\mathrm{G} 0 \mathrm{~F})$ to 510,000 plates $(\mathrm{G} 2 \mathrm{~F})$. The 
identities of these glycans were determined based on migration order and abundance based on characterization by $\mathrm{CE}$ and other methods in the literature. Other reported methods utilizing capillary electrophoresis utilize linear polyacrylamide gel separation media [31] and the same APTS tagging methods used in this study. However the efficiencies of separation were only an estimated 65,000 (value based on hand calculations from figures) compared to our 510,000. An additional benefit of the phospholipid separations media is that the low abundance glycans, which make up $\sim 1 \%$ of the total glycan can be efficiently resolved and detected. These glycans, which are not well-characterized in literature, are shown in Figure 4-5-B. Three of these lowabundance glycans were identified as high mannose structures (mannose 5 and mannose 6) as well a a branched dianntennary structure (AI). Although the use of glycan standards can be utilized to confirm structural identity of glycans from a sample, the high cost and limited commercial availability prevent this method from being truly viable, especially for users with limited resources. 

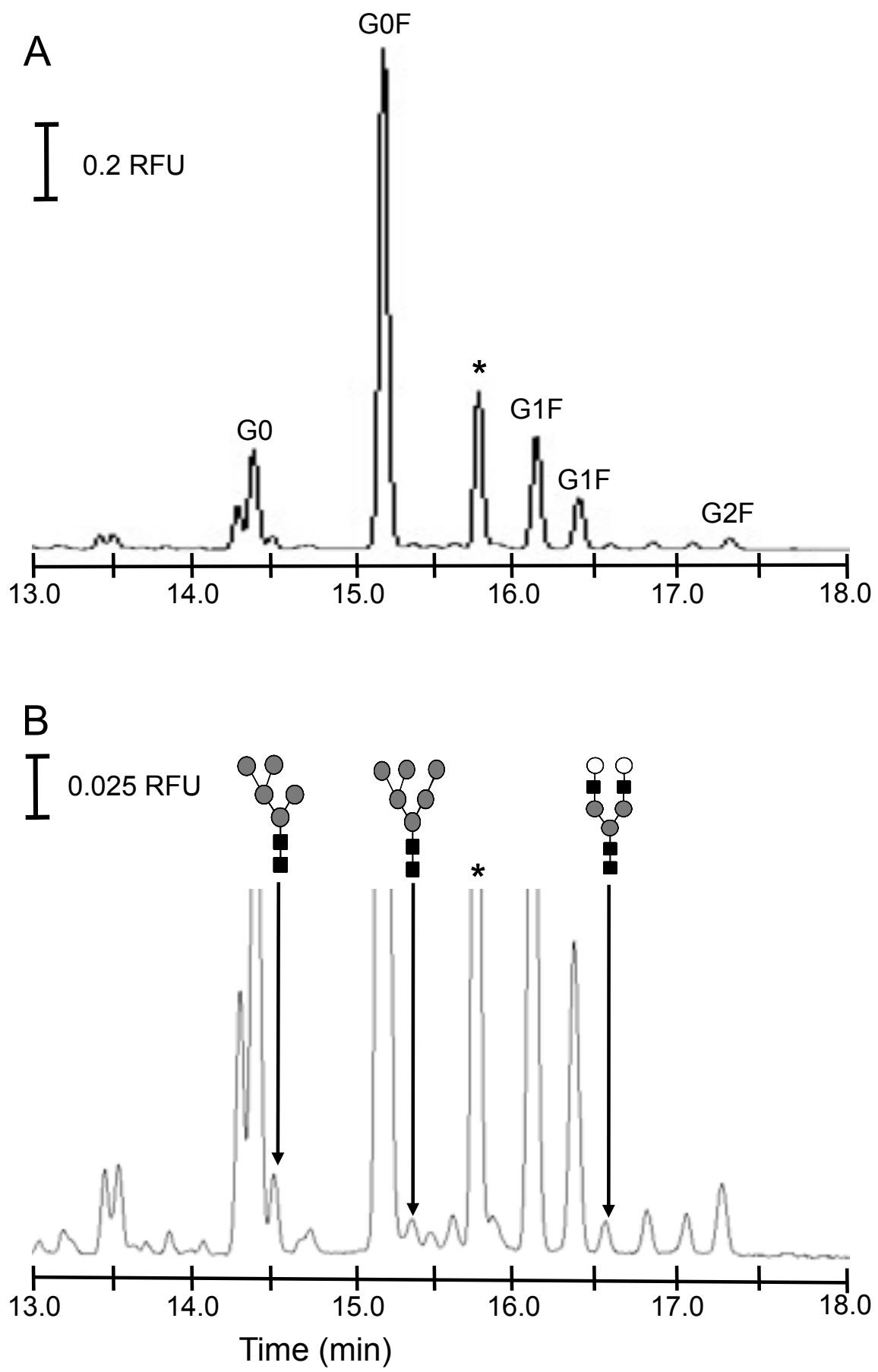

Figure 4-5 is the electropherogram of the labeled glycan fraction derived from Trastuzumab. The highest abundance glycans G0, G2F, G1F, G1F', and G0F are labeled based on literature characterization of glycosylation. The identities of three of the lower abundance peaks are confirmed using glycan standards (mannose 5, mannose 6 , and the branched diantennary A1). The peak labeled with an * is an internal standard. Peak efficiencies were as high as 510,000 peaks for G2F. Reproduced with permission from [4]. 


\subsubsection{Characterization of sialyated glycans from Trastuzumab}

The determination of the amounts of sialic acid ( $N$-Acetylneuraminic acid) is beneficial to biotherapuetic monitoring and production. Although sialic acids constitute $<10 \%$ of glycans derived from IgG antibody, they are nonetheless a valuable constituent. Terminal sialic acid has been found to increase the circulating half-life of a biotherapeutic drug, and thus its efficacy [30]. Sialic acids pose difficulty for analysis because, unlike other glycan residues, they each provide a minus one charge, altering the expected migration time. They are also thermally labile and hydrolyze at low $\mathrm{pH}$, which poses a challenge to analysis with mass spectrometry. Sialic acids are commonly removed from glycans prior to analysis with the enzyme neuraminidase, which is fast-acting and commercially available through a number of sources. To probe the solution of glycans taken from Trastuzumab, a small plug of neuraminidase in $\mathrm{pH} 5.0$ citrate buffer was injected into the capillary $(1.5 \mathrm{psi} 15 \mathrm{sec})$. The glycan was injected into the capillary, electrokinetically moved onto the enzyme plug and was subjected to a 5 minute incubation time, then separation through the capillary. The resulting electropherograms are shown in Figure 4-6-B, which is an expanded view of the low abundance glycans. The solid trace is of a separation following incubation for 5 minutes in a blank containing only pH 5 citrate buffer. The dashed trace is following incubation for 5 minutes in a plug containing the Neuraminidase enzyme. The four low-abundance glycans from Trastuzumab that are denoted in Figure 6 responded to the enzyme. As can be seen in Figure 4-6-B, which is a full-scale view of the same electropherograms, these glycans constitute only a minor portion of the total glycan composition. Based on this study and 
following comparison of the glycan areas, only $\sim 1 \%$ of the total glycan content of Trastuzumab is sialyated.

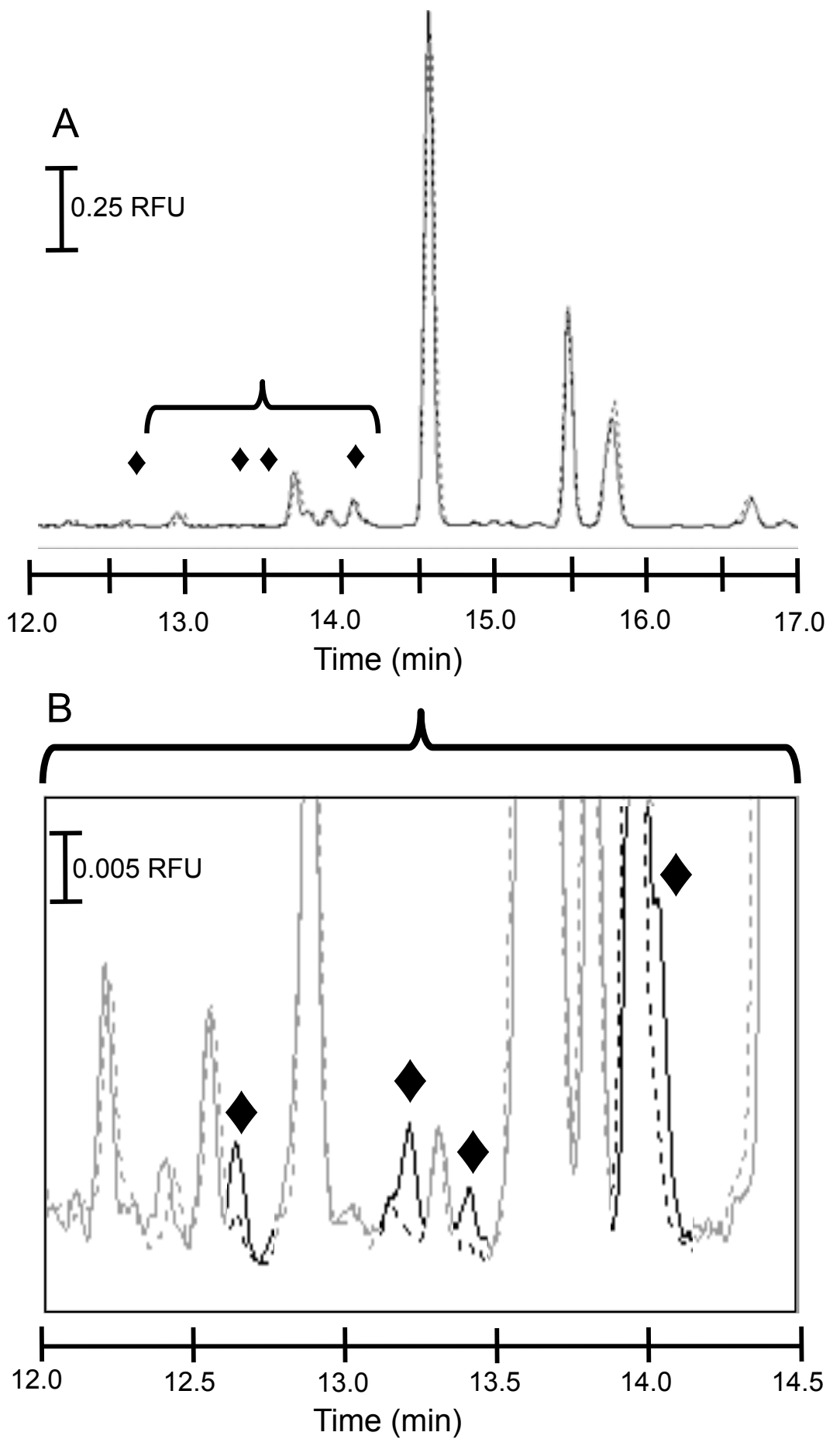


Figure 4-6 is the electropherogram demonstrates the use of the enzyme Neuraminidase for probing low abundance sialated glycans from Trastuzumab. The low abundance glycans that responded to Neuraminidase are denoted in Figure 6-A and shown in Figure 6-B. Glycans were incubated with an in-capillary plug of Neuraminidase for 5 minutes prior to separation and analysis with CE-LIF. Reproduced with permission from [4].

\subsubsection{Analysis with multiple in-capillary enzymes}

To determine the complete glycan structure the sample can be treated sequentially with multiple enzymes. Figure 4-7 and 4-8 show how two enzymes can be incorporated into the capillary through multiple incubation and separations steps. In figure 4-7-A, the glycan sample is injected into and incubated within a capillary containing only blanks and no enzymes. The glycan is unaffected by these blanks and separated in the capillary at the expected migration time. In figure 4-7-B, an enzyme that cleaves the terminal outer-most glycans is introduced into the capillary. The glycan is injected into the capillary and incubated, resulting in the enzymatic cleavage of that glycan residue. As a result, the electrophoretic mobility of this glycan has changed, and now during separation the glycan will have a different migration time. This process is continued in Figure 4-7-C where two enzymes are injected, the second enzyme specific for the next level of glycans. The glycan is injected, moved to the first enzyme plug and incubated, then moved to the next enzyme plug and incubated. Two levels of glycan residues are removed, and the glycan is then separated with a third migration time. During this process three different experimental separations following incubation are conducted. Because the identification of the glycan is dependent on migration time, it is critical that all methods utilize the same injection/incubation/transfer protocol. 


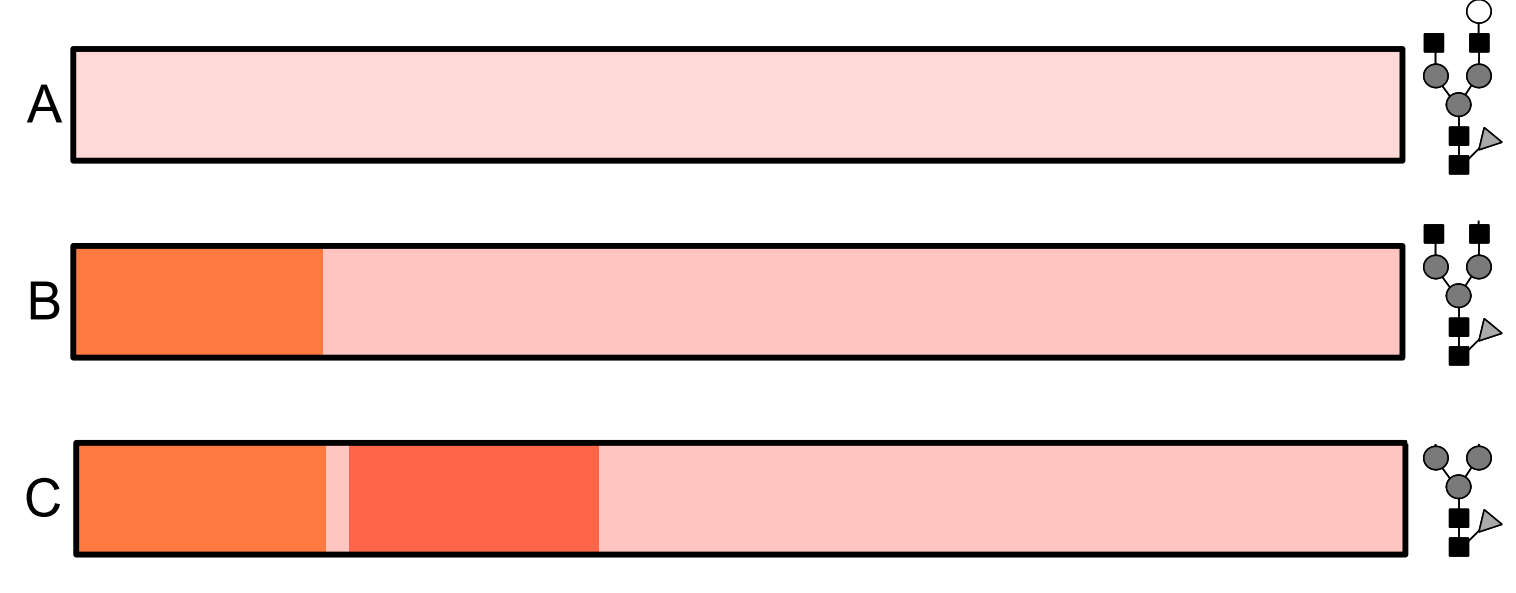

Figure 4-7 demonstrates how multiple enzyme plugs can be used to probe the glycan for sequential data. A glycan of interest is first separated in a capillary containing no enzyme (Figure 7-A). The glycan is then separated through a capillary containing a single enzyme to remove the terminal glycan residues, in this case the terminal $\beta 1-4$ galactose resides (Figure 7-B). The glycan is then separated in a capillary containing two enzymes to remove two sequential layers of glycans, first the galactose residues, then the glucosamine residues (Figure 7-C).

\subsubsection{Use of multiple enzyme plugs to Characterize Major Glycans from}

\section{Trastuzumab}

The enzymes used to characterize glycans from Trastuzumab were $\beta 1-4$ galactosidase and $\beta$ - $N$-Acetylglucosaminidase. A general schematic of the enzymes placement in the capillary is seen in Figure 8. MOPS plugs placed between the enzyme plugs and after the second plug, were used to prevent carryover between the enzyme vials, and contamination of the glycan sample. The Trastuzumab glycans were injected into the capillary, moved electrokinetically onto the first enzyme plug $(10 \mathrm{kV} 30 \mathrm{sec})$, incubated for 10 minutes, moved to the second plug $(10 \mathrm{kV} 30 \mathrm{sec})$, then incubated for another 10 minutes and separated. Figure 4-8 shows a blank reaction where both incubations took place in $\mathrm{pH} 5$ Citrate buffer plugs. The separation efficiency for G0F was $\sim 100,000$ plates (vs 410,000) in spite of longitudinal diffusion due to the 20 minute 
total incubation time and because of the electrokinetic movement steps. When the reactions took place with enzymes, the plate count decreased to $\sim 35,000$ following due specific and nonspecific interactions with the protein.

When the glycan is subjected to only $\beta 1-4$ galactosidase, it demonstrates that three of the four major glycans from Trastuzumab (G1F, G1F', and G2F) contain $\beta 1-4$ terminally linked Gal residues, as shown in Figure 4-9-B. This experiment can also be repeated with only $\beta-N$-Acetylglucosaminidase, to see if there are terminal GlcNAc resides (shown in Figure 4-9-C). In this experiment the peaks affected include (G0F, G1F, and $\mathrm{G}^{\prime} \mathrm{F}^{\prime}$ ). Because there are no exposed GlcNAc resides in G2F, this peak was unaffected by the enzyme. Treatment with both enzymes, as shown in Figure 4-9-D, show that all four peaks are reacted. If this reaction is continued, it will complete cleavage down to a fucosylated manose core. 

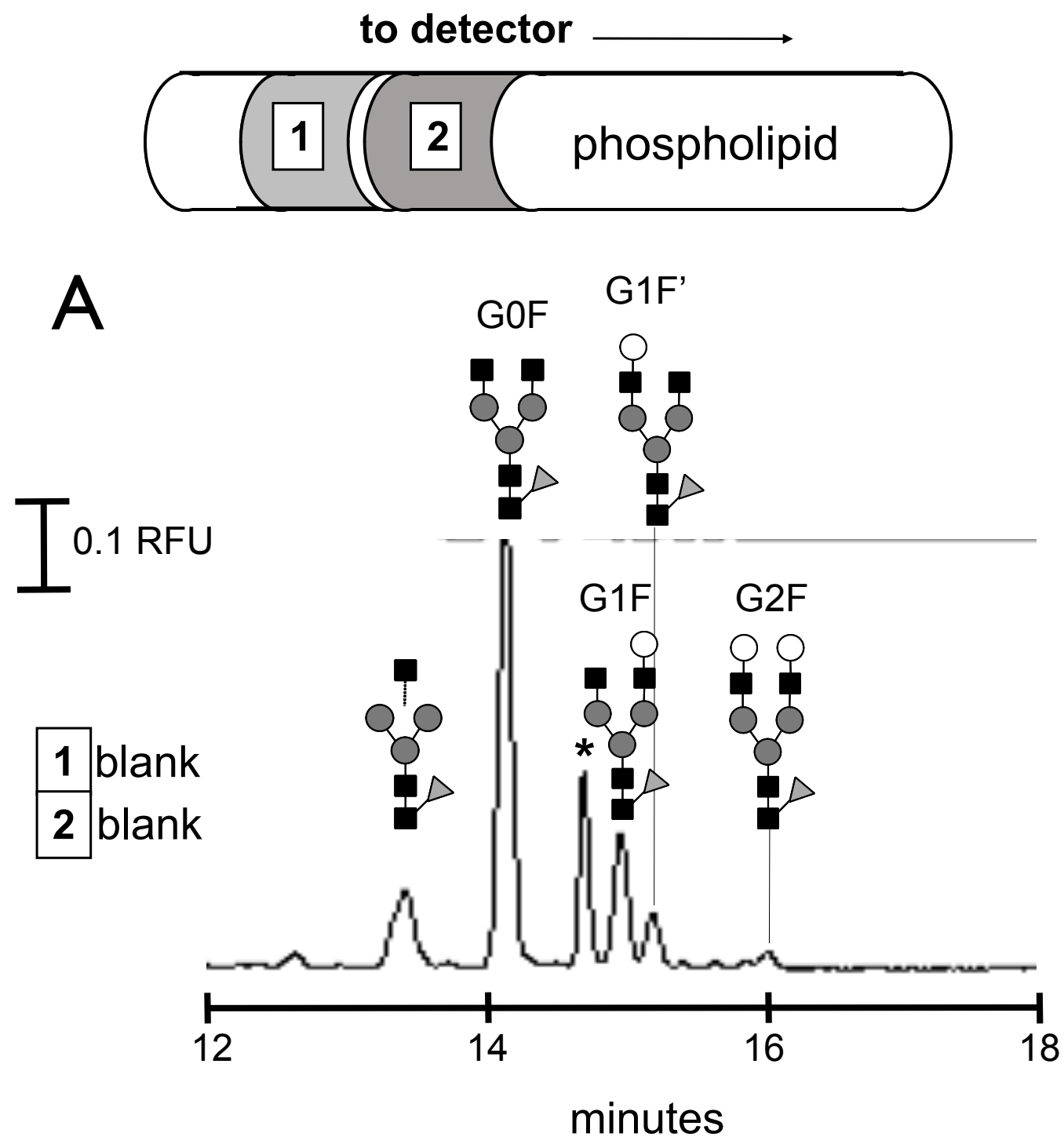

Figure 4-8 demonstrates the use of multiple in-capillary plugs of enzymes to analyze glycans from Herceptin. Small discrete plugs of enzymes may be injected into the capillary prior to introduction of the glycan. The glycan is injected, then moved onto each plug before incubation. Once the glycan has been incubated in each of the plugs it is separated and detected using CE-LIF. Reproduced with permission from [4]. 


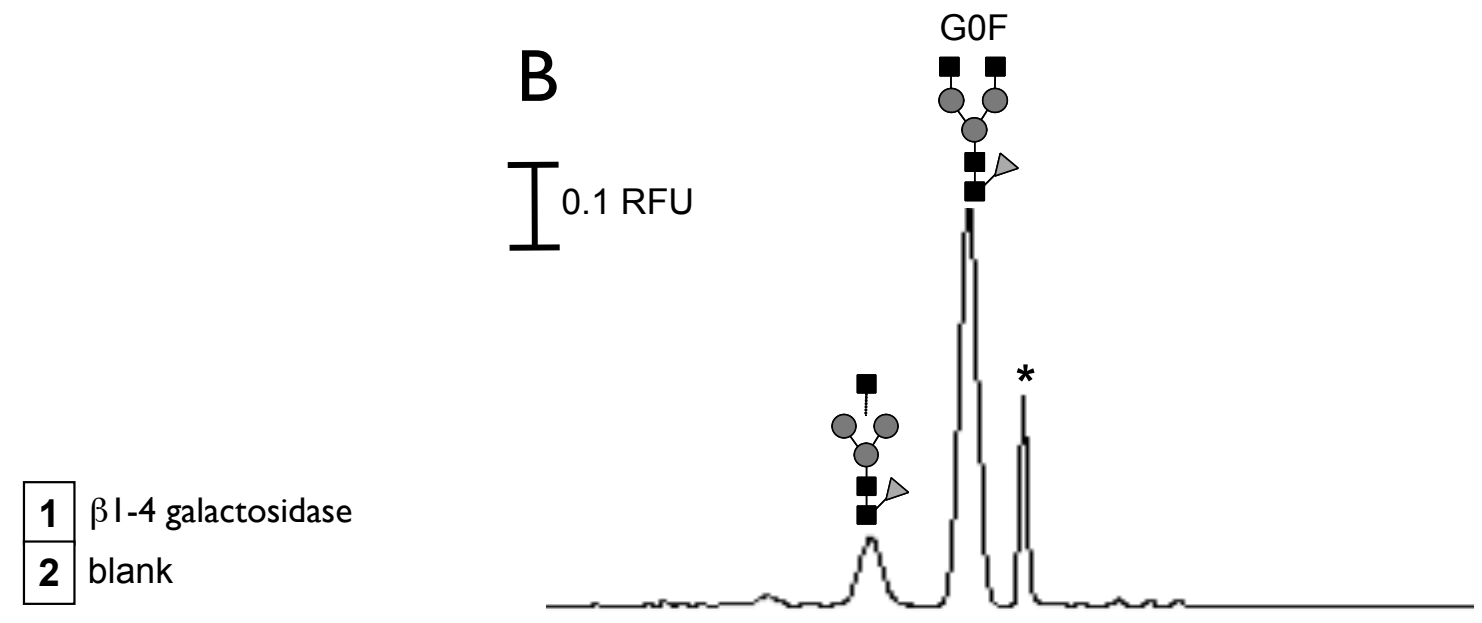

\begin{tabular}{|l|l}
\hline 1 & blank \\
2 & $\beta-N$-acetylglucosaminidase \\
\hline
\end{tabular}

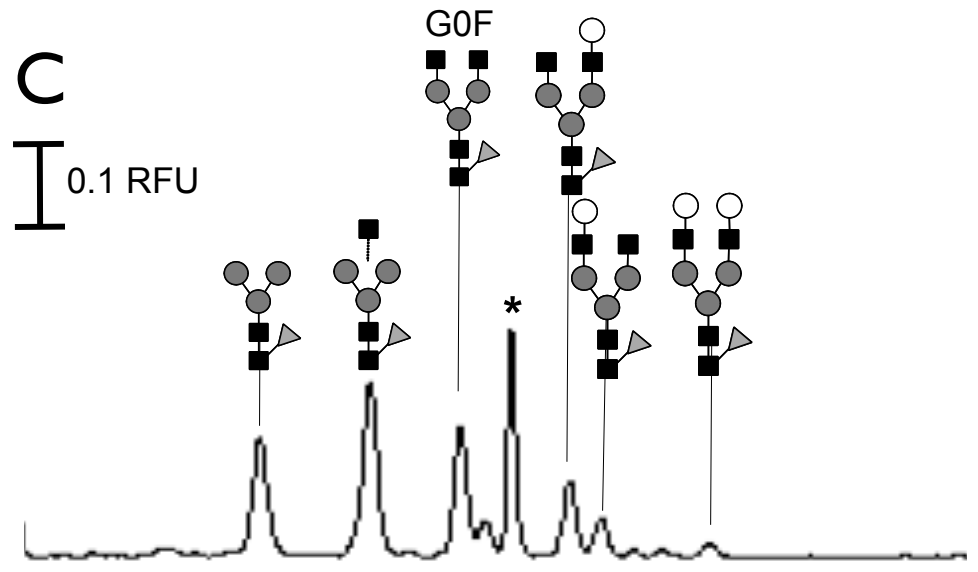

D

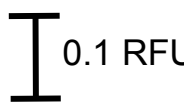

\begin{tabular}{|l|l}
\hline 1 & $\beta \mathrm{I}-4$ galactosidase \\
\hdashline 2 & $\beta-N$-acetylglucosaminidase \\
\hline
\end{tabular}

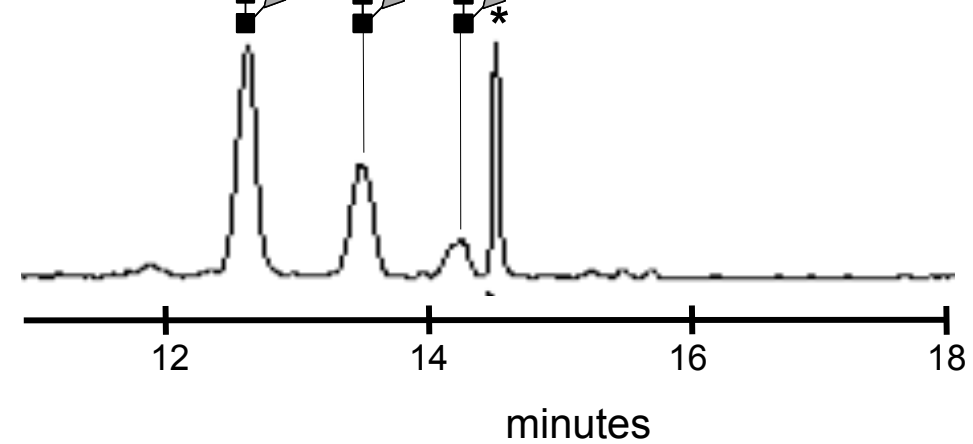

Figure 4-9 demonstrates the injection plug strategy described in Figure 8, using the enzymes $\beta$ I-4 galactosidase and $\beta-N$-acetylglucosaminidase, either singly (Figures 9-B and 9C) or sequentially (Figure 9-D). Reproduced with permission from [4]. 
This set of experiments can be expanded to include a number of other enzymes. Because sialic acid is in such a low abundance in Trastuzumab, it was not necessary to include the enzyme neuraminidase to the enzyme regimen. However, because this enzyme is fast-acting, having incubation times of roughly 5 minutes, it is simple to add neuraminidase into a three-enzyme set of analyses. It is important to note that the optimum $\mathrm{pH}$ for all exoglycosidases is similar ( $\sim \mathrm{pH} 4.5$ to $\mathrm{pH} 6)$. This means that, rather than individual plugs of enzyme within the capillary, various enzymes may be combined in cocktails for a single plug/ multiple reaction system. This method may provide improved plate counts, as the number of incubation and move steps have decreased. However, because this approach utilizes more total enzyme and total liquid handling, it was not tested.

\subsubsection{Benefits of Using In-Capillary Analysis for Multiple Enzyme Studies}

The benefits of utilizing this method include drastically reduced amounts of enzyme and sample, as well as time, as documented in Chapter 3. To emphasize the benefits of in-capillary reactions specifically for multiple enzymes, a comparison to an equivalent bench-top analysis must be made. In this system a glycan solution is being probed with two enzyme solutions, and a limit of $20 \mu \mathrm{L}$ volume size is required for injection by an automated CE system (Beckman P/ACE MDQ). Figure 10 shows the approaches that can be taken for multiple enzyme reactions, followed by analysis, either serially (top figure) or in parallel (bottom figure). Serial bench top reactions involve the full analysis of a sample, the enzymatic reaction of the entire sample followed analysis, 
followed by the final enzymatic reaction and more analysis. This method conserves the total consumption of the glycan by using a single sample for multiple reactions but increases the total experiment time. Additionally, sufficient analyses must be completed before the next enzyme is used. Once an enzyme has been added to the glycan sample it cannot be reused for repeated analyses of the prior steps. In contrast, parallel bench top reactions utilize multiple samples or aliquots for multiple enzymatic reactions to incubate simultaneously. Thus parallel analyses have faster experiment times, and samples that can be reused, but consume significant amounts of glycan sample. It is also important to note that the addition of enzyme in both parallel and series analyses affects both the glycan concentration and the injection into the capillary. In contrast to these methods, utilizing enzyme plugs in the capillary for on-line analyses utilizes a single glycan sample for multiple, repeatable analyses. In-capillary sequencing uses $\sim 2 \mathrm{~nL}$ of enzyme and $1 \mathrm{~nL}$ of glycan per injection, allowing for numerous reactions to be completed without compromising the original sample, making this method especially useful for volume limited glycan samples. 


\section{Benchtop Method 1: Serial Enzymatic Cleavage}

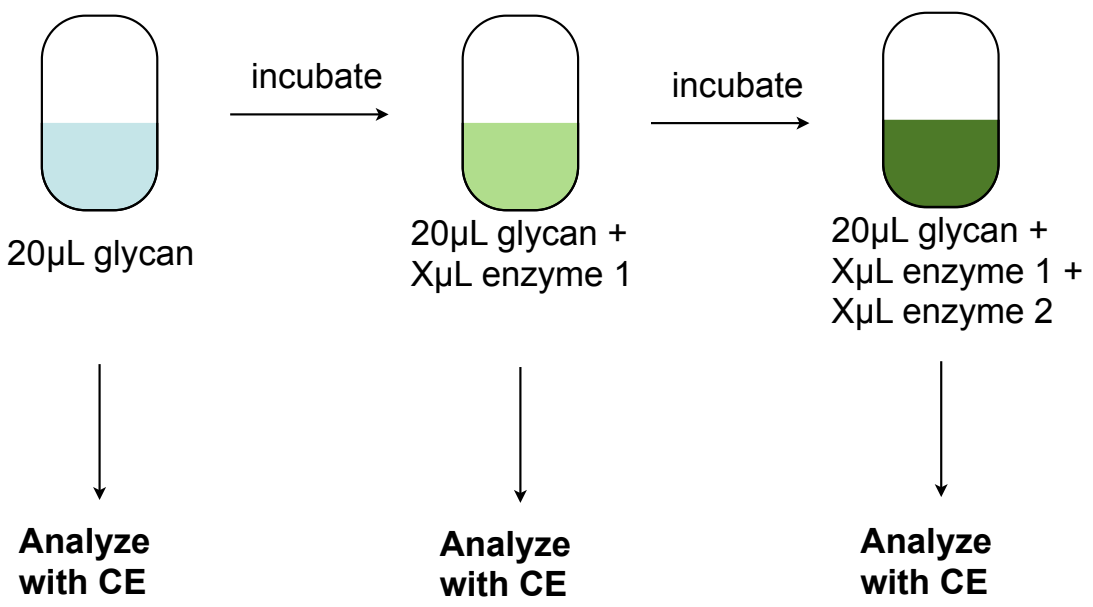

\section{Benchtop Method 2: Parallel Enzymatic Cleavage}

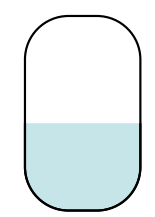

incubate

Analyze

$20 \mu \mathrm{L}$ glycan
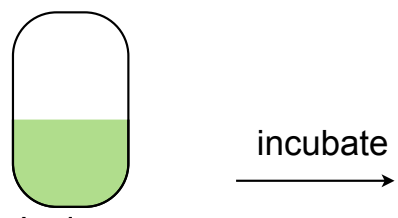

Analyze

$20 \mu \mathrm{L}$ glycan +

$\mathrm{X} \mu \mathrm{L}$ enzyme 1

with CE

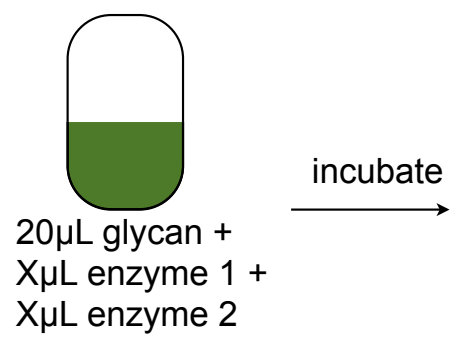

\section{Analyze}

with CE

Figure 4-10 demonstrates the various methods of bench-top enzymatic sequencing using multiple exoglycosidase enzymes 


\subsection{Conclusions}

The incorporation of exoglycosidase enzymes and lectins is an appealing strategy to probe complex solutions of glycans for structural characteristics. Phospholipid-assisted capillary electrophoresis provides a highly efficient separations $(\sim 500,000$ theoretical plates) and utilizes small sample volumes in an automated method. The temperatureresponsive phospholipid separations material also provides a rapid, noncovalent method to incorporate enzymes directly into the capillary. This method greatly reduces the amount of enzyme and sample. Additionally the sample may be utilized for multiple analyses. These methods were used to probe glycoprotein solutions of the immortalized MCF-7 breast cancer cell line, determining whether glycans were high-mannose glycans or had terminal mannose or galactose residues. Both high and low abundance glycans were analyzed using these methods. The therapeutic antibody, Trastuzumab (Herceptin ${ }^{\circledR}$ ) was also analyzed using similar methods. The enzyme neuraminidase was used to identify low abundance sialyated glycans, even though these glycans make up less than $1 \%$ of the total glycan content. The enzymes $\beta 1-4$ galactosidase and $\beta-N$ acetylglucosaminidase were used both individually in different separations, and sequentially in a single separation to determine the structure of the main glycans of Trastuzumab. 


\subsection{Future Directions:}

Lectin Bind-and-Release using Phospholipid Assisted Capillary Electrophoresis: Glycan analysis using lectins held within phospholipid is a powerful way to quickly probe diverse solutions of glycans for those with a specific set of characteristics. Glycans that have specificity to the lectin within the capillary, bind to the lectin and are also held within the capillary, while the rest of the glycans continue to move through the capillary. This means a selection of glycans sharing a common characteristic (i.e. high mannose or branched mannose structures) can be retained for further analysis. If the plug of enzyme is flooded with a glycan solution that disrupts the glycan binding and displaces these glycan, the previously bound glycans can be subsequently released and separated for further analysis, such as with CE-MS analysis.

Analysis of O-linked glycans and glycosaminoglycans: All studies completed in this body of work centered on the analysis of N-linked glycosylation. However these are not the entirety of glycans from protein sources. O-linked glycans attach via oxygen to serine and threonine and have a wide variety of structures. 


\subsection{Bibliography}

1. Peracaula, R., Barrabes, S., Sarrats, A., Rudd, P.M., de Llorens, R., Altered glycosylation in tumours focused to cancer diagnosis. Disease Markers, 2008. 25: p. $207-218$

2. Archer-Hartmann, S.A., Sargent, L.M., Lowry, D.T., Holland, L.A., Microscale Exoglycosidases Processing and Lectin Capture of Glycans with Phospholipid Assisted Capillary Electrophoresis Separations, Analytical Chemistry, 2011. 83: p. 2740-2747

3. Stadlmann, J., Pabst, M., Kolarich, D., Kunert, R., Altmann, F., Analysis of immunoglobulin glycosylation by LC-ESI-MS of glycopeptides and oligosaccharides. Proteomics 2008. 8, 2858-2871

4. Archer-Hartmann, S.A., Crihfield, C.L., Holland, L.A., On-Line Enzymatic Sequencing of Glycans from Trastuzumab by Phospholipid Capillary Electrophoresis, Electrophoresis, 2011. accepted

5. Helenius, A., Aebi, M., Intracellular Functions of N-Linked Glycans. Science, 2001. 23: p. 2364-2369

6. Hannun, Y.A., Obeid, L.M., Principles of bioactivie lipid signalling: lessons from sphingolipids. Nature Reviews Molecular Cell Biology, 2008. 9: p. 139-150

7. Larison, L.L., Henrissat, B., Davies, G.J., Withers, S.G., Glycosyltransferases: structures, functions, and mechanisms. Annual Review of Biochemistry, 2008. 77: p. $521-555$ 
8. M.H. Ravindranath, P. Yesowitch, C. Sumobay, D.L. Morton, Glycoimmunomics of human cancer: current concepts and future perspectives. Future Oncology, 2007. 3: p. 201-214

9. Soule HD, Vasquez J, Long A, Albert S, Brennan M., A human cell line from a pleural effusion derived from a breast carcinoma. Journal of the National Cancer Institute, 1973. 51:p.1409-1413.

10.S.E. Burdall, A.M. Hanby, M. R.J. Lansdown, V. Speirs, Breast Cancer Cell Lines: Friend or Foe?. Breast Cancer Research, 2003. 5: p.89-95

11.Beck, A., Wruch, T., Corvaïa, N., Therapeutic antibodies and derivatives: from the bench to the clinic. Current Pharmaceutical Biotechnology, 2008. 9: p.421-422

12. Beck, A., Biosimilar, biobetter, and next generation therapeutic antibodies. mAbs, 2011. 3: p. 107-110

13. Reichert, J.M., Monoclonal antibodies as innovated therapeutics. Current Pharmaceutical Biotechnology, 2008. 9: p. 423-430

14. Presta, L.G., Molecular engineering and design of therapeutic antibodies. Current Opinion in Immunology, 2008. 20: p.460-470

15. de Val, I.J., Kontorvadi, C., Nagy, J.M., Towards the implementation of quality by design to the production of therapeutic monoclonal antibodies with desired glycosylation patterns. Biotechnology Progress. 2010. 26: p. 1505-1527

16. Abès, R., Teillaud, J.-C., Impact of Glycosylation on Effector Functions of Therapeutic IgG. Pharmaceuticals, 2010. 3:p.146-157 
17. Jefferis, R., Recombinant antibody therapeutics: the impact of glycosylation on mechanisms of action. Trends in Pharmacological Sciences, 2009. 30: p. 356-362

18. Umaña, P., Jean-Mairet, J., Moudry, R., Amstutz, H. \& Bailey, J. E. Engineered glycoforms of an antineuroblastoma IgG1 with optimized antibody-dependent cellular cytotoxic activity. Nature Biotechnology, 1999. 17: p. 176-180

19. Herbst, R.S., Review of epidermal growth factor receptor biology. International Journal of Radiation Oncology, 2004. 59: p. S21-S26

20. Cho, H.S., Mason,K., Ramyar, K.X. et al. Structure of the extracellular region of HER2 alone and in complex with the Herceptin Fab. Nature, 2003. 421: p. 756-760

21. Yarden, Y., Sliwkowski, M.X., Untangling the ErbB signalling network. Nature Reviews Cell Biology, 2001. 2: p. 127-137

22. Slamon,D.J., Godolphin, W., Jones, L.A., Holt, J.A Wong, S.G. Keith, D.E. Levin, W.J. Stuart, S.G.,Udove, J., Ullrich, A., Press, M.F., Studies of the HER-2/neu protooncogene in human breast and ovarian cancer. Science, 1989. 244: p.707-712

23. Slamon, D.J. Clark, G.M Wong, S.G. Levin, W.J. Ullrich, U. McGuire, W.L. Human breast cancer: correlation of relapse and survival with amplification of the HER-2/neu oncogene. Science, 1987. 235: p. 177-182

24. Albanell, J., Bellmunt, J., Molina, R., et al, Node-negative breast cancers with p53 (-)/HER2-neu(-) status may identify women with very good prognosis. Anticancer Research, 1996. 16: p. 1027-1032 
25.Slamon, D.J., Leyland-Jones, B., Shak, S., et al.,Use of Chemotherapy plus a Monoclonal Antibody against HER2 for Metastatic Breast Cancer That Overexpresses HER2, New England Journal of Medicine 2001. 344: p.783-792

26. Vogel, C.L., Cobleigh, M.A., Tripathy, D., et al. Efficacy and Safety of Trastuzumab as a Single Agent in First-Line treatment of HER2-Overexpressing Metastatic Breast Cancer. Journal of Clinical Oncology, 2002. 20: p.719-726

27.Mukohara,T., Mechanisms of resistance to anti-human epidermal growth factor receptor 2 agents in breast cancer. Cancer Science, 2011, 102: p.1-8

28. Junttila, T.T., Parsons, K., Olisson, C., et al, Challenges in HER2 positive Breast Cancer. Cancer Research, 2010, 70: p. 4481-4489

29. Lattovà, E., Tomanek, B., Bartusik, D., Perreault, H. N-Glycomic Changes in Human Breast Carcinoma MCF-7 and T-Lymphoblastoid Cells After Treatment with Herceptin and Herceptin/Lipoplex. Journal of Proteome Research, 2010 9: p. $1533-1540$

30. Lee, A., Nakano, M. Hincapie, M., Kolarich, D., Baker, M.S.Hancock, W.S. Packer, N.H. The lectin riddle: glycoproteins fractionated from complex mixtures have similar glycomic profiles. OMICS: Journal of Integrative Biology, 2010. 14: p. 487-499

31. Kamoda, S., Nomura, C., Kinoshita, M., Nishiura, S., Ishikawa, R., Kakehi, K., Kawasaki, N., Hayakawa, T., Profiling analysis of oligosaccharides in antibody pharmaceuticals by capillary electrophoresis. Journal Chromatography A, 2004. 1050: p. 211-216. 
32.Lindhout, T. Iqbal, U. Willis, L.M., Reid, A.N., Li, J., Liu, X., Moreno, M., Wakarchuk, W. W., Site-specific enzymatic polysialylation of therapeutic proteins using bacterial enzymes. Proceedings of the National Academy of Sciences 2011. 108: p.7397-7402 


\title{
CURRICULUM VITAE
}

\section{Stephanie Archer-Hartmann}

217 CLARK HALL OF CHEMISTRY MORGANTOWN, WV

TEL 3043764552

stephanie.archer@gmail.com

www.stephaniearcher.com

www.linkedin.com/in/stephainiearcherhartmann

\section{Professional Experience}

\author{
08/06-present West Virginia University, Morgantown, WV \\ Ph.D. program in chemistry. Research advisor: Prof. Lisa Holland. \\ 8/02-5/06 \\ West Virginia University, Morgantown, WV \\ B.S. Chemistry Experience \\ Professional Experience \\ 08/06-present Graduate Research Assistant: West Virginia University, \\ Department of Chemistry (advisor Prof. Lisa. A. Holland) \\ 08/06-01/08 Teaching Assistant: West Virginia University \\ Department of Chemistry, General Chemistry Courses and Analytical Chemistry \\ 8/04-5/05 Biological Technician: AutoGentox Corp.

\section{Fellowships/Awards/Organization} \\ 08/11 Graduate Scholarship, WVU Science Technology Entrepreneurship Academy \\ 09/10 Tony B. Academic Travel Award (LabAutomation 2011 conference) \\ 08/10 - present United States Pharmacopeia Fellow (2010-2011) \\ 5/10 - present American Chemical Society, member \\ 07/08 - 07/09 WVNano Bridge Awardee \\ 01/08 - 08/10 WV EPSCoR STEM Cancer Nanotechnology Graduate Fellow \\ 01-07-present Phi Lambda Upsilon Chemistry Honorary, member \\ 08/06-present C. Eugene Bennett Fellow
}

\section{Publications}

S. A. Archer-Hartmann, L.A. Holland, On-Line Enzymatic Sequencing of Glycans from Trastuzumab by Phospholipid Assisted Capillary Electrophoresis, Electrophoresis, accepted

T. J. Langan, V. T. Nyakubaya, L. D. Casto, T.D. Dolan, S. A. Archer-Hartmann, L. A. Holland, DNA Aptamer Binding Analysis Using Stacking Enhanced Capillary Electrophoresis, Electrophoresis, submitted

S.A. Archer-Hartmann, L.A. Holland, R.E. Majors, Self-assembled nanomaterials for enhanced chemical separations, LCGC North America, 2011, 29, 390-393

S. A. Archer-Hartmann, L. Sargent, D. Lowrey, L.A. Holland, Microscale Exoglycosidase Processing and Lectin Capture of Glycans with Phospholipid Assisted Capillary Electrophoresis Separations, Analytical Chemistry, 2011, 83, $2740-2747$

L. Bykova, S.A. Archer-Hartmann, L.A. Holland, L. Iwanowicz, V.S. Blazer, Steroid Determination in Fish Plasma Using Capillary Electrophoresis, Environmental Toxicology and Chemistry, 2010, 29, 1950-1956

R. Luo, S.A. Archer-Hartmann, L. A. Holland, Transformable Capillary Electrophoresis for Oligosaccharide Separations Using Phospholipid Additives, Analytical Chemistry, 2010, 82, 1228-1233

C.M. White, R. Luo, S. A. Archer-Hartmann, L. A. Holland, Electrophoretic Screening of Ligands Under Suppressed Electroosmotic Flow with an Inert Phospholipid Coating, Electrophoresis, 2007, 28, 3049-3055

Selected Presentations (7 of 32 total)

SA Archer-Hartmann*, LA Holland " On-line Characterization of Therapeutic antibodies using Phospholipid Additives for Capillary electrophoresis " USP Standards Symposium Seattle, WA October 2011

SA Archer-Hartmann*, LA Holland "On-line Biomolecule Characterization Using Phospholipid-Based Additives in Capillary Electrophoresis” PITTCON ® 2011 Atlanta, GA March 2011

SA Archer-Hartmann*, LA Holland "On-line Biomolecule Characterization Using Phospholipid-Based "Nanodisk" 
SA Archer-Hartmann*, R Luo, L.A. Holland, "Analysis of Protein/Protein and Protein/Carbohydrate Interactions via Capillary Electrophoresis" PITTCON ® 2010 Orlando, FL March 2010

SA Archer-Hartmann*, S Rockett, D Beevers, OC Myers, D Lederman, L.A. Holland, "Antibody Immobilization to Gold Plated Microcantilevers" PITTCON ® 2008 New Orleans, LA, March 2008

SA Archer-Hartmann*, CM White, T Spontak, L.A Holland, "Monitoring Enyzme Cleavage Using Capillary Electrophoresis ", PITTCON ${ }_{\circledast}$ 2007, Chicago, IL, February 2007.

SA Archer*, T Langan, L.A Holland, "Reality Test: Using Cyber-infrastructure to Build Sophisticated Instrumentation" Undergraduate Research Day at the Capital. Charleston, WV April 2006

\section{Techniques and Skills:}

antibody manipulation, atomic force microscopy (AFM), liquid chromatography methods, capillary electrophoresis (free zone, affinity, MEKC), biopolymer analyses, phospholipid techniques, internet facilitated distance collaboration, , smart nanomaterials, single cell manipulation, protein expression, single cell gel electrophoresis (COMET) assay, bioanalytical separations techniques

\section{Graduate Coursework:}

Molecular Spectroscopy, Electrochemistry, Proteomics, Mass Spectrometry, Chemical Kinetics, Separations Chemistry, Bioanalytical Chemistry, Biochemistry, Molecular Recognition Elements, Nanoscale Science and Engineering.

\section{Professional Development/Community Service:}

WVU SCIENCE AND TECHNOLOGY ENTREPRENEURSHIP ACADEMY, AUGUST 2011, MORGANTOWN, WV

Attended week-long accredited "bootcamp" course on business fundamentals for scientists. Topics included project management, financial preparation, pitching, marketing, and developing innovative teams.

MICROFLUIDICS I/II, SHORT COURSE, LAB AUTOMATION 2011 CONFERENCE, PALM SPRINGS, CA,

Two-day course on the fundamentals and practical considerations of microfluidic separations and devices. Course instructors were Sabeth Verpoorte (U of Groningen), Johan Nilsson (Lund University), and Jörg P. Kutter (DTU)

PRESIDER DUTIES, PITTSBURGH CONFERENCE OF ANALYTICAL CHEMISTRY AND APPLIED SPECTROSCOPY (PITTCON) Presided over numerous technical sessions at PittCon, including: "ACS Subdivision of Separation Science: New Self Assembled nanomaterials for Chemical Separations II", "Surface Analysis and Surface Imaging Methods" (PITTCON 2011, Atlanta, GA) "Microchip Fluid Control", "Microdroplets in Analysis" (PITTCON 2010, Orlando, FL)

“HIGH TECH MIND, HIGH TECH FUTURE”, EBERLY COLLEGE ALUMNI MAGAZINE, FALL 2010

General interest article covering cutting-edge facilities and research at WVU and in the state of West Virginia

"CONSIDERING GRADUATE OPPORTUNITIES AT WVU", GLENVILLE STATE COLLEGE, SUMMER 2009

WVU graduate recruitment talk aimed to undergraduate students at Glenville State College, a small liberal arts college in rural WV

"NANOSCALE SCIENCE AND ENGINEERING", WEST VIRGINIA UNIVERSITY, 2007-PRESENT

Participation in a seminar course designed to foster interdisciplinary creativity and research on the subject of nanoscience. Participants include students from the Departments of Physics, Chemistry, Biology, Pharmaceutical Sciences, Mathematics, and Engineering

"ENTERING MENTORING - HOWARD HUGHES MEDICAL INSTITUTE NATIONAL ACADEMIES PROJECT SUMMER TRAINING,", WEST VIRGINIA UNIVERSITY, 2006

$\mathrm{HHMI}$ project designed to train mentors and future faculty in academia. 